RAFAEL LEMES BEIRIGO

\title{
Estratégias para Aplicação de Políticas Parciais com Motivação Intrínseca
}



RAFAEL LEMES BEIRIGO

\section{Estratégias para Aplicação de Políticas Parciais com Motivação Intrínseca}

Dissertação apresentada à Escola

Politécnica da Universidade de São Paulo para obtenção do título de

Mestre em Ciências

São Paulo

2014 



\section{RAFAEL LEMES BEIRIGO}

\section{Estratégias para Aplicação de Políticas Parciais com Motivação Intrínseca}

Dissertação apresentada à Escola

Politécnica da Universidade de São Paulo para obtenção do título de

Mestre em Ciências

Área de Concentração:

Engenharia de Computação

Orientadora: Professora Titular Anna Helena Reali Costa 


\section{Catalogação-na-publicação}

Beirigo, Rafael Lemes

Estratégias para aplicação de políticas parciais com motivação intrínsica / R.L. Beirigo. -- São Paulo, 2014.

$106 \mathrm{p}$.

Dissertação (Mestrado) - Escola Politécnica da Universidade de São Paulo. Departamento de Engenharia de Computação e Sistemas Digitais.

1.Aprendizado por reforço 2.Políticas parciais 3.Motivação intrínseca 4.Aplicação de política parcial I. Universidade de São Paulo. Escola Politécnica. Departamento de Engenharia de Computação e Sistemas Digitais Il.t. 
Este trabalho é dedicado aos que ensinam, trazendo luz ao mundo na forma de conhecimento, especialmente aos que aprendem ao fazê-lo. 



\section{Agradecimentos}

Primeiramente, agradeço à minha orientadora, exemplo vivo da intuição aliada ao pragmatismo, pela transparência refletida no sorriso que sempre acompanhou meus acertos e por deixar claros os pontos onde havia espaço para aprimoramento, tesouros coletados nesses dois anos e meio e guardados para a minha vida. Agradeço imensamente pela paciência de lapidadora frente a pedra bruta, por vezes acreditando mais na pedra que a própria, e pelo apoio, ambos transcendendo o contexto acadêmico nessa etapa de aprendizado e amadurecimento científico e pessoal. Os agradecimentos são estendidos ao professor Valdinei, cuja interlocução proveu a satisfação de apreciar o caráter não deletério da troca de perspectivas, multiplicativa e enriquecedora, e a todos do LTI, que me acompanharam nessa jornada.

Um agradecimento especial é direcionado ao Levi, que me fez perceber a beleza presente nos mistérios da Ciência, a eficácia da abordagem simples na solução dos mesmos e a importância de se dominar um assunto para poder ensiná-lo, fruto estelar do saber. Sem ele essa jornada muito provavelmente não teria iniciado, através da ameaça velada de me demitir se eu não entrasse em uma faculdade, durante uma das extraordinárias tardes pós-expediente em que, de chefe, passava a meu professor de Eletrônica. Esse "susto" acabou me trazendo à USP, onde a paixão pelo saber só fez aumentar.

Alan, obrigado por tornar as jornadas laboratoriais tão mais prazeirosas, pela amizade demonstrada no apoio e pelas risadas disparadas nos momentos mais inesperados. Tudo isso me fez ver o outro lado da vida, o quântico, onde a interferência modifica o observado (risadas). Isabel, obrigado por ser porto seguro, onde a bronca foi sempre certa, certeira e acertada, fazendo-me crer que acertei e acertarei. Elena, obrigado pelo apoio e apontamentos durante a escrita deste texto; foram de valor inestimável.

Aos que lutam para liberar o software, obrigado; ao Stallman, pelo GNU, especialmente pelo Emacs, e às enormes equipes que contribuem para o Linux, Org, e $\mathrm{IT}_{\mathrm{E}} \mathrm{X}$. Knuth, obrigado pelo TEX; obrigado pelo TAOCP. Esses recursos possibilitaram este trabalho e alavancaram meu crescimento.

Ao meu pai, obrigado pelo apoio inicial, que me fez trilhar o caminho de programador, e por fazer tudo ao seu alcance para cuidar da nossa família. À minha mãe, obrigado por me mostrar a beleza da vida pelo amor. Aos meus irmãos, obrigado por serem minha fonte certa de motivação: Kelem, por enxergar o que não quero ver; Rita, por encarar os fatos desnudados; Gislaine, por mostrar que a mudança é possível; Esio, por seu coração aberto e sabedoria de celeiro cheio; Álvaro, por mostrar que o amor independe das adversidades; Everton, pela sinceridade e alegria; Miguel, pelo exemplo da luta incessante 
no aprimoramento; Gabriel, pelo sorriso, simpatia e questões; e Mariana, pelo amor de caçula. Agradeço aos irmãos-surpresa, Caio, Breno e Fábio, pela diversão, e à Sônia, pelo carinho e apoio.

Finalmente, agradeço a Deus, por tudo, especialmente por permitir a cada criatura denominar e alcançar-Lhe da forma a si mais adequada. 
Science is what we understand well enough to explain to a computer. Art is everything else we do. — Donald Ervin Knuth, (foreword), $A=B$ (1995)

Why should we limit computers to the lies people tell them through keyboards? - Ralph William Gosper, Jr., (atrib.), Hackers: Heroes of the Computer Revolution (1984) 



\section{Resumo}

As técnicas de Aprendizado por Reforço permitem a solução de um problema através da escolha de ações que maximizem valores de recompensas recebidas que refletem a qualidade das ações tomadas pelo agente em um processo de tentativa e erro. Em problemas com estrutura hierárquica, a solução final depende do encadeamento de soluções para subproblemas aí presentes, sendo frequente a repetição de subproblemas nesse encadeamento. Nesses casos, a utilização de políticas parciais permite o aprendizado e armazenamento das soluções individuais para cada subproblema, que podem então ser utilizadas múltiplas vezes na composição de uma solução completa para o problema final, acelerando o aprendizado. Apesar de vantajosa, a utilização de políticas parciais necessita de definições por parte do projetista, o que representa uma sobrecarga. Para contornar esse problema, foram propostas técnicas de descoberta automática de políticas parciais, dentre as quais a utilização de motivação intrínseca se destaca por permitir ao agente aprender soluções de subproblemas úteis na solução do problema final sem a necessidade de se definir manualmente novas recompensas para esses subproblemas individualmente. Apesar de promissora, essa proposta utiliza um conjunto de componentes de aprendizado que ainda carece de investigação aprofundada acerca dos impactos individual e coletivo de cada componente, notadamente a aplicação das políticas parciais durante o aprendizado. Nesta dissertação são propostas duas abordagens para a aplicação de políticas parciais no Aprendizado por Reforço com Motivação Intrínseca: (i) armazenamento das políticas parciais em aplicação pelo agente e (ii) exploração interna à aplicação das políticas parciais. O impacto das propostas no desempenho de aprendizado é avaliado experimentalmente em um domínio com forte caracterização hierárquica.

Palavras-chaves: Aprendizado por reforço. Políticas parciais. Motivação intrínseca. Aplicação de políticas parciais. 



\section{Abstract}

Reinforcement Learning techniques allow an agent to learn the solution to a problem by interacting with the environment and executing actions, thus receiving rewards that reflect the value of the actions taken, on a process of trial and error. When a problem has a hierarchical structure, its final solution depends on several solutions to the subproblems it contains, and it is rather common the repetition of subproblems. On these cases, by using options it is possible to learn the solution to each subproblem individually, keeping and then using them multiple times to compose the complete solution to the problem, thus accelerating the learning process. But, despite this advantage, the use of options create the need for some definitions, what can represent a burden to the designer. To circumvent this problem, automatic option discovery techniques were proposed, among which the use of intrinsic motivation deserves special attention for allowing the agent to learn the solution of the subproblems, which are useful to compose the final solution, without the need to manually define new rewards to these subproblems individually. Despite being promising, this technique is built upon a set of several learning components that need a more deep investigation on the individual and collective impacts of each component, mostly the options' application strategies during the learning process. On this work two modifications are proposed concerning the application process of options on the Intrinsically Motivated Reinforcement Learning: ( $i$ ) storage of the history of the options applied by the agent and (ii) allow the agent to explore, even when following an option. These modifications were implemented on an algorithm present on the literature and evaluated on a domain with strong hierarchical characteristics.

Key-words: Reinforcement learning. Option discovery. Intrinsic motivation. Option application strategies. 



\section{Lista de ilustrações}

Figura 5.1 - Domínio utilizado nos experimentos: um robô dispõe de uma mão mecânica, mira laser e câmera, com os quais pode interagir com os 6 objetos marcados na figura com as letras $a-f$. As setas indicam que os objetos se encontram sobre o tabuleiro, sendo que as posições dos mesmos no tabuleiro podem variar livremente nos experimentos, de acordo com as ações executadas pelo robô. . . . . . . . . . . . .

Figura 5.2 - A figura mostra um exemplo de disposição inicial dos objetos no tabuleiro (interruptor, bloco azul, bloco vermelho, bola, sineta e alarme), juntamente com as posições relacionadas às partes do robô (câmera, mão mecânica e mira laser). Na parte superior da figura, encontram-se a situação atual (ON, OFF referentes aos elementos da sala ou do tabuleiro que interferem na luz e som ambientes (cuja variação dispara eventos salientes)). . . . . . . . . . . . . . . .

Figura 5.3-Grafo de dependência entre o problema de ativar o alarme (4) e os subproblemas ativar música (1), desativar luz (2) e ativar sineta(3), representados pelos eventos salientes que são disparados na solução dos respectivos (sub)problemas. No grafo, os nós representam o problema a ser resolvido e os respectivos subproblemas e as arestas representam a dependência entre as soluções: uma aresta $A \rightarrow B$ entre os nós $A$ e $B$ indica que a solução de $B$ depende primeiramente da solução de A. A numeração dos nós indica a ordem em que as soluções devem ser obtidas: devem ser resolvidos primeiramente os (sub)problemas de menor numeração. O grafo se refere à solução do problema, ou seja, ligar o alarme, caso a luz esteja ligada e a música, a sineta e o alarme estejam desligados. . . . . . . . . . . . . . . . . 73

Figura 5.4 - Grafo de dependência entre os eventos salientes associados aos (sub)problemas que precisam ser resolvidos para disparar alarme $_{O N}$ em uma configuração inicial em que luz, música, sineta e alarme iniciam desligados. . . . 75

Figura 5.5 - Vetor com 13 atributos binários que representa o estado do PSMD do problema. ....................... 76

Figura 5.6 - Atributos referentes à câmera - BO: bola; BA: bloco azul; BV: bloco vermelho; IN: interruptor. . . . . . . . . . . . . . 76

Figura 5.7 - Atributos referentes à mão mecânica - BO: bola; BA: bloco azul; BV: bloco vermelho; IN: interruptor. . . . . . . . . . . . . . . . . . 77

Figura 5.8 - Atributos referentes à situação dos objetos que interferem na luz e som ambientes — LU: luz; MU: música; SI: sineta; AL: alarme. . . . . . . . 
Figura 5.9-13 bits do vetor de estado — BO: bola; BA: bloco azul; BV: bloco vermelho; IN: interruptor; SI: sineta; LU: luz; MU: música; SI: sineta; AL: alarme. . . . . . . . . . . . . . . . 77

Figura 5.10-Atributos salientes — LU: luz; MU: música; SI: sineta; AL: alarme. . . 79

Figura 5.11-Valores das recompensas intrínsecas recebidas pelo robô para cada evento saliente que ele foi capaz de disparar nos primeiros vinte e cinco mil passos do aprendizado (abscissa). O robô foi capaz de disparar os eventos salientes mais simples, mas ainda não conseguiu resolver o problema (disparar alarme $_{O N}$ ). O gráfico mostra o valor recebido para cada ativação por passo do experimento. Dessa forma, a presença da barra indica a ocorrência do evento saliente e o comprimento da barra indica o valor recebido. Subproblemas mais simples, como disparar $l u z_{O N}$, são resolvidos mais rápida e frequentemente (as barras aparecem logo no início e com mais frequência); já subproblemas mais complexos, como disparar sineta $a_{O N}$, ocorrem após algum tempo de aprendizado e com menos frequência (as barras correspondentes aparecem mais tardiamente e em menor quantidade). . . . . . . . . . . . . . . . . 84

Figura 5.12-Exemplos de transições de estados que disparam o evento saliente luz $O N$, porém a partir de estados diferentes, implicando no cálculo em separado do decaimento das recompensas intrínsecas correspondentes. . . . . . . 86

Figura 5.13-Recebimento de recompensas intrínsecas por evento saliente por passo de aprendizado. . . . . . . . . . . . . . . . . . . . 91

Figura 5.14-Avaliação do efeito motivação intrínseca no aprendizado. O gráfico mostra a quantidade de passos necessários para o robô resolver o problema à medida que ele o resolve. . . . . . . . . . . . . . . . . . . . . . . . . 93

Figura 5.15-Avaliação da estratégia de pilhas de políticas parciais para exploração interna com diferentes valores de $\xi_{p}$, versus Q-Learning e comportamento aleatório. O gráfico mostra a quantidade média acumulada de vezes que cada agente conseguiu resolver o problema. . . . . . . . . . . . . . . . . 95

Figura 5.16-Avaliação do impacto da utilização da estratégia de pilhas. O gráfico é análogo ao da Figura 5.15, com a diferença de que este gráfico apresenta o desempenho dos robôs utilizando exploração interna sem utilizar empilhamento de políticas parciais. . . . . . . . . . . . . . . 98 
Figura 5.17-Avaliação do efeito do empilhamento de políticas parciais. O gráfico mostra a quantidade de passos necessários para resolver o problema à medida que o robô o resolve, considerando os robôs que utilizaram ou não empilhamento de políticas parciais, ambos utilizando exploração interna à política parcial com valor de $\xi_{p}=0,8$. Ambos os robôs recebem recompensas intrínsecas e extrínsecas, inclusive o robô que não utiliza a pilha de políticas parciais. . . . . . . . . . . . . . . . . 99 



\section{Lista de tabelas}

Tabela 5.1 - Objetos, ações e eventos salientes. . . . . . . . . . . . . . 70

Tabela 5.2 - Objetos e respectivas ações associadas. . . . . . . . . . . . . . 78

Tabela 5.3 - Exemplo de decaimento da recompensa intrínseca com a repetição do evento saliente associado. A tabela mostra exemplos de valores de recompensas intrínsecas recebidas à medida em que o agente dispara o evento saliente $l u z_{O N}$. . . . . . . . . . . . . . . . . . . . . . . . 82 



\title{
Lista de abreviaturas e siglas
}

\author{
AR Aprendizado por Reforço \\ ARMI Aprendizado por Reforço com Motivação Intrínseca \\ A-EIP $\quad$ ARMI com Exploração Interna e Pilha de Políticas Parciais \\ DT Diferenças Temporais \\ PMD Processo Markoviano de Decisão \\ PSMD Processo semi-Markoviano de Decisão
}





\section{Lista de símbolos}

$S$

A

$A_{s}$

$P_{s s^{\prime}}^{a}$

$R_{s s^{\prime}}^{a}$

$t$

$\pi$

$\pi^{*}$

$V^{\pi}$

$V^{\mu}$

$V^{*}$

$Q^{\pi}$

$Q^{\mu}$

$Q^{*}$

$\epsilon$

$\Phi$

$\phi$

Conjunto de estados

Conjunto de ações

Conjunto de ações aplicáveis no estado $s$

Probabilidade de transição do estado $s$ para $s^{\prime}$ ao executar a ação $a$

Recompensa recebida na transição do estado $s$ para $s^{\prime}$ ao executar a ação $a$

Passo discreto de tempo

Política: fornece a probabilidade de se executar a uma ação em um determinado estado

Política ótima, ou seja, a política que maximiza o valor esperado de recompensas futuras

Função valor-estado associada à política $\pi$; fornece o valor esperado de recompensas futuras descontadas ao, partindo do estado $s$, seguir a política $\pi$

Função valor-estado associada à política de políticas parciais $\mu$

Função valor-estado ótima, isto é, associa a cada estado o valor esperado máximo de recompensas futuras descontadas

Função valor-ação associada à política $\pi$; fornece o valor esperado de recompensas futuras descontadas ao executar a ação $a$ em um estado $s$, seguindo a política $\pi$ nos próximos estados

Função valor-ação associada à política de políticas parciais $\mu$

Função valor-ação ótima; associa a cada estado a ação que maximiza o valor esperado de recompensas futuras descontadas

Probabilidade de escolha de uma ação aleatória na estratégia $\epsilon$-gulosa

Conjunto das políticas parciais

Política parcial 
$\Phi_{s} \quad$ Políticas parciais aplicáveis no estado $s$, isto é, políticas parciais $\phi$ em que $s$ pertence ao seu conjunto iniciador $\mathcal{I}^{\phi}$

$\mathcal{I}^{\phi} \quad$ Conjunto iniciador de uma política parcial $\phi$; contém os estados onde $\phi$ pode ser iniciada

$\beta^{\phi} \quad$ Função de terminação de uma política parcial $\phi$; fornece a probabilidade de terminar a execução da política parcial $\phi$ em um determinado estado

$\mu$ Política de políticas parciais; associa a probabilidade de se executar uma política parcial em um determinado estado

$R_{s}^{\phi} \quad$ Função Modelo de Recompensa associado à política parcial $\phi$; fornece o valor esperado de recompensas futuras descontadas ao aplicar $\phi$ partindo de $s$

$P_{s s^{\prime}}^{\phi} \quad$ Função Modelo de Probabilidade de Transição associado à política parcial $\phi$; fornece a probabilidade de ocorrer a transição do estado $s$ para o estado $s^{\prime}$ na aplicação de $\phi$

$\gamma$

Fator de desconto para recompensas futuras

$E_{\pi} \quad$ Fornece o valor esperado, considerando-se o argumento da função, segundo uma política $\pi$

$r_{t+1}^{e} \quad$ Recompensa extrínseca recebida na transição $s_{t} \rightarrow s_{t+1}$; usualmente recebida ao solucionar o problema

$r_{t+1}^{i} \quad$ Recompensa intrínseca recebida na transição $s_{t} \rightarrow s_{t+1}$; usualmente recebida ao solucionar um subproblema

$\mathcal{A} \quad$ Conjunto de atributos da descrição fatorada dos estados

$\mathcal{A}_{\text {sal }} \quad$ Conjunto de atributos salientes da descrição fatorada dos estados

$\mathcal{L} \quad$ Função que determina o limiar da variação necessária no valor de um atributo saliente para que seja disparado um evento saliente

$\Pi \quad$ Pilha de políticas parciais

$\xi_{p} \quad$ Percentual de exploração interna a uma política parcial 


\section{Sumário}

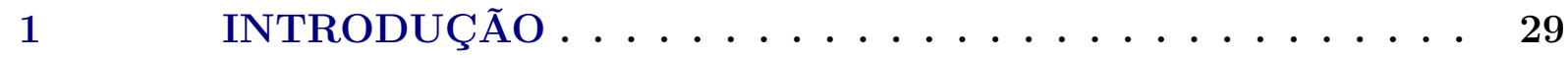

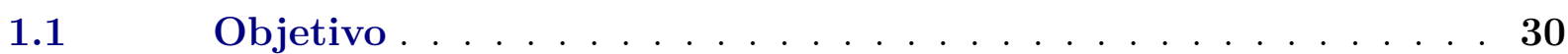

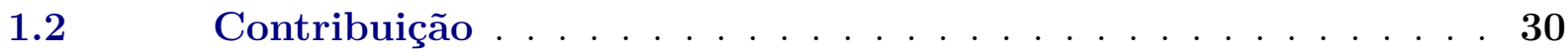

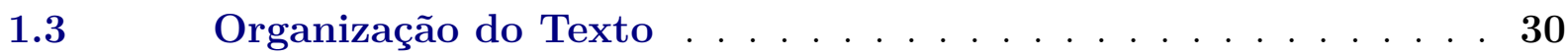

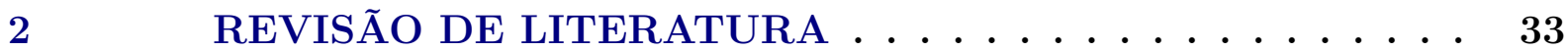

3 DEFINIÇÃO DO PROBLEMA E FUNDAMENTAÇÃO TEÓ-

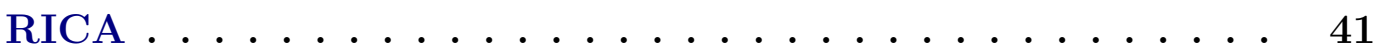

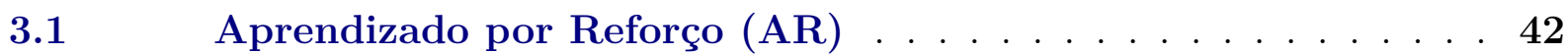

3.1.1 Processos Markovianos de Decisão (PMD) e AR . . . . . . . . . . 43

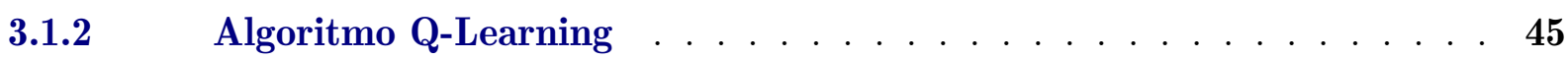

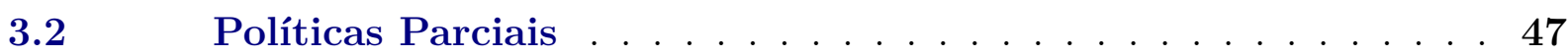

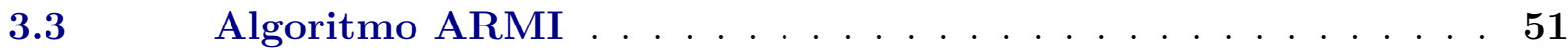

$4 \quad$ ALGORITMO A-EIP ${ }^{3} \ldots \ldots \ldots \ldots \ldots$

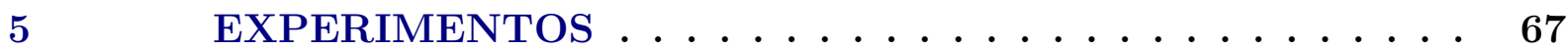

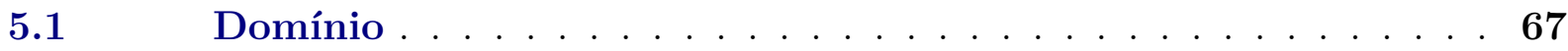

$5.2 \quad$ Modelagem do Problema . . . . . . . . . . . . . 75

5.2.1 Conjunto de Estados _ . . . . . . . . . . . . . . . . . . 75

5.2.2 Conjunto de Ações $\ldots \ldots \ldots \ldots$

5.2.3 Eventos Salientes . . . . . . . . . . . . . . . . . 79

5.2.4 Recompensas Intrínsecas e Recompensas Extrínsecas . . . . . . . . 8 80

$5.3 \quad$ Resultados e Discussão . . . . . . . . . . . . . . . . 83

5.3.1 Manutenção das características desejáveis do ARMI . . . . . . . 8 83

5.3.2 Desempenho de Aprendizado do A-EIP ${ }^{3} \ldots \ldots \ldots \ldots$

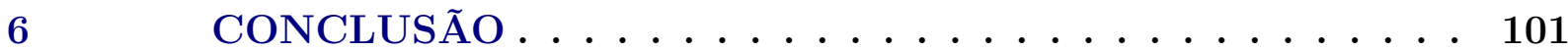

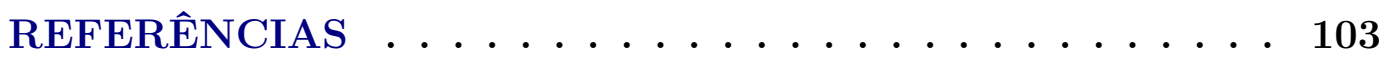





\section{Introdução}

Problemas nos quais o agente deve tomar uma série de decisões sequenciais podem ser resolvidos através de técnicas de Aprendizado por Reforço (AR) (SUTTON; BARTO, 1998; SZEPESVÁRI, 2010), em que o agente recebe um reforço numérico indicando a qualidade de cada ação tomada. Esse processo de aprendizado ocorre por tentativa e erro, no qual o agente alterna entre a aplicação do conhecimento adquirido até o momento para selecionar a melhor ação e a exploração do ambiente, onde o agente experimenta novas ações, aumentando o seu conhecimento sobre o ambiente e o problema. Apesar do sucesso apresentado na aplicação de técnicas AR a problemas reais (TESAURO, 1995; BARTO; CRITES, 1996; SCARDUA; CRUZ; COSTA, 2002; ABBEEL et al., 2007; O’NEILL et al., 2010; CHI et al., 2011; LITTMAN; BOYAN, 2013; EDWARDS et al., 2014), elas podem apresentar indesejada lentidão na obtenção das soluções (BARTO; MAHADEVAN, 2003).

Uma forma de mitigar essa lentidão é explorar características da representação do problema original que permitam a representação de subproblemas. Possibilitar que um problema de AR originalmente com representação monolítica seja representado de forma modular permite o uso de políticas parciais (SUTTON; PRECUP; SINGH, 1999). Na nova representação, são determinados subproblemas componentes do problema original, permitindo o aprendizado simultâneo da solução para o problema original e seus subproblemas. Quando o problema original possui uma estrutura hierárquica, é comum o agente ter de resolver mais de uma vez o mesmo subproblema em momentos diferentes. Nesses casos, a utilização de políticas parciais apresenta a vantagem de acelerar o aprendizado por eliminar a necessidade de se aprender a solução para o mesmo subproblema mais de uma vez, permitindo o reuso do conhecimento já adquirido na forma de políticas parciais (SUTTON; PRECUP; SINGH, 1999) e dessa forma acelerando o aprendizado.

Entretanto, para que as políticas parciais possam ser utilizadas, há a necessidade da definição de elementos cuja identificação pode não ser imediata à apreciação do problema, podendo causar sobrecarga em tempo de projeto. Para contornar esse revés, são estudadas técnicas de descoberta automática de políticas parciais (STOLLE; PRECUP, 2002; BAKKER; SCHMIDHUBER, 2004; MCGOVERN; BARTO, 2001; SINGH; BARTO; CHENTANEZ, 2005), em que a definição das mesmas fica a cargo de um algoritmo responsável por identificar subproblemas e criar políticas parciais para resolvê-los. Das diversas técnicas empregadas, pode ser destacada a utilização de motivação intrínseca em AR (SINGH; BARTO; CHENTANEZ, 2005), em que o agente recebe recompensas adicionais através de um mecanismo interno associado a variações de características do ambiente que lhe despertam marcado interesse. Nessas técnicas, o agente é codificado de forma a associar subproblemas a variações significativas de atributos selecionados 
na descrição fatorada de cada estado do problema, reduzindo o trabalho de definição das políticas parciais à determinação dos atributos relevantes para a identificação dos subproblemas.

Essa técnica foi aplicada com sucesso na solução de um problema com forte estrutura hierárquica (SINGH; BARTO; CHENTANEZ, 2005), através da proposta de um algoritmo que utiliza em conjunto múltiplas técnicas de AR. Apesar da apresentação detalhada do papel da motivação intrínseca no aprendizado, não há uma investigação mais aprofundada dos diversos componentes de aprendizado envolvidos no algoritmo, notadamente a estratégia de aplicação das políticas parciais aprendidas.

\subsection{Objetivo}

O objetivo deste trabalho é propôr estratégias de aplicação de políticas parciais no Aprendizado por Refoço com Motivação Intrínseca. Especificamente, são investigados os aspectos de utilização do histórico de aplicação de políticas parciais de forma a auxiliar o processo de seleção de ações por parte do agente. Dessa forma, a meta deste trabalho é a de propôr estratégias de aplicação de políticas parciais que visem a um impacto positivo no desempenho de aprendizado do agente em um processo de Aprendizado por Refoço com Motivação Intrínseca.

\subsection{Contribuição}

Neste trabalho são investigadas estratégias de aplicação de políticas parciais, sendo realizada a avaliação experimental das mesmas em relação ao impacto no desempenho de aprendizado. A primeira contribuição se dá pela proposta de estratégia de armazenamento do histórico de políticas parciais aplicadas pelo agente, através de uma estrutura de dados que armazena sequencialmente as políticas parciais aplicadas pelo agente durante o aprendizado. Propõe-se também a adição do elemento exploratório ao processo de aprendizado interno às políticas parciais. Com a adição do mecanismo, a seleção de ações através da política parcial passa a dispor também da possibilidade de executar ações aleatórias, possibilitando ao agente realizar exploração, buscando auxiliar o processo de aprendizado.

\subsection{Organização do Texto}

Esta dissertação está organizada da seguinte maneira: no Capítulo 2 é apresentada uma revisão da literatura científica associada ao trabalho desenvolvido nesta dissertação. Em seguida, no Capítulo 3, apresenta-se a definição do problema investigado neste trabalho, 
juntamente à sua formalização, onde são apresentados os algoritmos utilizados neste trabalho, juntamente aos conceitos teóricos subjacentes, sendo as propostas deste trabalho apresentadas e formalizadas no Capítulo 4. A avaliação experimental das propostas deste trabalho foi realizada em um domínio com forte caracterização hierárquica, que é descrito no Capítulo 5, juntamente à modelagem utilizada nos experimentos e aos resultados obtidos e correspondente discussão. Finalmente, no Capítulo 6, são apresentadas as conclusões deste trabalho, baseadas nos resultados experimentais obtidos na avaliação das propostas, juntamente à discussão de possibilidades de trabalhos futuros envolvendo o ferramental de aprendizado investigado neste trabalho. 



\section{Revisão de Literatura}

Aprendizado por Reforço (SUTTON; BARTO, 1998) (AR) consiste de um campo de pesquisa com substanciais arcabouços teórico e algorítmico (SZEPESVÁRI, 2010), o que pode ser explicado pelo extremo poder e relativa simplicidade subjacentes às técnicas investigadas nesse campo. A simplicidade é explicada pelo fato de o agente de AR ser representado essencialmente por um mecanismo de interpretação de recompensas imediatas e futuras recebidas pelas ações executadas, sendo essa informação utilizada para guiar o agente em um processo de tentativa e erro, o que confere marcada flexibilidade às técnicas de AR, permitindo ao agente adaptar-se a ambientes com significativo dinamismo, isto é, problemas nos quais o mecanismo responsável por fornecer as recompensas é não-determinista (SUTTON; BARTO, 1998).

Apesar do sucesso obtido na aplicação de AR a uma vasta gama de problemas (TESAURO, 1995; BARTO; CRITES, 1996; SCARDUA; CRUZ; COSTA, 2002; ABBEEL et al., 2007; O'NEILL et al., 2010; CHI et al., 2011; LITTMAN; BOYAN, 2013; EDWARDS et al., 2014), os problemas de AR são afetados pela maldição da dimensionalidade: o número de parâmetros que o agente necessita aprender cresce exponencialmente com a cardinalidade do espaço de estados. O resultado disso é um alto custo computacional associado à aplicação de algoritmos de AR a problemas de interesse prático. Para contornar esse problema, podem ser aplicadas técnicas que exploram características da representação do problema de forma a obter compactação dos elementos a serem aprendidos através da remoção de elementos desnecessários, isto é, técnicas de abstração (BERGAMO et al., 2011; MATOS et al., 2011a; MATOS et al., 2011b; BEIRIGO et al., 2012; KOGA et al., 2013; SUTTON; PRECUP; SINGH, 1998; SUTTON; PRECUP; SINGH, 1999; STOLLE; PRECUP, 2002; ŞIMŞEK; BARTO, 2004).

Problemas que possuem estrutura hierárquica podem ser decompostos em subproblemas, sendo que, nessa classe de problemas, é comum o agente ter de resolver o mesmo subproblema mais de uma vez para obter a solução final. Para essa classe de problemas, podem ser utilizadas técnicas em que a solução para os subproblemas é aprendida uma única vez e reusada pelo agente quando necessário (BARTO; MAHADEVAN, 2003).

Esse conceito é aplicado na técnica de Hierarquia de Máquinas Abstratas (PARR, 1998), onde o problema é subdividido em subproblemas, aos quais são associadas ações abstratas denominadas HMAs, que representam "planos" ou "estratégias" de solução para os subproblemas. As HMAs podem ser estruturadas hierarquicamente de forma a corresponderem a soluções de partes ou regiões específicas do problema, podendo ser disponibilizadas ao agente somente as que são aplicáveis ou úteis no estado em que ele 
se encontra. O controle é realizado através de supervisão de políticas por outras, em camadas, ou seja, é possível o encadeamento estruturado de HMAs, onde uma ação abstrata representada por uma HMA pode invocar outra HMA de forma hierárquica.

MAXQ (DIETTERICH, 2000) aborda o problema de representação hierárquica de uma perspectiva na qual o problema a ser resolvido inicialmente pelo agente é decomposto em subproblemas menores, gerando um conjunto de problemas e subproblemas encadeados hierarquicamente. O problema-raiz consiste do problema original, cuja solução depende da solução dos demais. A estrutura final do problema pode ser representada na forma de um grafo, onde cada nó corresponde a um subproblema e as arestas indicam relações de dependência de solução entre os problemas e subproblemas conectados.

A abordagem para o problema de representação hierárquica utilizada neste trabalho é a de políticas parciais (SUTTON; PRECUP; SINGH, 1999), onde cada subproblema é associado a uma política parcial própria. A essa política parcial são associados dois elementos: $(i)$ um conjunto de estados onde a política parcial é aplicável e (ii) uma função de terminação que indica a probabilidade de cessar a execução da política parcial após alcançar um determinado estado. Dessa forma, um problema ao qual seria associada uma política de solução completa é dividido em subproblemas menores, sendo a solução final obtida pelo encadeamento das políticas parciais responsáveis por resolver cada um dos subproblemas.

Foi apresentada recentemente uma análise formal do impacto positivo no desempenho de aprendizado obtido através da utilização de políticas parciais (BRUNSKILL; LI, 2014). Essa vantagem pode ser explicada pelo fato de as políticas parciais permitirem o encapsulamento de subproblemas. Com esse encapsulamento, a solução para um subproblema pode ser obtida pela invocação de uma política parcial uma única vez, em oposição à necessidade de se aplicar diversas ações primitivas, como apontado por Konidaris e Barto (2009). Assim, uma vez aprendida a solução para um subproblema, ela pode ser executada múltiplas vezes sem implicar novamente em custo computacional de aprendizado da sequência de ações primitivas necessárias para resolvê-lo, gerando melhoria de desempenho no aprendizado.

Para contornar a eventual sobrecarga relacionada à necessidade de aprendizado de múltiplas políticas parciais foi proposta a técnica de Aprendizado Interno à Política Parcial (SUTTON; PRECUP; SINGH, 1998), onde fragmentos de conhecimento aprendido sobre uma única política parcial podem ser utilizados para atualizar mútiplas políticas parciais que os compartilham, permitindo ainda que essa atualização seja realizada mesmo antes de ocorrer a terminação da política parcial, potencialmente acelerando o processo de aprendizado.

Apesar de vantajosa, a utilização das políticas parciais necessita da definição dos estados onde ela pode ser iniciada e de uma função que relaciona estados a uma 
probabilidade de terminação, potencialmente gerando sobrecarga em tempo de projeto. De forma a contornar esse revés, foram propostas técnicas de Descoberta Automática de Políticas Parciais, cuja premissa geral recai sobre a identificação de um subproblema através de heurística e consequente associação de uma política parcial para resolvê-lo, por exemplo, por densidade de visitação de estados (MCGOVERN; BARTO, 2001), redes Bayesianas dinâmicas (MUGAN; KUIPERS, 2009), grafos de conectividade de estados (ŞIMŞEK; BARTO, 2009), novidade no processo de visitação de estados (ŞIMŞEK; BARTO, 2004) e motivação intrínseca (SINGH; BARTO; CHENTANEZ, 2005).

Desses, pode-se destacar a utilização de motivação intrínseca, um mecanismo interno ao agente que fornece recompensas independentemente da solução completa do problema, podendo ser utilizado para promover o aprendizado de habilidades necessárias à solução do problema completo, tendo despertado interesse da comunidade científica pela aplicabilidade com sucesso a diversos domínios. A utilização de motivação intrínseca promove a execução de tarefas, como a solução de um subproblema, sem que necessariamente haja a busca por uma recompensa externa, ou seja, o agente engaja na solução de um subproblema motivado por um mecanismo interno de recompensas.

A utilização de motivação intrínseca em Inteligência Artificial não é estritamente recente, tendo sido utilizada por Lenat (1976) através da implementação de heurísticas baseadas em uma medida de "interesse", utilizada pelo agente para a descoberta de novos conceitos matemáticos com base em um conhecimento rudimentar inicial, e por Schmidhuber (1991) para a proposta de um modelo computacional de controles neurais com a função de simular "curiosidade" em um agente de aprendizado, sendo que revisões abrangentes da literatura associada à utilização de motivação intrínseca em Inteligência Artificial são apresentadas em (OUDEYER; KAPLAN, 2007; OUDEYER; KAPLAN; HAFNER, 2007; MERRICK; MAHER, 2009).

Şimşek e Barto (2006) utilizaram motivação intrínseca para aprimorar o processo de exploração, dividindo o processo de aprendizado em duas etapas: ( $i$ ) em uma etapa inicial, o agente aprendiz direciona seus esforços à aquisição de "habilidades", representadas por políticas parciais para solucionar subproblemas, sem buscar, nessa fase inicial, acumular recompensas por resolver o problema completo; (ii) após a etapa inicial, o agente aplica as "habilidades" aprendidas na primeira etapa, concentrando-se nesse momento na solução do problema completo, ou seja, maximizar as recompensas recebidas ao solucionar o problema. Para isso, os autores propõem uma técnica que deriva um segundo PMD a partir do PMD referente ao problema original, de tal forma que a política ótima para PMD gerado realiza a exploração ótima para o PMD original, ou seja, a política ótima para o PMD gerado é responsável por executar um processo exploratório que seja ótimo para a solução do PMD original.

A relação entre recompensas extrínsecas e intrínsecas é investigada sob a perspectiva 
evolucionária por Singh et al. (2010), onde os autores utilizam o ferramental de obtenção de funções de recompensa ótimas, proposto por Singh, Lewis e Barto (2009). O trabalho apresenta resultados que sugerem que ambas, motivações extrínseca e intrínseca, podem ser consideradas propriedades emergentes da função de recompensas, sendo a distinção dada mais expressivamente por um posicionamento espectral, ou seja as naturezas das motivações podem ser encaradas como indistintas. Em outras palavras, a distinção é expressa mais significativamente por um grau de impacto no aprendizado, sendo as recompensas intrínsecas relacionadas com mais expressividade a motivações imediatas e as recompensas extrínsecas, às motivações de longo prazo. Os autores apontam para o risco de uma má escolha das funções de recompensa intrínseca e extrínseca, que podem implicar em um agente cujo interesse recai mais sobre a solução dos subproblemas do que do problema propriamente dito, mas os resultados obtidos apontam para a possibilidade de acrescentar conhecimento prévio ao agente através de funções de recompensa.

O conceito de motivação intrínseca foi aplicado à Teoria dos Jogos por Merrick e Shafi (2013), onde agentes foram implementados com diferentes mecanismos de recompensas intrínsecas e avaliados em domínios multi-agentes. Os resultados obtidos nos experimentos sugerem que os valores de recompensas intrínsecas podem impactar significativamente no comportamento dos agentes. Assim, por exemplo, agentes com mecanismos que forneciam valores menores de recompensas intrínsecas tenderam a perceper o problema de maneira enviesada, obtendo um desempenho final inferior, enquanto os agentes que receberam altos valores de recompensas intrínsecas apresentaram uma percepção correta das regras, apresentando um melhor desempenho. Os autores concluem afirmando que o mecanismo de recompensas intrínsecas poderia ser utilizado para conferir diferentes "personalidades" aos agentes, ou seja, codificar diferentes percepções de maximização do valor esperado de recompensas futuras.

No trabalho de Singh, Barto e Chentanez (2005) foi proposto o algoritmo de Aprendizado por Reforço com Motivação Intrínseca (ARMI), onde o agente recebe recompensas associadas a variações significativas de determinados atributos da descrição fatorada do estado, denominados atributos salientes. As variações de um ou mais atributos salientes dispara o que é denominado evento saliente. Essas variações são então associadas a subproblemas, cujo objetivo é disparar o evento saliente correspondente. Cria-se então uma política parcial para resolver esse subproblema, ou seja, disparar o evento saliente, que é aprendida pelo agente.

Como detalhado em um trabalho associado (BARTO; SINGH; CHENTANEZ, 2004), o ARMI modela a motivação intrínseca através de um mecanismo de simulação de "curiosidade" no agente aprendiz. O agente utiliza o modelo de transição das políticas parciais para controlar a predictibilidade das transições nas quais ocorrem as variações dos atributos salientes. No referido trabalho, os atributos salientes correspondem a leituras de 
sensores de luz e som presentes no agente. Dessa forma, um evento saliente é disparado quando o agente liga a luz da sala em que se encontra ou desliga a música, por exemplo. Quanto menos previsível for a variação de luz ou som, maior é a recompensa fornecida pelo mecanismo interno de motivação intrínseca presente no agente. Dito de outra maneira, quanto mais "inesperada" for a variação de luz ou som, maior será a recompensa intrínseca recebida pelo agente; consequentemente, maior será a motivação do agente a repetir o evento saliente correspondente. À medida que o agente dispara consecutivas vezes um evento saliente, o modelo da política parcial associada é aprimorado, dessa forma diminuindo gradualmente o valor das recompensas intrínsecas recebidas. Como resultado, o agente tende a repetir os eventos salientes menos conhecidos, direcionando os esforços de aprendizado às políticas parciais cujos modelos estão menos aprimorados, dessa forma promovendo o aprendizado da política parcial correspondente.

No trabalho de Şimşek e Barto (2005), foi proposta uma alternativa ao mecanismo de recompensas intrínsecas do algoritmo ARMI (SINGH; BARTO; CHENTANEZ, 2005), na qual o cálculo da recompensa intrínseca considera não somente o modelo da política parcial sendo aplicada atualmente pelo agente, como em (SINGH; BARTO; CHENTANEZ, 2005), mas o modelo de todas as políticas parciais conhecidas pelo agente. A proposta foi avaliada experimentalmente em uma versão simplificada do domínio Playroom (SINGH; BARTO; CHENTANEZ, 2005) e os resultados obtidos sugerem um impacto positivo na fase inicial do aprendizado, mas apontam para o compromisso entre as recompensas extrínsecas e intrínsecas: dependendo dos parâmetros utilizados, é possível que o agente direcione mais esforços de aprendizado à solução dos subproblemas do que à solução do problema completo.

Stout, Konidaris e Barto (2005) apontam que ( $i$ ) o potencial de generalização do aprendizado para tarefas que compartilhem eventos salientes, (ii) a capacidade de aprendizado "auto-motivado" através de recompensas intrínsecas, e ( $i i i)$ o aprendizado hierárquico do problema e respectivos subproblemas tornam o ARMI um candidato adequado para o aprendizado estruturado em navegação robótica. Os autores apresentam resultados experimentais que sugerem a aplicabilidade da estratégia para o aprendizado estruturado em camadas de uma hierarquia de comportamentos, nesse caso utilizados pelo robô para controlar a luz ambiente de forma a abrir uma porta e alcançar o carregador de sua bateria em um conjunto de salas.

Schembri, Mirolli e Baldassarre (2007) abordam a limitação representada pela necessidade da definição prévia dos atributos salientes através da proposta de um mecanismo que utiliza técnicas de Robótica Evolutiva, representando os eventos salientes e as soluções para os mesmos por redes neurais artificiais, evoluídas através de algoritmo genético, no lugar de atributos salientes e políticas parciais. Os autores apontam como vantagem adicional da utilização de redes neurais a capacidade das mesmas de lidar com domínios 
contínuos, dessa forma estendendo a gama de problemas possíveis de serem abordados pela técnica proposta. A técnica é avaliada em uma plataforma de simulação de navegação robótica, onde, de maneira similar ao realizado por Şimşek e Barto (2006), o aprendizado é dividido em duas etapas, sendo a primeira responsável pela aquisição de soluções para diferentes subproblemas, que são então aplicadas na segunda etapa para a solução do problema de navegação. Os resultados obtidos são promissores, sugerindo a viabilidade da técnica na identificação e solução dos subproblemas através de eventos salientes com a utilização de redes neurais artificiais e algoritmos genéticos. Entretanto, como os próprios autores apontam, ao optar por não utilizar políticas parciais, o algoritmo resultante perde a capacidade de abstração temporal e deixa de ser capaz de invocar soluções para subproblemas recursivamente, ou seja, a tomada de decisões é feita no nível das ações primitivas e a solução de um subproblema não é capaz de utilizar a solução para outro subproblema em sua composição.

Uma proposta relacionada à limitação imposta pela necessidade de atribuição prévia dos atributos salientes foi apresentada por Beirigo, Silva e Costa (2014), onde sugere-se que a descoberta dos atributos salientes se dê através da avaliação do impacto que a remoção de um atributo da descrição fatorada dos estados teria na função valor caso aplicada na nova descrição fatorada que não utiliza o atributo saliente removido. Dessa forma, os atributos salientes seriam identificados pelos atributos cuja remoção implicou no maior impacto nas funções-valor resultantes, motivados pela expectativa de que, em um problema com forte caracterização hierárquica, os atributos salientes desempenham papel relativamente central na descrição fatorada dos estados, dessa forma, sua remoção implicaria em um expressivo impacto no cálculo da função-valor resultante.

O ARMI foi investigado quanto à capacidade de descoberta e aprendizado de políticas parciais (SINGH; BARTO; CHENTANEZ, 2005; BARTO; SINGH; CHENTANEZ, 2004), alternativas de mecanismos de recompensas intrínsecas (ŞIMŞEK; BARTO, 2005), aplicabilidade ao domínio de navegação robótica (STOUT; KONIDARIS; BARTO, 2005) e descoberta automática de eventos salientes, eliminando a necessidade de definição dos atributos salientes (SCHEMBRI; MIROLLI; BALDASSARRE, 2007; BEIRIGO; SILVA; COSTA, 2014). Entretanto, o mecanismo de aplicação das políticas parciais no ARMI não foi investigado de forma aprofundada. Essa questão é importante para o processo de aprendizado, dado que a correta aplicação do conhecimento adquirido possui potencial de melhora significativa no desempenho do agente. Dessa forma, neste trabalho essa questão é investigada, sendo propostas estratégias de aplicação de políticas parciais no algoritmo ARMI.

Especificamente, são investigados os impactos no aprendizado obtidos através da implementação de estratégias de 
- armazenamento das políticas parciais em aplicação pelo agente - em problemas hierárquicos, a sequência de subproblemas resolvidos pelo agente, logo, a sequência de políticas parciais aplicadas pode conter informações sobre a estrutura do problema enfrentado pelo agente; dessa forma, espera-se que o agente, ao armazenar as políticas parciais em aplicação e utilizar essa informação, possa obter uma melhora no desempenho de aprendizado;

- exploração interna à aplicação das políticas parciais - no ARMI, as políticas parciais não são definidas a priori, mas descobertas automaticamente pelo agente e aprendidas em paralelo ao aprendizado da solução do problema; dessa forma, espera-se que, ao permitir ao agente explorar nos estágios iniciais de aprendizado das políticas parciais, ele possa ser obter uma melhora no processo de aprendizado, utilizando o processo de exploração para o aprimoramento das políticas parciais nos estágios iniciais, nos quais ele ainda não pode contar com políticas parciais que puderam ser aprimoradas expressivamente.

Dessa forma, neste capítulo buscou-se apresentar uma visão geral dos trabalhos realizados em Aprendizado por Reforço com Motivação Intrínseca, apresentando os aspectos investigados em trabalhos da literatura relacionada à utilização de Motivação Intrínseca em Inteligência Artificial e os correspondentes resultados obtidos. Com base nos trabalhos apresentados, procurou-se motivar os aspectos de aplicação das políticas parciais, investigados nesta dissertação. No próximo capítulo, é apresentada a definição formal do problema abordado neste trabalho, juntamente aos fundamentos teóricos relacionados aos algoritmos de aprendizado utilizados neste trabalho. 



\section{Definição do Problema e Fundamenta- ção Teórica}

Em sua forma mais geral, o problema abordado neste trabalho é o de Aprendizado por Reforço (AR) (SUTTON; BARTO, 1998), onde um agente obtém a solução de um problema de decisão sequencial na forma de uma política ótima através da execução de ações em um ambiente e observação das recompensas recebidas. Como esse processo ocorre por tentativa e erro, ele pode apresentar lentidão.

Para acelerar o processo de aprendizado, podem ser utilizadas técnicas de reuso de conhecimento, que exploram características da representação de problemas conhecidos pelo agente, buscando identificar fragmentos do conhecimento adquirido potencialmente úteis na solução de problemas futuros.

Em particular, problemas com estrutura hierárquica são resolvidos através da composição de soluções de subproblemas aí presentes. Nesses casos é vantajoso para o agente, em termos de desempenho de aprendizado, identificar os subproblemas, obtendo as respectivas soluções parciais, armazenando-as para reuso futuro.

O formalismo adotado neste trabalho para a representação de soluções para os subproblemas é o de políticas parciais (SUTTON; PRECUP; SINGH, 1999), de forma a permitir a utilização do arcabouço teórico e algorítmico de identificação e solução de subproblemas (SINGH; BARTO; CHENTANEZ, 2005).

No trabalho de Singh, Barto e Chentanez (2005) é proposto o algoritmo de Aprendizado por Reforço com Motivação Intrínseca (ARMI), no qual é realizada a descoberta automática de subproblemas e o aprendizado de políticas parciais para solucioná-los. Entretanto, não foi realizada uma investigação aprofundada acerca dos aspectos de aplicação das políticas parciais no ARMI. Dessa forma, neste trabalho esses aspectos são investigados através da implementação de estratégias de armazenamento e exploração interna às políticas parciais, que são implementadas no ARMI, gerando o algoritmo A-EIP 3 .

O problema abordado por este trabalho é o de, com base no histórico de políticas parciais selecionadas pelo agente durante um experimento de ARMI, manter um subconjunto dessas políticas parciais, atualizando-o segundo uma heurística, de forma a obter uma estratégia de seleção da próxima ação a ser executada que contemple esse subconjunto, buscando maximizar o desempenho de aprendizado. Formalmente,

Problema Em um experimento utilizando Aprendizado por Reforço com Motivação Intrínseca, no qual são definidos os eventos salientes utilizados no mecanismo de recompensa intrínseca, dados 
- um histórico ${ }^{1} \mathcal{H}=\phi_{1}, \phi_{2}, \ldots, \phi_{n}$ de políticas parciais, não necessariamente distintas, selecionadas nessa ordem e

- uma subsequência $\Pi$ de $\mathcal{H}$ de políticas parciais ativas,

determinar, no momento da seleção da próxima ação a ser executada:

- a subsequência $\bar{\Pi}$ de $\Pi$ de políticas parciais que se tornarão inativas, no passo atual e antes da seleção da próxima ação e

- a próxima ação primitiva ou política parcial a ser executada.

A seguir, será apresentada a fundamentação teórica utilizada neste trabalho. Na próxima seção será apresentada a formalização dos problemas de decisão sequenciais através de Processos Markovianos de Decisão (PMD). Em seguida serão apresentados os fundamentos das técnicas de Aprendizado por Reforço (SUTTON; BARTO, 1998) como solucionadoras de PMDs, finalizando com a descrição de um exemplo através da apresentação do algoritmo Q-Learning (WATKINS, 1989).

Após isso, são introduzidas as políticas parciais (SUTTON; PRECUP; SINGH, 1999), formalizadas por Processos semi-Markovianos de Decisão (PSMD), juntamente às técnicas de aprendizado relacionadas: aprendizado do modelo (SUTTON; PRECUP; SINGH, 1999) e interno (SUTTON; PRECUP; SINGH, 1998) às políticas parciais.

Finalmente, é apresentado o conceito de descoberta de políticas parciais, descrevendo a relação entre motivação intrínseca e eventos salientes e como eles são aplicados no algoritmo de descoberta automática de políticas parciais ARMI (SINGH; BARTO; CHENTANEZ, 2005), ao qual a contribuição deste trabalho é direcionada.

\subsection{Aprendizado por Reforço (AR)}

Em um problema de decisão sequencial, um agente imerso em um sistema busca maximizar uma medida numérica de desempenho no longo prazo. Para isso, esse agente dispõe de dois mecanismos, um situacional e um atuador, podendo o primeiro ser utilizado para perceber (aproximadamente) o estado em que o agente se encontra e o segundo podendo modificá-lo através da execução de ações que podem levá-lo a outro estado.

Em outras palavras, em um problema de decisão sequencial um agente, ao perceber o estado em que se encontra, deve decidir a cada momento a ação a executar de forma a que, no longo prazo, ele maximize o valor de recompensas recebido.

1 É importante notar que o armazenamento da sequência completa $\mathcal{H}$ de políticas parciais é impraticável do ponto de vista computacional. Dessa forma, o que é de fato armazenado é somente um subconjunto $\Pi$ de interesse para a heurística de aprendizado, em processo detalhado mais adiante. 
Devido à sua simplicidade e flexibilidade, muitos problemas de interesse prático podem ser modelados como problemas de decisão sequencial, cujas soluções podem ser obtidas por técnicas de Programação Dinâmica (BELLMAN, 1954). Entretanto, a menos de problemas com uma quantidade relativamente pequena de estados, a aplicação de Programação Dinâmica é impraticável devido ao alto custo computacional (SZEPESVÁRI, 2010).

Nas próximas subseções é apresentada a formalização do problema de decisão sequencial por um Processo Markoviano de Decisão e como eles podem ser resolvidos através de Aprendizado por Reforço (AR) (SUTTON; BARTO, 1998), um conjunto sofisticado de técnicas que buscam atenuar a complexidade dos problemas com substancial quantidade de estados.

Finalmente, é apresentado um algoritmo de AR, o Q-Learning (WATKINS, 1989), cuja função é a de atualizar constantemente a previsão do valor esperado de recompensas ao se executar cada ação nos estados do problema, dessa forma guiando o agente na seleção das ações.

\subsubsection{Processos Markovianos de Decisão (PMD) e AR}

Para ser resolvido por técnicas de Aprendizado por Reforço (AR) (SUTTON; BARTO, 1998), um problema de decisão sequencial pode ser modelado por um Processo Markoviano de Decisão (PMD), no qual o agente interage com o ambiente em passos discretos $t=0,1,2, \ldots$ Um PMD é definido pela quádrupla $\langle S, A, P, R\rangle$, em que $S$ e $A$ são conjuntos finitos de estados e ações, respectivamente, onde $A=\bigcup_{s \in S} A_{s}$, em que $A_{s}$ é o conjunto de ações possíveis em um estado $s \in S$. A função $P: S \times A \times S \rightarrow[0,1]$ fornece a probabilidade de transição, denotada por $P_{s s^{\prime}}^{a}$, de o agente, estando em $s$, migrar para o estado $s^{\prime} \in S$ ao executar a ação $a \in A$, sendo a recompensa imediata recebida na mesma transição fornecida pela função $R: S \times A \times S \rightarrow \Re$ e denotada por $R_{s s^{\prime}}^{a}$. As funções $P$ e $R$, em conjunto, constituem o modelo do ambiente. Vale ressaltar que é possível definir a função $R: S \times A \rightarrow \Re$, que fornece a recompensa recebida ao se executar uma ação em um estado e $R: S \rightarrow \Re$, que fornece a recompensa ao se alcançar um determinado estado.

Uma política $\pi: S \times A \rightarrow[0,1]$ fornece a probabilidade $\pi(s, a)$ de se executar uma ação a em um estado $s$. Fixada uma política $\pi$, define-se a função valor-estado associada a $\pi, V^{\pi}: S \rightarrow \Re$, que fornece o valor esperado de recompensas futuras descontadas associado a um estado s segundo $\pi, V^{\pi}(s)$. Em outras palavras, $V^{\pi}(s)$ fornece o valor esperado de recompensas descontadas que o agente receberá ao, partindo de $s$, realizar as ações indicadas por $\pi$, sendo sua definição dada por

$$
V^{\pi}(s)=E_{\pi}\left\{\sum_{k=0}^{\infty} \gamma^{k} r_{t+k+1} \mid s_{t}=s\right\},
$$


onde $E_{\pi}\{\cdot\}$ fornece o valor esperado associado à política $\pi$ e $\gamma \in[0,1]$ representa um fator de desconto, que indica quão significativa é uma recompensa futura no momento presente ${ }^{2}$.

De forma análoga, define-se $Q^{\pi}: S \times A \rightarrow \Re$, a função valor-ação, denotada por $Q^{\pi}(s, a)$, que fornece o valor esperado de recompensas futuras descontadas associado $\grave{a}$ execução de uma ação a em um estado s seguindo a política $\pi$ daquele momento em diante, por

$$
Q^{\pi}(s, a)=E_{\pi}\left\{\sum_{k=0}^{\infty} \gamma^{k} r_{t+k+1} \mid s_{t}=s, a_{t}=a\right\}
$$

$V^{\pi}$ pode ser escrita em função de $Q^{\pi}$ por

$$
\begin{aligned}
V^{\pi}(s) & =E_{\pi}\left\{\sum_{k=0}^{\infty} \gamma^{k} r_{t+k+1} \mid s_{t}=s\right\} \\
& =\sum_{a} \pi(s, a) E_{\pi}\left\{\sum_{k=0}^{\infty} \gamma^{k} r_{t+k+1} \mid s_{t}=s, a_{t}=a\right\} \\
& =\sum_{a} \pi(s, a) Q^{\pi}(s, a) .
\end{aligned}
$$

A função $V^{\pi}$ é denominada função-valor e, para aprender uma função-valor, isto é, encontrar $V^{\pi}(s), \forall s \in S$, pode-se utilizar a respectiva equação de Bellman, que estabelece uma relação recursiva entre valores de uma sequência temporal de instâncias de uma função. A equação de Bellman associada a $V^{\pi}$ é dada por

$$
\begin{aligned}
V^{\pi}(s) & =E_{\pi}\left\{\sum_{k=0}^{\infty} \gamma^{k} r_{t+k+1} \mid s_{t}=s\right\} \\
& =E_{\pi}\left\{r_{t+1}+\gamma \sum_{k=0}^{\infty} \gamma^{k} r_{t+k+2} \mid s_{t}=s\right\} \\
& =\sum_{a} \pi(s, a) \sum_{s^{\prime}} P_{s s^{\prime}}^{a}\left[R_{s s^{\prime}}^{a}+\gamma E_{\pi}\left\{\sum_{k=0}^{\infty} \gamma^{k} r_{t+k+2} \mid s_{t+1}=s^{\prime}\right\}\right] \\
& =\sum_{a} \pi(s, a) \sum_{s^{\prime}} P_{s s^{\prime}}^{a}\left[R_{s s^{\prime}}^{a}+\gamma V^{\pi}\left(s^{\prime}\right)\right] .
\end{aligned}
$$

A solução de um PMD é uma política ótima, $\pi^{*}$, que associa a cada estado as probabilidades de execução de ações que maximizam o valor esperado de recompensas descontadas futuras, ou seja, $\pi^{*}$ é tal que ${ }^{3}$

$$
V^{\pi^{*}}(s) \geq V^{\pi}(s), \forall \pi, \forall s \in S
$$

$\overline{2}$ Ou seja, $\gamma$ fornece um meio de diferenciar valores iguais de recompensas futuras que podem ser obtidas mais ou menos rapidamente pelo agente.

3 Vale ressaltar que é possível também definir-se uma política parcial determinista, que associa a cada estado um conjunto de ações que maximizam o valor esperado de recompensas descontadas futuras. 
As funções valor-estado e valor-ação ótimas, isto é, associadas a $\pi^{*}$, são, respectivamente, $V^{*}$ e $Q^{*}$ e satisfazem

$$
\begin{aligned}
V^{*}(s) & =\max _{\pi} V^{\pi}(s), \forall s \in S \\
Q^{*}(s, a) & =\max _{\pi} Q^{\pi}(s, a), \forall s \in S, \forall a \in A .
\end{aligned}
$$

Para solucionar o PMD é necessário aprender uma política ótima $\pi^{*}$. Uma vez obtida $V^{*}$ ou $Q^{*}, \pi^{*}$ pode ser obtida da seguinte maneira: de posse de $Q^{*}$ associa-se um valor não-nulo a $\pi^{*}(s, a)$ para as ações que maximizam o valor de $Q^{*}$ e zero às demais; caso se obtenha $V^{*}, Q^{*}$ pode ser obtida a partir de $Q^{*}$ através da relação

$$
Q^{*}(s, a)=E\left\{r_{t+1}+\gamma V^{*}\left(s_{t+1}\right) \mid s_{t}=s, a_{t}=a\right\},
$$

após isso extraindo-se $\pi^{*}$ a partir de $Q^{*}$ da maneira supra mencionada.

Para obter $V^{*}$ e $Q^{*}$, é comum serem utilizadas as respectivas equações de Bellman,

$$
\begin{aligned}
V^{*}(s) & =E_{\pi^{*}}\left\{\sum_{k=0}^{\infty} \gamma^{k} r_{t+k+1} \mid s_{t}=s\right\} \\
& =E_{\pi^{*}}\left\{r_{t+1}+\gamma \sum_{k=0}^{\infty} \gamma^{k} r_{t+k+2} \mid s_{t}=s\right\} \\
& =\max _{a \in A_{s}} \sum_{s^{\prime}} P_{s s^{\prime}}^{a}\left[R_{s s^{\prime}}^{a}+\gamma E_{\pi}\left\{\sum_{k=0}^{\infty} \gamma^{k} r_{t+k+2} \mid s_{t+1}=s^{\prime}\right\}\right] \\
& =\max _{a \in A_{s}} \sum_{s^{\prime}} P_{s s^{\prime}}^{a}\left[R_{s s^{\prime}}^{a}+\gamma V^{*}\left(s^{\prime}\right)\right]
\end{aligned}
$$

e

$$
\begin{aligned}
Q^{*}(s, a) & =E_{\pi^{*}}\left\{r_{t+1}+\gamma \max _{a^{\prime}} Q^{*}\left(s_{t+1}, a^{\prime}\right) \mid s_{t}=s, a_{t}=a\right\} \\
& =\sum_{s^{\prime}} P_{s s^{\prime}}^{a}\left[R_{s s^{\prime}}^{a}+\gamma \max _{a^{\prime}} Q^{*}\left(s^{\prime}, a^{\prime}\right)\right] .
\end{aligned}
$$

Nesta seção, foram apresentados os fundamentos relacionados à solução de PMDs por técnicas de AR. De posse desse ferramental, é possível utilizar técnicas de AR para aprender a solução de um PMD, como será mostrado na próxima seção, onde é apresentado o algoritmo de AR Q-Learning (WATKINS, 1989).

\subsubsection{Algoritmo Q-Learning}

O algoritmo Q-Learning (WATKINS, 1989) é referido como "uma das conquistas mais importantes em Aprendizado por Reforço" (SUTTON; BARTO, 1998, 6.5, tradução própria).

$4 \quad$ Excerto original: "One of the most important breakthroughs in reinforcement learning was the development of an [...] algorithm known as Q-learning" (SUTTON; BARTO, 1998, 6.5). 
O Q-Learning é um algoritmo de diferenças temporais (DT), um conceito central ao Aprendizado por Reforço. As técnicas de DT envolvem dois elementos importantes: Monte Carlo e Programação Dinâmica. A aplicação de Monte Carlo permite o aprendizado através de amostras de transições de estados coletadas pelo agente e a aplicação de Programação Dinâmica permite a utilização das amostras no aprendizado sem a necessidade de esperar $o$ resultado final.

O conhecimento adquirido pelo agente na transição que ocorre em um passo de aprendizado é propagado retroativamente pela equação

$$
Q\left(s_{t}, a_{t}\right) \stackrel{\alpha}{\leftarrow} r_{t+1}+\gamma \max _{a} Q\left(s_{t+1}, a\right),
$$

em que

$$
x \stackrel{\alpha}{\leftarrow} y=(1-\alpha) x+\alpha y,
$$

$\alpha \in[0,1]$. Essa equação é utilizada no Q-Learning para aproximar $Q^{*}$ de forma iterativa. $\mathrm{O}$ algoritmo pode ser executado de forma contínua, como foi realizado neste trabalho, em que é estabelecida uma condição de parada, através de limite de passos de experimento, e o processo de aprendizado ocorre até que a condição de parada seja atingida, como apresentado no algoritmo 3.1 .

Uma política $\epsilon$-gulosa seleciona a ação da seguinte maneira: determina-se $\epsilon \in[0,1]$ e sorteia-se um valor também no intervalo $[0,1]$; caso o valor sorteado seja maior do que $\epsilon$, o agente seleciona a ação de maior valor para executar; caso contrário, o agente seleciona uma ação a executar de forma aleatória dentre as possíveis no estado em que se encontra.

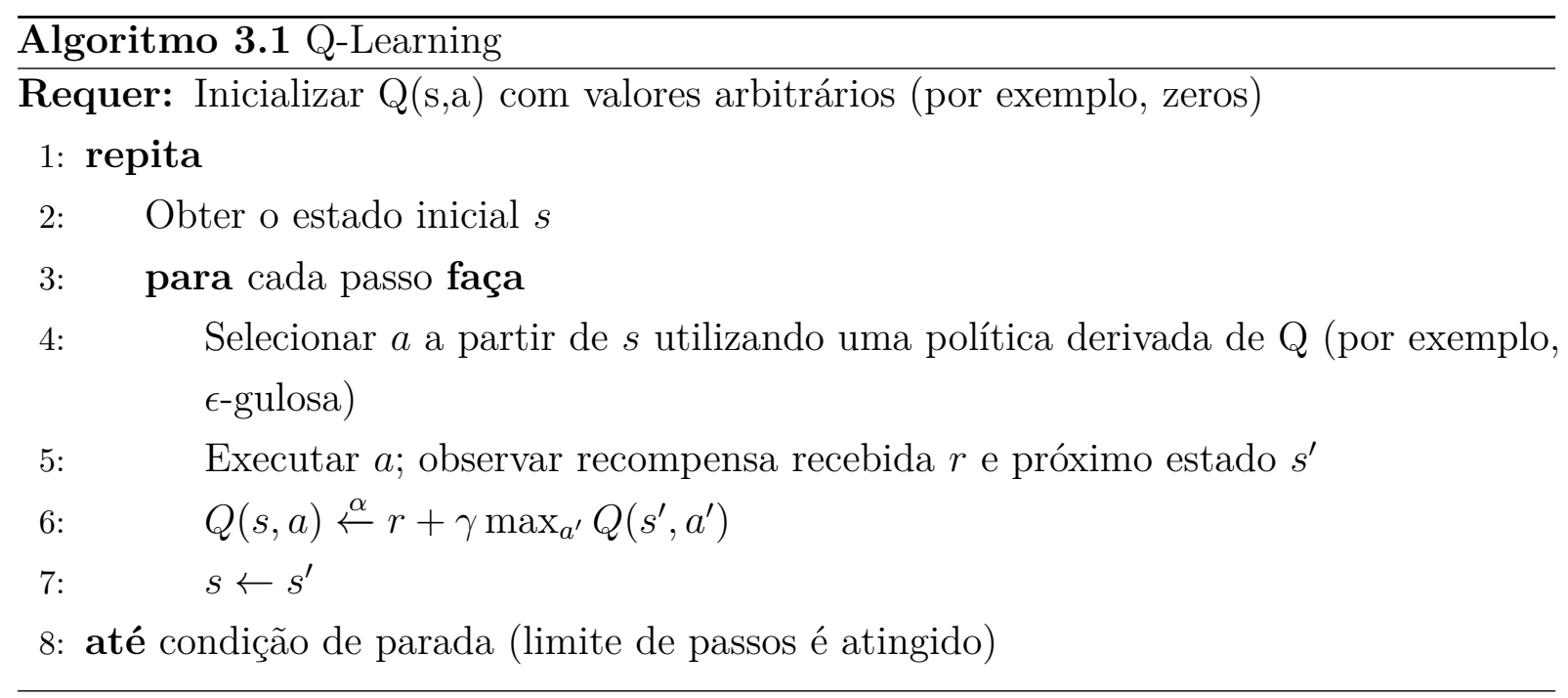

Dessa forma, o Q-Learning aproxima diretamente a função valor-ação ótima, $Q^{*}$, através de atualizações consecutivas dos valores de $Q$. Caso os pares estado-ação $(s, a), \forall s \in$ $S, \forall a \in A$ sejam experimentados pelo agente um número infinito de vezes, o algoritmo converge com probabilidade 1 para $Q^{*}$. De posse de $Q^{*}$, é possível obter a política ótima $\pi^{*}$ através da equação 3.6 , sendo que a política ótima $\pi^{*}$ corresponde à solução do PMD. 


\subsection{Políticas Parciais}

Nesta seção, apresenta-se o formalismo referente às políticas parciais (SUTTON; PRECUP; SINGH, 1999), através de Processos semi-Markovianos de Decisão (PSMD). Em seguida, são apresentados métodos de aprendizado do modelo e interno, ambos relativos à política parcial (SUTTON; PRECUP; SINGH, 1998). Finalmente, é apresentado o algoritmo ARMI (SINGH; BARTO; CHENTANEZ, 2005), que utiliza motivação intrínseca para a descoberta automática de políticas parciais.

As políticas parciais são adequadas para subdividir um problema em subproblemas menores através da identificação de objetivos intermediários (SUTTON; PRECUP; SINGH, 1999; BARTO; MAHADEVAN, 2003). A correta identificação de um objetivo intermediário potencialmente acelera a solução de um problema hierárquico, onde em geral ocorrem repetições dos subproblemas na composição da solução final. Assim, uma vez identificado um subproblema, uma política parcial pode ser associada a ele. Uma vez aprendida, a política parcial pode ser reusada múltiplas vezes sem a sobrecarga de aprendê-la novamente, potencialmente acelerando o processo de aprendizado.

Uma política parcial (SUTTON; PRECUP; SINGH, 1999) $\phi \in \Phi$ é definida pelos elementos $\langle\mathcal{I}, \pi, \beta\rangle$, onde $\mathcal{I} \subseteq S$ é o conjunto de estados onde a política parcial pode ser iniciada, $\pi: S \times A \cup \Phi \rightarrow[0,1]$ associa a probabilidade de executar uma ação primitiva $a \in A$ ou uma política parcial ${ }^{5} \phi \in \Phi$ em um estado $s \in S$, e $\beta: S^{+} \rightarrow[0,1]$ fornece a probabilidade de terminação de uma política parcial em um estado $s \in S^{+}$, onde $S^{+}$ corresponde ao conjunto completo de estados do problema, ou seja, $S^{+}$corresponde ao conjunto de estados terminais e não-terminais do problema, sendo que $S$ corresponde ao conjunto dos estados não-terminais, somente. Essa diferenciação é importante para a definição de $\mathcal{I}$, pois impede a iniciação de uma política parcial em um estado terminal, e para a definição de $\beta$, de forma a permitir a terminação de uma política parcial em um estado terminal do problema.

Por exemplo, caso um robô esteja em uma sala e sua tarefa seja ligar a luz, ele poderia utilizar uma política parcial definida pelos elementos:

- $\mathcal{I}=S$ : a política parcial pode ser aplicada em qualquer estado não-terminal, ou seja, em qualquer estado em que a luz esteja desligada;

- $\pi$ associa a cada estado de $\mathcal{I}$ as probabilidades adequadas de execução das ações de forma a guiar o robô no processo de ligar a luz: encontrar o interruptor e digirir-se a ele, caso o mesmo esteja fora do alcance do robô, e pressioná-lo, caso esteja ao alcance do robô;

5 É importante notar que, dessa forma, é possível a uma política parcial invocar outras políticas parciais de forma hierárquica, dessa forma auxiliando na solução de subproblemas encadeados, como será detalhado mais adiante. 
- $\beta(s)=1$ para todo estado $s$ em que a luz esteja ligada, ou seja, a aplicação da política parcial termina quando o robô consegue ligar a luz; $\beta(s)=0$ para todo estado $s$ em que a luz esteja desligada, ou seja, a política parcial não termina até que o robô consiga ligar a luz.

Dessa forma, as políticas parciais correspondem a "ações estendidas", ou seja, ações que duram mais de um passo. Esse fato foi ilustrado no exemplo acima, no qual a política parcial correspondente a ligar a luz pode implicar na execução de mais de uma ação primitiva. Por exemplo, caso o robô tenha encontrado o interruptor, mas o mesmo esteja além do alcance de seu braço, a aplicação da política parcial ligar a luz implicará na execução de duas ações primitivas: 1) aproximar-se do interruptor e 2) pressionar o interruptor.

Entretanto, como o formalismo de Processos Markovianos de Decisão (PMD) somente prevê ações com duração fixa de um passo, para a formalização de políticas parciais é necessário utilizar Processos semi-Markovianos de Decisão (PSMD), nos quais é possível a ocorrência de ações com durações variáveis, de um ou mais passos. Dessa forma, dados um PMD e um conjunto $\Phi$ de políticas parciais, a obtenção do PSMD resultante é relativamente direta, pois é necessário somente definir a duração das políticas parciais, como será apresentado a seguir.

Um Processo semi-Markoviano de Decisão (PSMD) é composto por:

- $S$ - conjunto de estados;

- $\Phi_{P S M D}$ - conjunto de ações, cujas durações podem compreender um passo (ações primitivas) ou múltiplos passos (políticas parciais);

- $P: S \times A \times S \rightarrow[0,1]$ - função de probabilidade de transição, em que $P_{s s^{\prime}}^{a}$ indica a probabilidade de alcançar o estado $s^{\prime}$ a partir de $s$ executando a ação $a$;

- $R: S \times A \times S \rightarrow \Re$ - função de recompensa, onde $R_{s s^{\prime}}^{a}$ é a recompensa recebida ao alcançar $s^{\prime}$ a partir de $s$ executando a ação $a$;

- $\mathcal{D}$ - função de duração das transições correspondentes à execução das ações pertencentes ao conjunto $\Phi$.

A definição de um PSMD a partir de um PMD acrescido do conjunto $\Phi$ de políticas parciais é realizada por:

- $S_{(P S M D)}=S_{(P M D)}$;

- $\Phi_{P S M D}=A_{(P M D)} \cup \Phi$;

- $R_{(P S M D)}=R_{(P M D)}$;

- $P_{(P S M D)}=P_{(P M D)}$; 
- $\mathcal{D}$ - a duração das transições no PSMD é dada em conjunto pela política de atuação $\pi$ e pela função de terminação $\beta$ referentes às políticas parciais, que indicam, respectivamente, os estados para os quais o agente transitará e em que estados a política parcial terminará.

Assim, a obtenção de um PSMD a partir de um PMD pode ser realizada de forma relativamente direta, bastando para isso obter a função $\mathcal{D}$ através do conjunto $\Phi$ de políticas parciais, sendo as funções $S, A, P$ e $R$ obtidas diretamente do PMD original.

Uma ação primitiva $a \in A$ pode ser definida como uma política parcial da seguinte maneira:

- $\mathcal{I}=\left\{s: a \in A_{s}\right\}$, ou seja, a política parcial correspondente à ação primitiva pode ser iniciada em todos os estados em que a ação primitiva pode ser executada;

- $\pi(s, a)=1, \forall s \in \mathcal{I}$, ou seja, a ação primitiva correspondente é sempre executada ao aplicar a política parcial correspondente;

- $\beta(s)=1, \forall s \in S$, ou seja, a política parcial correspondente termina em qualquer estado para o qual o agente transitou ao aplicá-la (dura somente um passo).

Dessa forma, ações primitivas e políticas parciais podem ser referidas pelo termo políticas parciais. O conjunto de políticas parciais possíveis de serem executas em um estado $s$ é dado pelo conjunto $\Phi_{s}$, sendo o conjunto geral de políticas parciais dado por $\Phi=\bigcup_{s \in S} \Phi_{s}$.

Uma política parcial, uma vez iniciada, pode invocar outras políticas parciais, uma característica que permite às políticas parciais significativa vantagem na exploração das características hierárquicas de um problema. Dessa maneira, define-se a função $\mu: S \times \Phi \rightarrow$ $[0,1]$ que fornece a probabilidade de iniciar uma política parcial em um determinado estado, ou seja, corresponde a uma política de políticas parciais.

O modelo de uma política parcial é compreendido pelas funções $R_{s}^{\phi}$, de recompensa, e $P_{s s^{\prime}}^{\phi}$, de probabilidade de transição, dadas por

$$
R_{s}^{\phi}=E\left\{\sum_{k=0}^{\infty} \gamma^{k} r_{t+k+1} \mid \mathcal{E}(\phi, s, t)\right\},
$$

onde $\mathcal{E}(\phi, s, t)$ indica que a política parcial $\phi$ foi iniciada em $s$ no instante $t$, e

$$
P_{s s^{\prime}}^{\phi}=\sum_{k=1}^{\infty} \gamma^{k} p\left(s^{\prime}, k\right), \forall s^{\prime} \in S,
$$

em que $p\left(s^{\prime}, k\right)$ fornece a probabilidade de terminação da política parcial $\phi$ em $s^{\prime}$ após $k$ passos. A equação de Bellman associada à função valor-estado é definida por

$$
\begin{aligned}
V^{\mu}(s) & =E\left\{r_{t+1}+\cdots+\gamma^{k-1} r_{t+k}+\gamma^{k} V^{\mu}\left(s_{t+k}\right) \mid \mathcal{E}(\mu, s, t)\right\} \\
& =\sum_{\phi \in \Phi_{s}} \mu(s, \phi)\left[R_{s}^{\phi}+\sum_{s^{\prime}} P_{s s^{\prime}}^{\phi} V^{\mu}\left(s^{\prime}\right)\right]
\end{aligned}
$$


onde $\Phi_{s}$ corresponde ao conjunto das políticas parciais que podem ser aplicadas no estado $s$ e $k$ indica a duração da primeira política parcial selecionada por $\mu$. A equação de Bellman associada à função valor-ação é definida por

$$
\begin{aligned}
Q^{\mu}(s, \phi) & =E\left\{r_{t+1}+\cdots+\gamma^{k-1} r_{t+k}+\gamma^{k} V^{\mu}\left(s_{t+k}\right) \mid \mathcal{E}(\phi, s, t)\right\} \\
& =E\left\{r_{t+1}+\cdots+\gamma^{k-1} r_{t+k}+\gamma^{k} \sum_{\phi^{\prime} \in \Phi_{s}} \mu\left(s_{t+k}, \phi^{\prime}\right) Q^{\mu}\left(s_{t+k}, \phi^{\prime}\right) \mid \mathcal{E}(\phi, s, t)\right\} \\
& =R_{s}^{\phi}+\sum_{s^{\prime}} P_{s s^{\prime}}^{\phi} \sum_{\phi^{\prime} \in \Phi_{s}} \mu\left(s^{\prime}, \phi^{\prime}\right) Q^{\mu}\left(s^{\prime}, \phi^{\prime}\right) .
\end{aligned}
$$

A equação de Bellman referente à função valor-estado ótima é dada por

$$
\begin{aligned}
V_{\Phi}^{*}(s) & =\max _{\mu} V^{\mu}(s) \\
& =\max _{\phi \in \Phi_{s}} E\left\{r_{t+1}+\cdots+\gamma^{k-1} r_{t+k}+\gamma^{k} V_{\Phi}^{*}\left(s_{t+k}\right) \mid \mathcal{E}(\phi, s, t)\right\} \\
& =\max _{\phi \in \Phi_{s}}\left[R_{s}^{\phi}+\sum_{s^{\prime}} P_{s s^{\prime}}^{\phi} V_{\Phi}^{*}\left(s^{\prime}\right)\right]
\end{aligned}
$$

onde $\mathcal{E}(\phi, s, t)$ denota o evento de $\phi$ ser iniciada em $s$ no instante $t$ e $k$ fornece a duração, em passos, de $\phi$.

Analogamente, temos para a função valor-ação ótima

$$
\begin{aligned}
Q_{\Phi}^{*}(s, \phi) & =\max _{\mu} Q^{\mu}(s, \phi) \\
& =E\left\{r_{t+1}+\cdots+\gamma^{k-1} r_{t+k}+\gamma^{k} V_{\Phi}^{*}\left(s_{t+k}\right) \mid \mathcal{E}(\phi, s, t)\right\} \\
& =E\left\{r_{t+1}+\cdots+\gamma^{k-1} r_{t+k}+\gamma^{k} \max _{\phi^{\prime} \in \Phi_{s}} Q_{\Phi}^{*}\left(s_{t+k}, \phi^{\prime}\right) \mid \mathcal{E}(\phi, s, t)\right\} \\
& =R_{s}^{\phi}+\sum_{s^{\prime}} P_{s s^{\prime}}^{\phi} \max _{\phi^{\prime} \in \Phi_{s_{t+k}}} Q_{\Phi}^{*}\left(s^{\prime}, \phi^{\prime}\right) .
\end{aligned}
$$

Dado um conjunto de políticas parciais $\Phi$, a política ótima correspondente, $\mu_{\Phi}^{*}$ é tal que satisfaz

$$
V^{\mu_{\Phi}^{*}}(s)=V_{\Phi}^{*}(s), \forall s \in S
$$

Para fins de aprendizado da função-valor para um PSMD, utiliza-se a função de atualização iterativa

$$
Q(s, \phi) \stackrel{\alpha}{\leftarrow} R+\gamma^{k} \max _{\phi^{\prime} \in \Phi_{s^{\prime}}} Q\left(s^{\prime}, \phi^{\prime}\right) .
$$

De forma a acelerar o processo de aprendizado de políticas parciais, podem ser utilizadas técnicas de Aprendizado Interno à Política Parcial, onde fragmentos de experiência do agente são utilizados na atualização do modelo para todas as políticas parciais que os compartilham, através das equações

$$
\hat{R}_{s}^{\phi} \stackrel{\alpha}{\leftarrow} R
$$


$\mathrm{e}$

$$
\hat{P}_{s x}^{\phi} \stackrel{\alpha}{\leftarrow} \gamma^{k} \delta_{s^{\prime} x}
$$

para todo $x \in S$, onde $\hat{R}$ e $\hat{P}$ correspondem às estimativas das funções de recompensa e probabilidade de transição, respectivamente, $\delta_{s^{\prime} x}=1$ se $s^{\prime}=x$ e 0 caso contrário, podendo o valor de $\alpha$ ser dado por uma constante ou parametrizado de forma a depender do estado, política parcial e/ou duração.

As equações de Bellman para o modelo das políticas parciais são dadas por

$$
R_{s}^{\phi}=\sum_{a \in A_{s}} \pi(s, a)\left[R_{s}^{a}+\sum_{s^{\prime}} P_{s s^{\prime}}^{a} \gamma\left(1-\beta^{\phi}\left(s^{\prime}\right)\right) R_{s^{\prime}}^{\phi}\right]
$$

e

$$
P_{s x}^{\phi}=\sum_{a \in A_{s}} \pi(s, a) \sum_{s^{\prime}} P_{s s^{\prime}}^{a} \gamma\left[\left(1-\beta\left(s^{\prime}\right)\right) P_{s^{\prime} x}^{\phi}+\beta\left(s^{\prime}\right) \delta_{s^{\prime} x}\right]
$$

cujas versões para atualização iterativa são dadas por

$$
\hat{R}_{s_{t}}^{\phi} \stackrel{\alpha}{\leftarrow} r_{t+1}+\gamma\left(1-\beta\left(s_{t+1}\right)\right) \hat{R}_{s_{t+1}}^{\phi}
$$

e

$$
\hat{P}_{s_{t} x}^{\phi} \stackrel{\alpha}{\leftarrow} \gamma\left(1-\beta\left(s_{t+1}\right)\right) \hat{P}_{s_{t+1} x}^{\phi}+\gamma \beta\left(s_{t+1}\right) \delta_{s_{t+1} x}
$$

Dessa forma, finaliza-se a apresentação das técnicas de aprendizado relacionadas às políticas parciais utilizadas neste trabalho. Na próxima seção é apresentado o algoritmo ARMI (SINGH; BARTO; CHENTANEZ, 2005), que utiliza as técnicas apresentadas aliadas à descoberta de políticas parciais através de motivação intrínseca.

\subsection{Algoritmo ARMI}

Apesar da vantagem apresentada pelas políticas parciais em termos de decomposição hierárquica de um problema em subproblemas e consequente potencial de impacto positivo no aprendizado, as políticas parciais podem representar sobrecarga em tempo de projeto devido à necessidade de definição de seus elementos componentes, $\mathcal{I}, \beta$ e $\pi$.

O algoritmo de Aprendizado por Reforço com Motivação Intrínseca (ARMI) (SINGH; BARTO; CHENTANEZ, 2005) foi desenvolvido de forma a contornar esse problema através da descoberta de políticas parciais utilizando-se motivação intrínseca. O termo motivação intrínseca refere-se às recompensas intrínsecas, que são recebidas pelo agente ao solucionar os subproblemas, sendo que o termo motivação extrínseca refere-se à recompensa recebida pelo agente ao solucionar o problema, denominada recompensa extrínseca e fornecida pela função $R$.

O papel das recompensas extrínsecas é auxiliar o aprendizado da política que representa a solução para o problema completo, enquanto o papel da recompensa intrínseca 
é o de auxiliar o agente no aprendizado das políticas parciais utilizadas nas soluções dos subproblemas.

Neste trabalho, as recompensas extrínsecas são denotadas por $r^{e}$ e as intrínsecas por $r^{i}$. A definição da motivação intrínseca no algoritmo ARMI está associada à novidade relacionada a um evento, ou seja, quão inesperada é uma determinada transição de estados tendo em vista o modelo de transição $P$ atual do agente.

O ARMI desempenha a função de descoberta automática de políticas parciais através da identificação de submetas, ou seja, através da identificação de objetivos para subproblemas. A ocorrência de uma submeta é associada a um evento saliente, definido pela alteração significativa dos valores de determinados atributos da descrição fatorada do estado.

Formalmente, sendo o estado $s \in S$ descrito por um conjunto $\mathcal{A}$ de $n$ atributos, $\mathcal{A}=\left[a_{1}, a_{2}, \ldots, a_{n}\right]$, define-se o subconjunto dos atributos salientes $\mathcal{A}_{\text {sal }} \subseteq \mathcal{A}$. A alteração brusca dos valores dos atributos salientes denotará a ocorrência de um evento saliente, definido pela variação do valor de um elemento $a_{i} \in \mathcal{A}_{\text {sal }}$ que ultrapassa um limiar pré-definido através da função $\mathcal{L}: \mathcal{A}_{\text {sal }} \rightarrow \Re$.

A utilização dos eventos salientes para a descoberta automática de políticas parciais ocorre durante o processo de aprendizado. Simultaneamente à interação do agente com o ambiente através de ações, os estados visitados são observados quanto aos atributos salientes. Durante uma transição $s_{t}, a_{t} \rightarrow s_{t+1}$, caso ocorra variação significativa no valor de um ou mais atributos salientes, isto é, $\exists i,\left|a_{i_{t+1}}-a_{i_{t}}\right| \geq \mathcal{L}$, é criada uma política parcial $\phi=\left\langle\mathcal{I}^{\phi}, \beta^{\phi}, \pi^{\phi}\right\rangle$, sendo $s_{t}$ incluído em $\mathcal{I}^{\phi}$ e a função de terminação atualizada em relação a $s_{t+1}$ através de $\beta^{\phi}\left(s_{t+1}\right)=1$. A política parcial termina em $s_{t+1}$ porque o evento saliente foi disparado na transição $s_{t} \rightarrow s_{t+1}$, sendo $s_{t+1}$ identificado como submeta. No momento da criação da política parcial também inicializa-se a estrutura de dados utilizada para o aprendizado da política $\pi^{\phi}$ pertencente à política parcial $\phi$ recém-criada.

O valor correspondente à recompensa intrínseca recebida pelo agente ao disparar um evento saliente é calculado pela fórmula

$$
r_{t+1}^{i}=\tau\left[1-P^{\phi_{e}}\left(s_{t+1} \mid s_{t}\right)\right],
$$

onde o valor de $P^{\phi_{e}}\left(s_{t+1} \mid s_{t}\right)$ reflete a probabilidade de se alcançar $s_{t+1}$ partindo de $s_{t}$. Esse valor é inicializado com zero para toda política parcial criada e tende a aumentar à medida que o modelo da política parcial é aprimorado. Intuitivamente, o valor da recompensa intrínseca tende a ser cada vez menor à medida que o agente repete a ocorrência do evento saliente associado, pois o modelo da política parcial associado à ocorrência do evento saliente é aprimorado, e os valores correspondentes tendem a aumentar, à medida que o evento saliente é repetido.

O decaimento das recompensas intrínsecas gera um efeito duplo no processo de 
aprendizado: nas ocorrências iniciais do evento saliente, as estruturas de aprendizado da correspondente política parcial são inicializadas e estão em fase inicial de aprendizado/aprimoramento. Dessa forma, os valores da função $P$ tendem a ser menores, resultando em valores de recompensas intrínsecas maiores, conforme a fórmula apresentada anteriormente. Como a recompensa intrínseca é maior nessa etapa, o agente é motivado a repetir o disparo desse evento saliente, aplicando a política parcial correspondente. Nessa aplicação, ambos, modelo e política interna, relativos à política parcial, são refinados através do aprendizado.

À medida que o agente atinge repetidas vezes o mesmo evento saliente, espera-se que o refinamento seja cada vez menos necessário, pois espera-se que o modelo da política parcial tenha obtido expressivo aprimoramento. Dessa forma, o decaimento da recompensa intrínseca de um evento saliente já disparado repetidas vezes, diminui a motivação do agente na execução da política parcial correspondente ao evento saliente. Perdendo a motivação por esse evento saliente, o agente pode buscar disparar um evento saliente anteriormente desconhecido, passando a concentrar os esforços de aprendizado na solução de um novo subproblema.

Adicionalmente à utilização do modelo da política parcial relacionado ao valor da motivação intrínseca, o ARMI aplica o Aprendizado Interno à Política Parcial. Dessa maneira, múltiplas políticas parciais são atualizadas simultaneamente utilizando-se transições compartilhadas.

O Algoritmo 3.2 apresenta o ARMI em pseudocódigo. Para fins de clareza, as respectivas funções são apresentadas separadamente, em seguida. Foram realizadas algumas adaptações neste trabalho em relação ao ARMI, que são apontadas juntamente com o trecho adaptado. Em seguida, o algoritmo é apresentado através de um exemplo de uma iteração completa, onde são detalhadas as funções utilizadas, juntamente com a intuição subjacente.

Vale ressaltar que o conjunto $\Phi$ contém todas as políticas parciais $\phi$ conhecidas pelo agente. Dessa forma, quando uma função presente no algoritmo recebe $\Phi$, essa função recebe todas as políticas parciais $\phi \in \Phi$, e, para cada $\phi \in \Phi$, são recebidos também os componentes da política parcial $\phi$, quais sejam, $\mathcal{I}^{\phi}, \pi^{\phi}$ e $\beta^{\phi}$. Adicionalmente, para fins de clareza nas explicações e exemplos de aplicação dos algoritmos, optou-se por utilizar a notação apresentada a seguir, juntamente com a notação correspondente utilizada na formalização apresentada anteriormente:

$$
\begin{gathered}
R^{\phi}(s) \equiv R_{s}^{\phi} \\
P^{\phi}\left(s^{\prime} \mid s\right) \equiv P_{s s^{\prime}}^{\phi},
\end{gathered}
$$

É importante notar que os valores das funções $R^{\phi}, P^{\phi}$ e também de $\beta^{\phi}$ são inicializados com zeros no momento da criação da política parcial $\phi$. Vale ressaltar também que, neste 
trabalho, $\beta^{\phi}$ assume somente valores binários ${ }^{6}$.

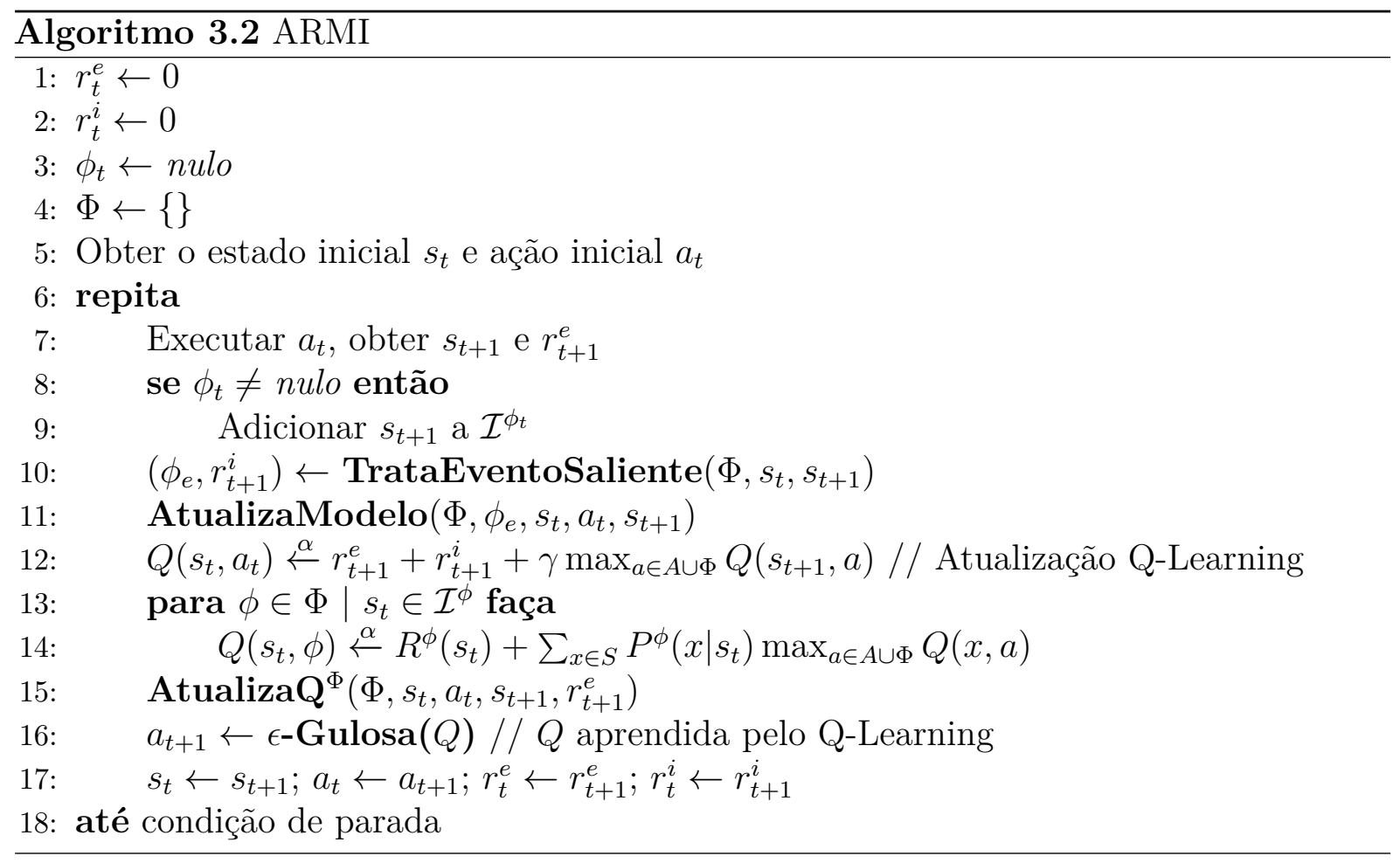

Para exemplificar a aplicação do algoritmo ARMI, considere-se a iteração em que ocorre a transição $s_{t}, a_{t} \rightarrow s_{t+1}$, na qual foi disparado o evento saliente $e$, para o qual ainda não havia uma política parcial associada, ou seja, ainda não havia sido criada a política parcial $\phi_{e}$ para disparar $e$. Nesse caso, o Algoritmo 3.2 obtém, inicialmente, a recompensa extrínseca $r_{t+1}^{e}$, correspondente à transição $s_{t}, a_{t} \rightarrow s_{t+1}$. Suponha-se que, neste caso, $s_{t+1}$ é um estado terminal, ou seja, um estado-objetivo do problema. Dessa forma, o agente recebe a recompensa $r_{t+1}^{e}$ por ter alcançado o objetivo, sendo esse valor utilizado posteriormente na atualização das funções-valor $Q$, pelo Q-Learning e pela função Atualiza $Q^{\Phi}$. Os valores correspondentes às recompensas extrínsecas são recebidos imediatamente após a transição de estados. De forma análoga, para os cálculos que utilizam os valores de $r^{e}$ e $r^{i}$, são utilizados os valores correspondentes à transição $s_{t}, a_{t} \rightarrow s_{t+1}$, $r_{t+1}^{i}$ e $r_{t+1}^{e}$. Adicionalmente, o estado $s_{t+1}$ será adicionado ao conjunto $\mathcal{I}^{\phi_{t}}$, caso o agente esteja aplicando uma política parcial. Por exemplo, caso o agente esteja seguindo a política parcial $\phi_{a}, s_{t}$ será incluído em $\mathcal{I}^{\phi_{a}}$, pois, nesse caso, como a política parcial sendo seguida no instante $t$ é $\phi_{a}$, tem-se $\phi_{t}=\phi_{a}$, ou seja, além da adição de estados retroativa, que ocorre nas funções TrataEventoSaliente e AtualizaModelo, detalhadas a seguir, neste trabalho é realizada a adição de estados pró-ativa, nas transições de estados.

Em seguida, a função TrataEventoSaliente, apresentada no Algoritmo 3.3, onde a transição $s_{t}, a_{t} \rightarrow s_{t+1}$ é testada para verificar se um evento saliente foi disparado.

$\overline{6}$ Isso ocorre porque a única atualização possível nos valores da função $\beta^{\phi}$, após a inicialização, é através da atribuição do valor 1 , como pode ser observado pela análise dos algoritmos que serão apresentados a seguir. 
No exemplo que está sendo apresentado, ocorre um evento saliente na transição, logo, é realizado o teste interno, que verifica se a política parcial para o evento saliente disparado já existe. Como dito anteriormente, o evento saliente em questão está ocorrendo pela primeira vez, logo, ainda não existe uma política parcial associada a ele. Em seguida, são criadas as estruturas de dados referentes à política parcial $\phi_{e}$, que é então incluída no conjunto de todas as políticas parciais, $\Phi$, sendo o estado $s_{t}$ incluído no conjunto-iniciador de $\phi_{e}, \mathcal{I}^{\phi_{e}}$. Isso ocorre porque, como a transição de $s_{t} \rightarrow s_{t+1}$ é possível, tem-se que é possível executar uma política parcial em $s_{t}$ que leve o agente a $s_{t+1}$, disparando o correspondente evento saliente, ou seja, $\phi_{e}$ pode ser iniciada em $s_{t}$.

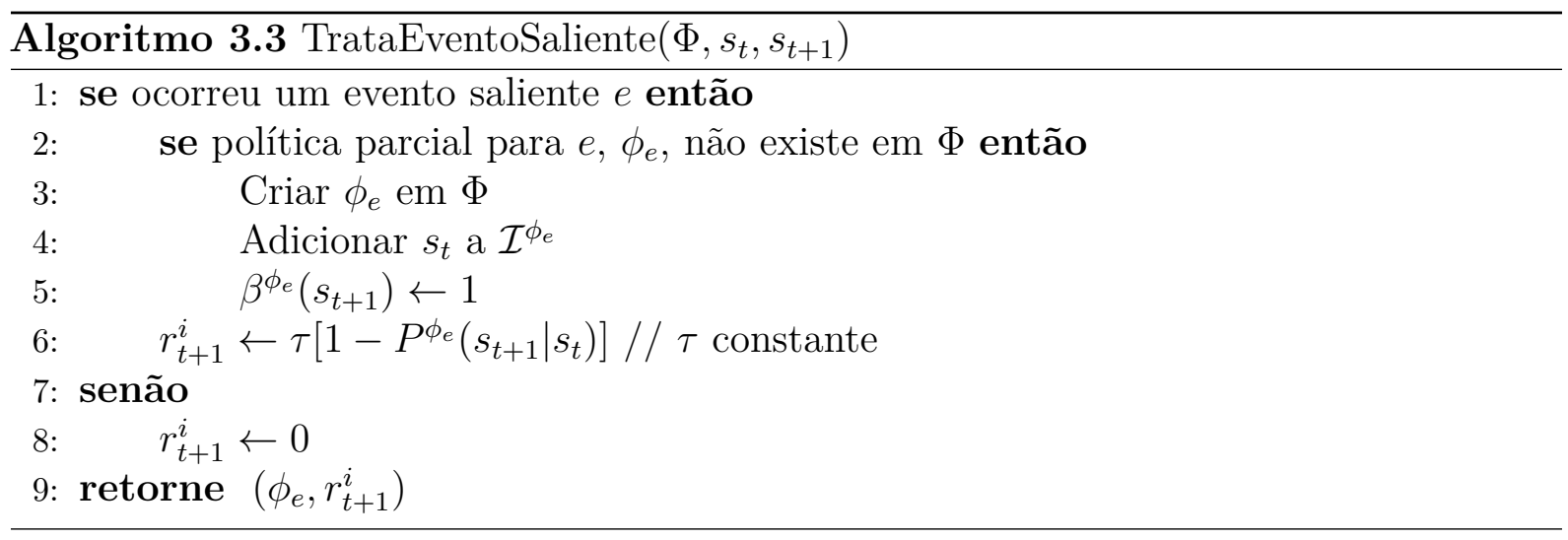

Em seguida, o valor para a função de terminação da política recém-criada é setado em 1 (100\% de probabilidade de terminação) para o estado $s_{t+1}$. Isso é realizado pois, como a transição $s_{t} \rightarrow s_{t+1}$ dispara o evento saliente associado à política parcial em questão, essa política parcial finaliza em $s_{t+1}$, pois $s_{t+1}$ é identificado como a submeta da política parcial. Como foi disparado um evento saliente na transição $s_{t} \rightarrow s_{t+1}$, o agente recebe a recompensa intrínseca correspondente. $\mathrm{O}$ valor da recompensa intrínseca recebida, por sua vez, depende do valor de $P^{\phi_{e}}\left(s_{t+1} \mid s_{t}\right)$, sendo que a função $P^{\phi_{e}}$ é inicializada com zeros no momento da sua criação (como é o caso, pois $\phi_{e}$ acabou de ser criada). Analisando a fórmula de cálculo da recompensa intrínseca,

$$
r_{t+1}^{i}=\tau\left[1-P^{\phi_{l u z} O N}\left(s_{t+1} \mid s_{t}\right)\right]
$$

tem-se que, para um valor de $P^{\phi_{e}}\left(s_{t+1} \mid s_{t}\right)=0$, o valor da recompensa intrínseca recebido nesse passo será o valor máximo. Nas próximas iterações, à medida que o agente for aprimorando a política parcial, os valores de $P^{\phi_{e}}$ tenderão a aumentar, logo, a recompensa intrínseca correspondente tenderá a uma diminuição gradual. O parâmetro $\tau$ é dado por uma constante que pode ser utilizada para ponderar a expressividade dos valores das recompensas intrínsecas em relação aos valores das recompensas extrínsecas no aprendizado. Por exemplo, se as recompensas extrínsecas valem sempre 10 e as intrínsecas possuem valor máximo de 1 , estabelecer o valor de $\tau=10$ fará com que as primeiras recompensas intrínsecas tenham valores comparáveis aos das recompensas extrínsecas; caso o valor 
estabelecido seja $\tau=0.1$, o peso das primeiras recompensas intrínsecas será 100 vezes menor em relação ao valor das recompensas extrínsecas. Dessa forma, o parâmetro $\tau$ pode ser utilizado para controlar a motivação que o agente tem para resolver os subproblemas em relação à motivação do agente para resolver o problema completo. A função TrataEventoSaliente finaliza com o retorno da variável de controle $\phi_{e}$ e da recompensa intrínseca $r_{t+1}^{i}$, recebida na transição $s_{t} \rightarrow s_{t+1}$.

Em seguida, a função AtualizaModelo, exibida no Algoritmo 3.4, é chamada, e lida com a inclusão do estado $s_{t}$ nos conjuntos iniciadores $\mathcal{I}^{\phi}$ caso:

- $s_{t+1}$ também pertença a $\mathcal{I}^{\phi}$ - isso ocorre devido ao fato de que, se a política parcial $\phi$ pode ser iniciada em $s_{t+1}$ e $s_{t+1}$ pode ser alcançado a partir $s_{t}$, então a política parcial $\phi$ também pode ser iniciada em $s_{t}$;

- $\beta^{\phi}\left(s_{t}\right) \neq 1$ - ou seja, a política parcial $\phi$ não é terminada em $s_{t}$; esse teste é necessário, pois, como dito acima, a função AtualizaModelo lida com todas as políticas parciais e, para a política parcial em que $s_{t}$ é um estado terminal, $s_{t}$ não deve ser incluído no conjunto-iniciador, como visto na Seção $3.2^{7}$.

Após isso, a função valor-ação utilizada pelo Q-Learning é atualizada para a ação primitiva $a_{t}$, que foi executada na iteração em questão, juntamente com a atualização correspondente à aplicação no estado atual $s_{t}$ de cada política parcial $\phi \in \Phi$ conhecida pelo agente, sendo esta atualizaçao realizada somente para as políticas parciais $\phi$ aplicáveis em $s_{t}$, ou seja, as políticas parciais $\phi \in \Phi$ tais que $s_{t} \in \mathcal{I}^{\phi}$.

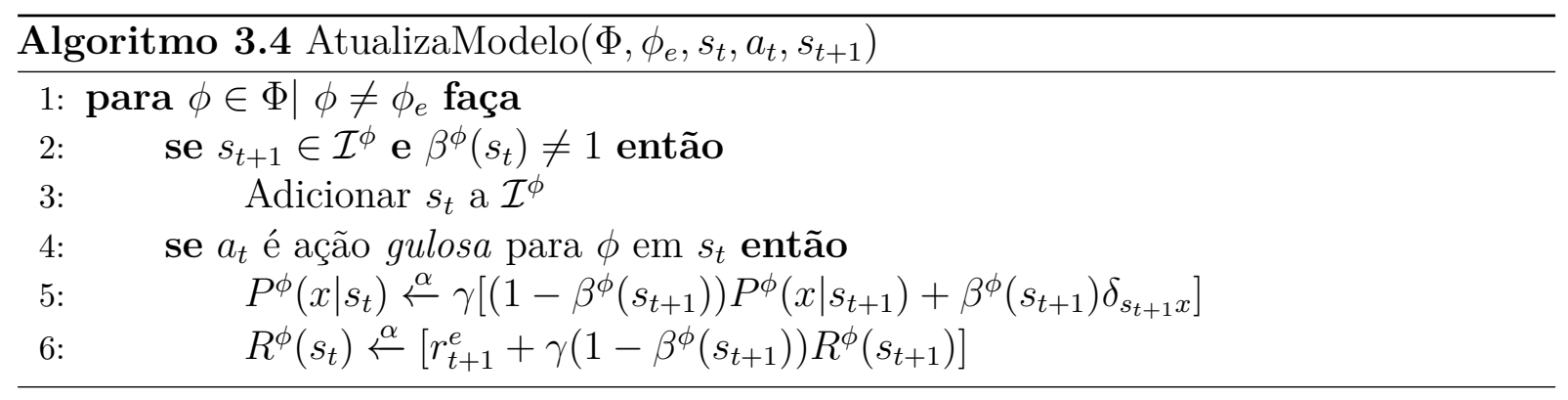

A função Atualiza $Q^{\Phi}$ (Algoritmo 3.5) é então chamada para atualizar as funçõesvalor $Q^{\phi}$ para todas as políticas parciais $\phi \in \Phi$ através de técnicas de Aprendizado Interno à Política Parcial, nas quais fragmentos de conhecimento adquiridos pelo agente através da transição $s_{t}, a_{t} \rightarrow s_{t+1}$ são utilizados para atualizar todas as políticas parciais que compartilham essa transição. Finalmente, o Algoritmo 3.5 apresenta a estratégia

$\overline{7} \quad$ Esse fato pode parecer contra-intuitivo, à primeira vista, pois a transição ocorreu e estaria sendo desconsiderada para uma determinada política parcial. Entretanto, neste caso, a transição $s_{t} \rightarrow s_{t+1}$ pode ter ocorrido porque o agente estaria aplicando outra política parcial que não a $\phi$, em que $s_{t}$ não seria um estado terminal para essa política parcial em questão, logo, a transição $s_{t} \rightarrow s_{t+1}$ seria possível para essa política parcial, ou mesmo porque o agente não estaria seguindo uma política parcial no momento. 
de atualização das funções valor-ação relacionadas às políticas parciais, que utilizam Aprendizado Interno à Política Parcial. O valor terminal para uma política parcial $\phi$ é o valor recebido ao realizar uma transição $s_{t} \rightarrow s_{t+1}$ em que $\beta^{\phi}\left(s_{t+1}\right)=1$, ou seja, o valor recebido pelo agente ao executar $\phi$ até a terminação.

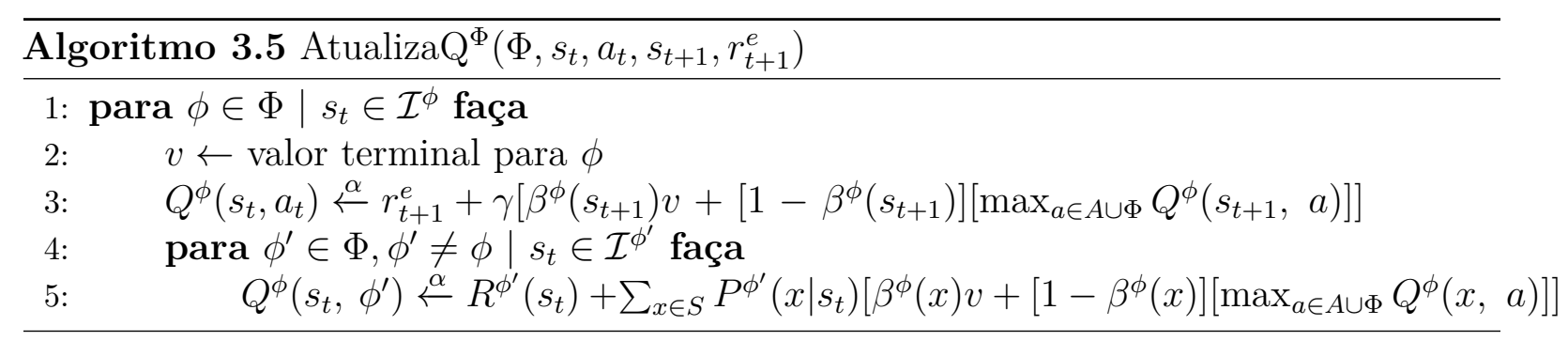

Finalmente, a próxima ação a ser executada é obtida através de estratégia $\epsilon$-gulosa, sendo as variáveis de estado, ação e recompensas são atualizadas para a próxima iteração. O processo é repetido até que uma condição de parada previamente estabelecida seja alcançada, por exemplo, limite máximo de passos.

Assim, conclui-se a apresentação do algoritmo ARMI, na qual buscou-se apontar a intuição subjacente ao mesmo e os mecanismos de aprendizado utilizados. Neste capítulo, foi apresentada a definição do problema abordado neste trabalho, juntamente ao formalismo subjacente às técnicas de aprendizado utilizada para solucioná-lo. No próximo capítulo, será detalhada a proposta desta dissertação, que corresponde à implementação de estratégias de exploração interna e armazenamento de políticas parciais no algoritmo ARMI, gerando o algoritmo A-EIP . 



\section{Algoritmo A-EIP 3}

Neste capítulo, detalha-se a proposta desta dissertação: modificação de dois aspectos da aplicação de políticas parciais no ARMI, gerando o algoritmo A-EIP ${ }^{3}$, quais sejam: (i) armazenamento das políticas parciais em aplicação pelo agente e (ii) exploração interna às políticas parciais.

Na proposta original do ARMI, caso o agente inicie a aplicação de uma política parcial, as ações serão selecionadas a partir dessa política parcial até que o agente atinja um estado no qual ocorra a terminação da mesma (SINGH; BARTO; CHENTANEZ, 2005, página 5, item "Skill-KB"). Dessa forma, caso o agente inicie a execução da política parcial $\phi_{1}$ no instante $t$, a seleção de ações será feita a partir $\phi_{1}$ nos instantes $t, t+1, t+2, \ldots, t+k-1$, em que $k$ indica a duração, em número de passos, de $\phi_{1}$, ou seja, $\phi_{1}$ é terminada em $k$ passos após ser iniciada. Isso ocorre mesmo que, durante sua aplicação, $\phi_{1}$ invoque outras políticas parciais $\phi_{2}, \phi_{3}, \ldots, \phi_{n}$.

Entretanto, caso o problema a ser resolvido possua forte caracterização hierárquica, a sequência de políticas parciais invocadas pode possuir, de forma implícita, o conjunto de subproblemas atualmente enfrentados pelo agente. Isso decorre do fato de que, a cada subproblema, é associada uma política parcial, logo, armazenando o histórico de políticas parciais invocadas, a estrutura de subproblemas será também armazenada. Dessa forma, pode ser útil para o agente armazenar a sequência $\phi_{1}, \phi_{2}, \phi_{3}, \ldots, \phi_{n}$ de políticas parciais invocadas, para dispor de um suporte de aprendizado representado pela estrutura dos subproblemas que estão sendo resolvidos.

No processo de solução hierárquica de um problema, o agente direciona seus esforços primeiramente à solução dos subproblemas gerados a partir do problema original. Após obter a solução dos subproblemas gerados, o agente direciona seus esforços à solução do problema que os gerou, eventualmente resolvendo novos subproblemas que venham a ser gerados, e assim sucessivamente, até a obtenção da solução completa para o problema original. Em outras palavras, no processo de solução hierárquica de um problema, o agente direcionará seus esforços na solução do subproblema gerado mais recentemente.

Com a finalidade de fornecer suporte de aprendizado ao agente através da estrutura de subproblemas sendo enfrentados, propõe-se o armazenamento do histórico das políticas parciais aplicadas pelo agente na solução do problema e subproblemas gerados. Como a estruturação do problema em subproblemas menores sugere o foco, por parte do agente, na solução do subproblema que surgiu mais recentemente, propõe-se a utilização de uma estrutura de armazenamento em forma de pilha. Nessa estrutura, a última política parcial a ser incluída, ou seja, referente ao subproblema que surgiu mais recentemente, será a 
primeira a ser aplicada para solucionar esse subproblema. A estrutura proposta, juntamente com os procedimentos de adição e remoção das políticas parciais da pilha são detalhadas a seguir.

Adição de uma política parcial à pilha - No momento da obtenção da próxima ação, feita de forma aleatória ou gulosa, caso a próxima ação selecionada seja uma política parcial $\phi_{1}$, esta é adicionada ao topo da pilha П. Dessa forma, um agente que inicia com uma pilha vazia $\Pi=$ [ ] e obtém como próxima ação a política parcial $\phi_{1}$ resultará com $\Pi=\left[\phi_{1}\right]$. Caso a aplicação de $\phi_{1}$ sugira a execução de uma nova política parcial $\phi_{2}$, essa será então empilhada, resultando em $\Pi=\left[\phi_{2}, \phi_{1}\right]$ e assim sucessivamente para novas políticas parciais.

Remoção de uma política parcial da pilha - Uma política parcial é removida da pilha no momento em que o subproblema associado a ela é solucionado. Como citado acima, uma política parcial $\phi_{1}$, invocada para resolver um determinado subproblema, pode, durante sua aplicação, invocar outras políticas parciais $\phi_{2}, \phi_{3}, \ldots, \phi_{n}$ para resolver os subproblemas gerados durante a aplicação de $\phi_{1}$. No momento em que o subproblema associado a $\phi_{1}$ for resolvido, é de se esperar que os subproblemas gerados também tenham sido resolvidos. Dessa forma, no momento da remoção de $\phi_{1}$ da pilha, as políticas parciais $\phi_{2}, \phi_{3}, \ldots, \phi_{n}$, invocadas por $\phi_{1}$ são também removidas, pois espera-se que não sejam mais necessárias, pois os subproblemas aos quais são associadas já foram solucionados. Esse processo está representado no Algoritmo 4.1, explicado em detalhes a seguir.

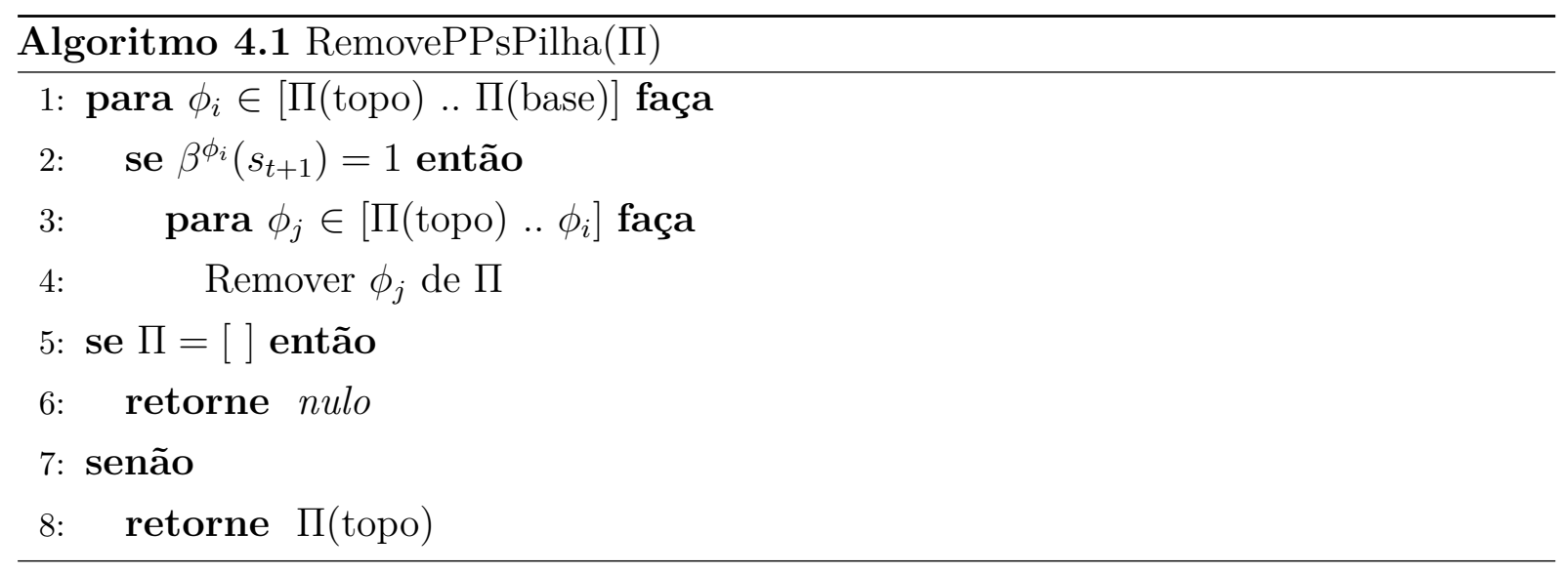

Inicialmente, convém explicar brevemente o formalismo envolvido. A pilha de políticas parciais é representada por $\Pi$, sendo os elementos do topo e da base da pilha representados por $\Pi$ (topo) e $\Pi$ (base), respectivamente. Dessa maneira, uma sequência de aplicações de políticas parciais em que $\phi_{1}$ invoca $\phi_{2}$, que por sua vez invoca $\phi_{3}$ resultará em $\Pi=\left[\phi_{3}, \phi_{2}, \phi_{1}\right]$, em que $\Pi($ topo $)=\phi_{3}$ e $\Pi($ base $)=\phi_{1}$.

O Algoritmo 4.1 procede da seguinte maneira: antes da seleção da próxima ação a ser executada, resolve-se a pilha de políticas parciais para verificar se, das políticas parciais atualmente presentes na pilha (se houver), uma ou mais devem ser removidas. Para isso, 
obtém-se o conjunto de todas as políticas presentes em $\Pi$, ou seja, a sequência de políticas parciais do topo à base de П. Como visto anteriormente, $\beta^{\phi_{i}}\left(s_{t+1}\right)$ indica a probabilidade de terminação da política parcial $\phi_{i}$ no estado $s_{t+1}$. Dessa forma, caso $\beta^{\phi_{i}}\left(s_{t+1}\right)=1$ para uma política $\phi_{i}$ parcial testada, $\phi_{i}$ é removida de $\Pi$. Nesse momento, todas as políticas parciais invocadas após $\phi_{i}$ também são removidas, pois se relacionam a subproblemas gerados a partir do subproblema que $\phi_{i}$ acabou de resolver. Dessa forma, são removidas as políticas parciais partindo de $\Pi$ (topo) até $\phi_{i}$. Após o processo de remoção, a função RemovePPsPilha retorna a política parcial presente no topo da pilha $\Pi$, se houver, ou nulo, caso a pilha П esteja vazia. Esse valor de retorno (política parcial ou nulo) é utilizado no processo de obtenção da próxima ação a ser executada e será apresentado em detalhes e

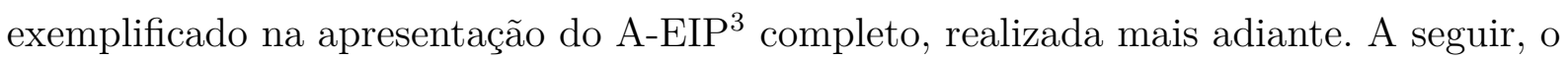
procedimento de remoção de políticas parciais de П é ilustrado com um exemplo.

Suponha que a função RemovePPsPilha receba como entrada a pilha $\Pi=\left[\phi_{4}, \phi_{3}, \phi_{2}, \phi_{1}\right]$; adicionalmente, $s_{t+1}$ é o estado terminal somente para $\phi_{2}$, ou seja $\beta^{\phi_{1}}\left(s_{t+1}\right)=0$, $\beta^{\phi_{2}}\left(s_{t+1}\right)=1, \beta^{\phi_{3}}\left(s_{t+1}\right)=0$ e $\beta^{\phi_{4}}\left(s_{t+1}\right)=0$. Nesse caso, na primeira iteração do Algoritmo 4.1, a política parcial que será avaliada será $\Pi($ topo $)=\phi_{4}$. Para $\phi_{4}$, o teste "se $\beta^{\phi_{i}}\left(s_{t+1}\right)=1$ " retornará falso, passando para a próxima iteração, em que se avalia $\phi_{3}$, com resultado semelhante, pois $\beta^{\phi_{3}}\left(s_{t+1}\right)=0$. Na próxima iteração, $\phi_{2}$ será avaliada e, como, para $\phi_{2}, \beta^{\phi_{2}}\left(s_{t+1}\right)=1$, o teste "se $\beta^{\phi_{i}}\left(s_{t+1}\right)=1$ " retorna verdadeiro, sendo realizadas as instruções internas de remoção. Nessa iteração, $\phi_{i}=\phi_{2}, \operatorname{logo},\left[\Pi(\right.$ topo $\left.) .. \phi_{i}\right]=\left[\phi_{4}, \phi_{3}, \phi_{2}\right]$, que são as políticas parciais que serão removidas, ou seja, $\phi_{2}$, que atingiu seu estado terminal $s_{t+1}$, e as políticas parciais invocadas após $\phi_{2}$. A pilha П não está vazia, possuindo ainda a política parcial $\phi_{1}$, no topo de $\Pi^{1}$. Dessa forma, a função RemovePPsPilha irá retornar a política parcial $\phi_{1}$ para ser utilizada na seleção da próxima ação.

Essa proposta visa a uma melhora no desempenho de aprendizado do agente na solução de problemas com características hierárquicas através do armazenamento das políticas parciais aplicadas pelo agente, que, por sua vez, relacionam-se aos subproblemas que o agente deve resolver a um determinado momento. Em seguida, apresenta-se a proposta relacionada ao aspecto de aplicação das políticas parciais, que adiciona a possibilidade de exploração interna.

Na proposta original do ARMI, quando o agente seleciona uma política parcial a ser aplicada, as ações são sempre obtidas a partir dessa política parcial de forma gulosa até o momento em que a política parcial é terminada. Entretanto, as políticas parciais não são fornecidas previamente para o agente: o agente cria as políticas parciais e as refina durante o processo de aprendizado. Dessa forma, nas fases iniciais do aprendizado, as políticas parciais de que o agente dispõe podem não ser tão significativamente úteis

$\overline{1}$ Nesse caso específico, a pilha $\Pi$ contém somente um elemento, $\phi_{1}$. Logo, esse elemento corresponde simultaneamente ao topo e à base da pilha $\Pi$. 
para o agente quanto elas seriam nas fases finais, pois o agente ainda não pôde aprender as políticas parciais de forma substancial.

Assim, nas fases iniciais do aprendizado, em que o agente está aprendendo as políticas parciais, pode ser vantajoso permitir ao agente explorar, ou seja, selecionar ações aleatórias a serem executadas mesmo enquanto estiver aplicando uma política parcial, dessa forma coletando novas informações sobre o subproblema que está sendo solucionado, informação essa que pode ser então utilizada para refinar a política parcial que está sendo seguida, aprimorando-a.

Considerando isso, neste trabalho é proposto um mecanismo de exploração interna à política parcial. Dessa forma, o agente não fica restrito a executar somente as ações sugeridas pela política parcial que está seguindo. Essa modificação é motivada pelo fato de que, apesar de a estratégia gulosa ser a melhor no caso de a política parcial ser ótima para o subproblema sendo resolvido, ela implica em uma restrição que potencialmente atrapalharia o desempenho de aprendizado do agente nos passos iniciais, em que as políticas parciais estão em fase inicial de aprendizado.

Para isso, introduziu-se o parâmetro $\xi_{p} \in[0,1]$, que indica o percentual de exploração interna à aplicação de uma política parcial. O processo de exploração interna é exibido no Algoritmo 4.2, explicado a seguir. No momento de selecionar a próxima ação a ser executada, caso o agente esteja executando uma política parcial $\phi$, sorteia-se um valor no intervalo $[0,1]$; caso esse valor seja maior que $\xi_{p}$, o agente aplica a política parcial sendo seguida de forma gulosa, ou seja, obtém a ação de maior valor segundo $\phi$; caso esse valor seja menor que $\xi_{p}$, o agente realiza exploração, ou seja, executa uma ação aleatória dentre as possiveis para o estado atual. A função ExploraçãoInternaPP retorna a ação primitiva ou a política parcial que foi selecionada através da variável $\dot{a}$, que é utilizada no A-EIP 3 para o empilhamento de políticas parciais e obtenção da próxima ação primitiva $a_{t+1}$ a ser executada, como será detalhado a seguir.

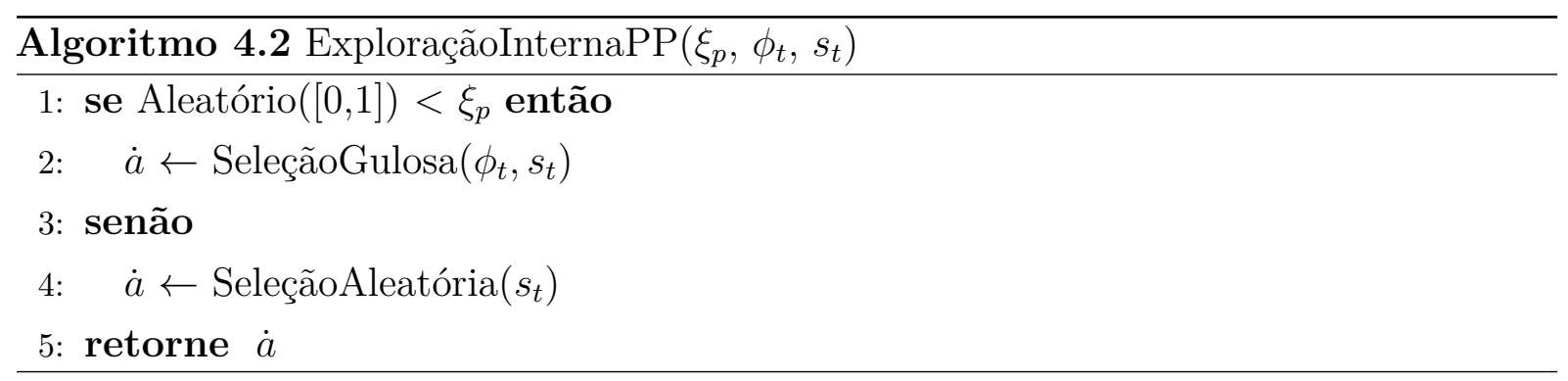

O A-EIP ${ }^{3}$, contendo as modificações realizadas no ARMI, discutidas anteriormente, é apresentado no Algoritmo 4.3. Na linha 5, foi incluída a inicialização da pilha $\Pi$, vazia no início do aprendizado, sendo as políticas parciais adicionadas e removidas durante o processo de aprendizado. As demais modificações relacionadas às implementações deste trabalho estão presentes no intervalo das linhas 17-25. 
Na linha 17 a política parcial atualmente em aplicação, $\phi_{t}$, é atualizada através de uma chamada à função RemovePPsPilha, que, como detalhado acima, resolve a pilha de políticas parciais, removendo aquelas cujo subproblema de origem já tenha sido solucionado. Caso o processo de remoção deixe a pilha vazia, $\phi_{t}$ receberá o valor nulo, indicando que o agente não está aplicando uma política parcial no instante $t$. Caso a função RemovePPsPilha retorne uma política parcial, esta será atribuída a $\phi_{t}$, indicando que o agente está aplicando $\phi_{t}$ no instante $t$. Após isso, o algoritmo busca obter uma ação primitiva a ser executada de duas maneiras:

- através da estratégia $\epsilon$-gulosa, caso o agente não esteja aplicando uma política parcial, ou seja, $\phi_{t}=$ nulo;

- através da aplicação da política parcial em aplicação pelo agente; durante o processo de obtenção de uma ação primitiva a ser executada, o algoritmo aplica a função ExploraçãoInternaPP até que uma ação primitiva seja retornada, empilhando as políticas parciais que forem retornadas no processo.

Finalmente, após os processos de $(i)$ resolução da pilha, $(i i)$ exploração interna e $(i i i)$ eventual empilhamento de políticas parciais, o algoritmo obtém a próxima ação $a_{t+1}$ a ser executada pelo agente.

Por exemplo, caso a pilha de políticas parciais esteja vazia, ou seja, $\Pi=[]$, na linha 17, a função RemovePPsPilha retornará nulo, resultando em $\phi_{t}=$ nulo. Dessa forma, no teste da linha 18, a próxima ação primitiva ou política parcial a ser executada ou aplicada (representada no algoritmo pela variável $\dot{a}$ ) é obtida pela função $\epsilon$-Gulosa. Utilizando o exemplo apresentado anteriormente, no qual $\Pi=\left[\phi_{4}, \phi_{3}, \phi_{2}, \phi_{1}\right]$, o processo de remoção resultou em $\Pi=\phi_{1}$. Nesse caso, seria atribuído $\phi_{t} \leftarrow \phi_{1}$, fazendo com que a próxima ação primitiva ou política parcial fosse obtida através da função ExploraçãoInternaPP aplicada à política parcial $\phi_{t}=\phi_{1}$.

Dessa forma, a obtenção da próxima ação primitiva ou política parcial a ser executada é atribuída à variável $\dot{a}$. Após a obtenção, caso d seja uma política parcial, o algoritmo aplica a função ExploraçãoInternaPP quantas vezes forem necessárias até que seja obtida uma ação primitiva, empilhando as políticas parciais invocadas durante o processo. Ao final desse processo, $\dot{a}$ conterá a ação primitiva que será atribuída a $a_{t+1}$ e executada na próxima iteração do algoritmo.

Para fins de comparação, foi utilizada nos experimentos uma versão do algoritmo A-EIP ${ }^{3}$ em que não foi utilizado o empilhamento de políticas parciais. O pseudocódigo referente ao algoritmo utilizados nesses experimentos é apresentado no Algoritmo 4.4. Pela análise do algoritmo, pode-se perceber que a única modificação foi realizada na linha 23, 


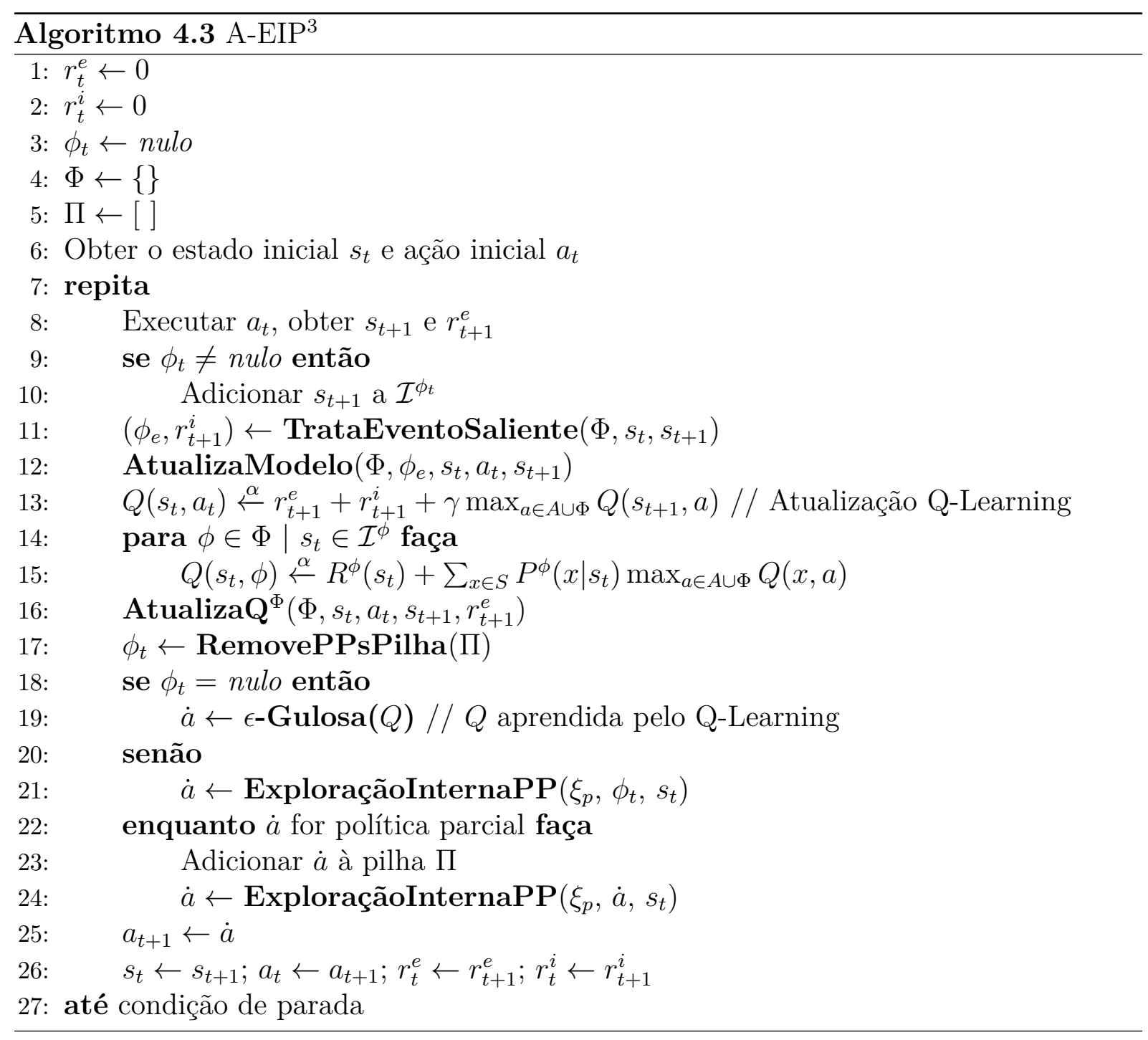

na qual foi adicionado um teste para permitir a adição de uma política parcial à pilha somente se ela estiver vazia, dessa forma, impedindo o empilhamento.

Com isso, conclui-se a apresentação das propostas desta dissertação, que procuram auxiliar o aprendizado do agente através do armazenamento das políticas parciais aplicadas, as quais, por sua vez, espera-se que contenham, implicitamente, a estrutura de problemas sendo enfrentados pelo agente; para contornar uma eventual restrição das ações possíveis de serem executadas, introduz-se o processo exploratório na aplicação das políticas parciais.

Uma característica importante de nota relacionada às propostas, o que poderia ser encarada como uma limitação, ou, pelo menos, uma questão a ser investigada cuidadosamente, é que elas desempenham um papel relativamente central no ARMI, pois as políticas parciais são aplicadas de forma a auxiliar o aprendizado, melhorando o desempenho. Dessa forma, uma modificação na estrutura de aplicação de políticas parciais pode impactar tanto positiva quanto negativamente no desempenho de aprendizado do agente que utiliza o A-EIP ${ }^{3}$. 


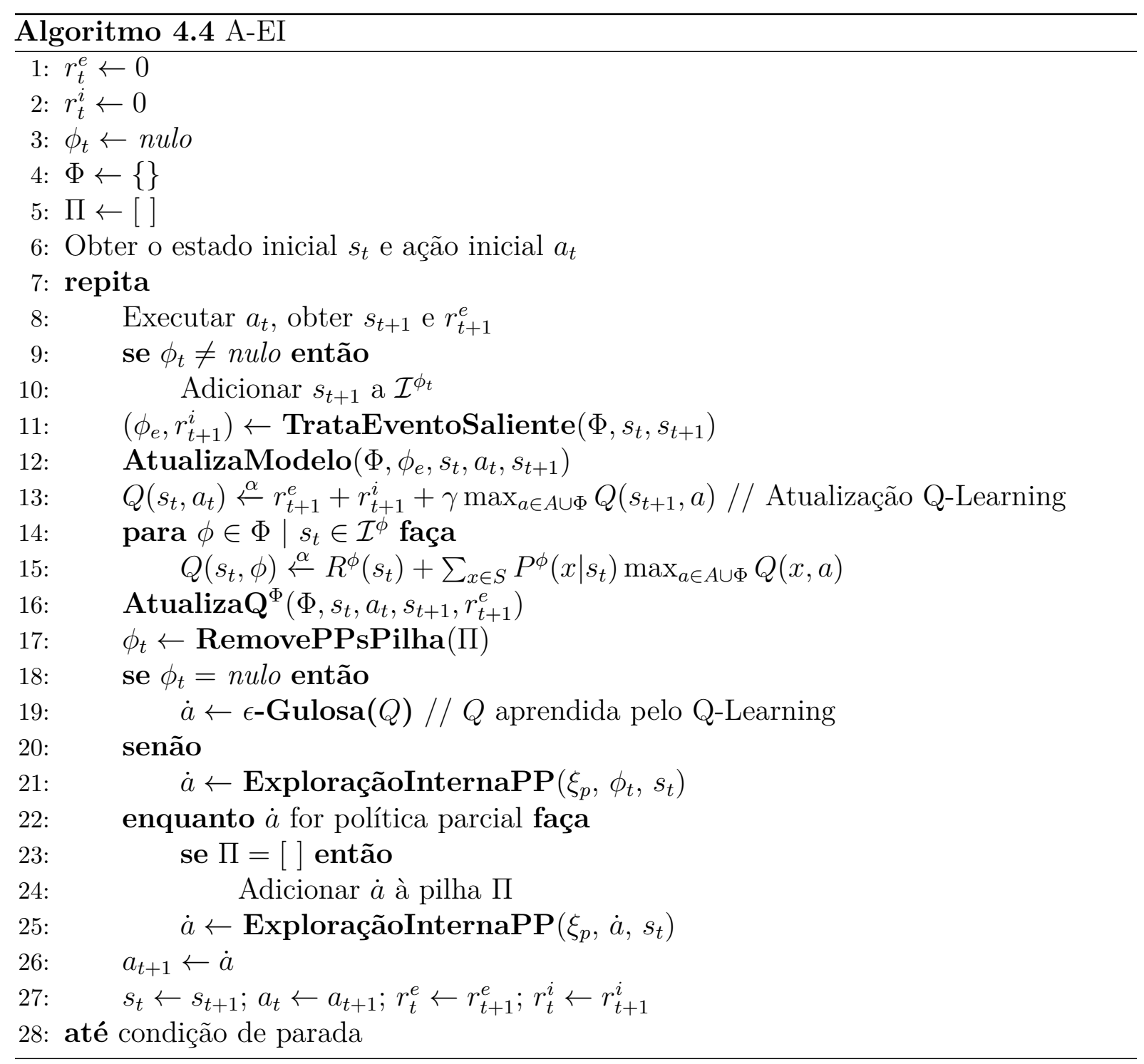

No próximo capítulo são apresentados os experimentos realizados para avaliar as propostas, juntamente à descrição do domínio utilizado. Os resultados obtidos são apresentados e discutidos em relação ao desempenho de aprendizado apresentado pela implementação do ARMI acrescido das propostas deste trabalho. 



\section{Experimentos}

Neste capítulo são apresentados os elementos relacionados à validação experimental das propostas desta dissertação. Na Seção 5.1, detalha-se o domínio utilizado para validar experimentalmente as propostas, apresentando a característica hierárquica do problema a ser enfrentado pelo agente e como elas podem ser exploradas utilizando-se eventos salientes para identificar os subproblemas. Em seguida, na Seção 5.2, é apresentada a modelagem do problema utilizando-se o formalismo relacionado às técnicas de aprendizado aplicadas neste trabalho. Finalmente, na Seção 5.3, apresenta-se a configuração experimental e os resultados obtidos na validação das propostas deste trabalho, que procuram testar se a implementação das propostas mantém as características positivas do algoritmo original e se são capazes de apresentar uma melhora no desempenho de aprendizado.

\subsection{Domínio}

No domínio utilizado para os experimentos deste trabalho, um robô deve aprender a disparar um alarme executando a menor quantidade de ações possíveis. Esse domínio foi adaptado do Playroom (SINGH; BARTO; CHENTANEZ, 2005), utilizado em trabalhos de Aprendizado por Reforço com utilização de motivação intrínseca para o aprendizado de políticas parciais.

No artigo em que foi proposto (SINGH; BARTO; CHENTANEZ, 2005), o domínio foi utilizado para validar o algoritmo ARMI, que identifica e aprende políticas parciais através de eventos salientes, fornecendo recompensas intrínsecas associadas aos modelos individuais das políticas parciais associadas aos eventos salientes. Em (ŞIMŞEK; BARTO, 2005), o Playroom foi utilizado para validar a proposta de um novo mecanismo de recompensa intrínseca, baseado no modelo geral das políticas parciais conhecidas pelo agente, através do erro de previsão associado aos valores dos modelos de transição em dois instantes consecutivos do aprendizado.

A escolha desse domínio e subsequente adaptação foram motivadas pela forte caracterização hierárquica do problema, na qual a identificação de subproblemas através de eventos salientes e subsequente aprendizado de políticas parciais pode ter um impacto expressivo no aprendizado, tornando-o adequado à validação das propostas deste trabalho. Adicionalmente, a dificuldade de interação com os objetos presentes no domínio aumenta gradualmente, dessa forma sendo possível avaliar o impacto obtido através do aprendizado das políticas parciais para os subproblemas simples e posterior utilização na composição de soluções para problemas mais complexos. 
No domínio utilizado, um robô encontra-se de frente a um tabuleiro, de forma análoga a um robô que jogaria xadrez, com a diferença de que esse tabuleiro possui dimensões $5 \times 5$ e, no lugar das peças de xadrez, encontram-se nesse tabuleiro objetos cuja ativação pode afetar a luz e o som no ambiente, como ilustrado na Figura 5.1.

O robô possui um braço mecânico que pode ser movimentado por toda a extensão do tabuleiro. Na extremidade do braço há uma mão mecânica, que pode ser movimentada para qualquer posição do tabuleiro, sendo então utilizada para interagir com os objetos aí presentes. O robô dispõe também de uma mira laser, que pode ser apontada para as posições do tabuleiro.

As seguintes ações estão sempre disponíveis para o robô: apontar a câmera para a posição onde se encontra a mão mecânica ou para a posição onde se encontra a mira laser; mover a mão mecânica ou a mira laser para a posição atualmente apontada pela câmera; apontar a câmera para um objeto ${ }^{1}$ sobre o tabuleiro sorteado aleatoriamente.

Para que ele possa executar uma ação associada a um objeto presente no tabuleiro, é necessário que sua mão mecânica esteja sobre a posição do tabuleiro onde se encontra o objeto e a câmera também esteja apontando para essa posição. Os objetos presentes no tabuleiro e respectivos efeitos nas luz e som ambientes são listados a seguir:

- um interruptor que controla a luz do ambiente (liga/desliga a luz da sala em que se encontra o robô);

- um bloco azul e um bloco vermelho, cada um contendo um botão na face superior. Quando o botão do bloco azul é pressionado, uma música começa a tocar. A música para de tocar se o botão do bloco vermelho for pressionado. Esses blocos também podem ser empurrados pelo robô; nesse caso eles são movidos para céluas vizinhas sorteadas aleatoriamente (vizinhança-8). O agente consegue diferenciar os blocos e executar as ações associadas a eles quando a luz estiver ligada;

- uma bola, que permite a ação mover. Ao executar essa ação, o robô move a bola para a posição atualmente apontada pela mira laser;

- uma sineta, ativada da seguinte maneira: ao mover a bola, caso a posição de destino da bola esteja ocupada pela sineta, a sineta é ativada, emitindo um som característico e movendo-se para uma célula vizinha aleatória (vizinhança-8), ficando a bola na posição anteriormente ocupada pela sineta;

- um alarme, ativado quando simultaneamente a luz do ambiente está desligada, a música ligada e a bola é movida para a posição da sineta, ativando-a; o alarme é desativado quando o estado da luz ou da música for modificado.

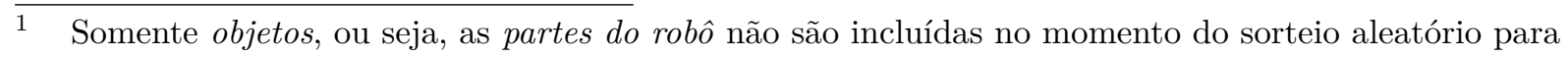
verificar a posição de destino para a qual a câmera será movida ao executar essa ação. 


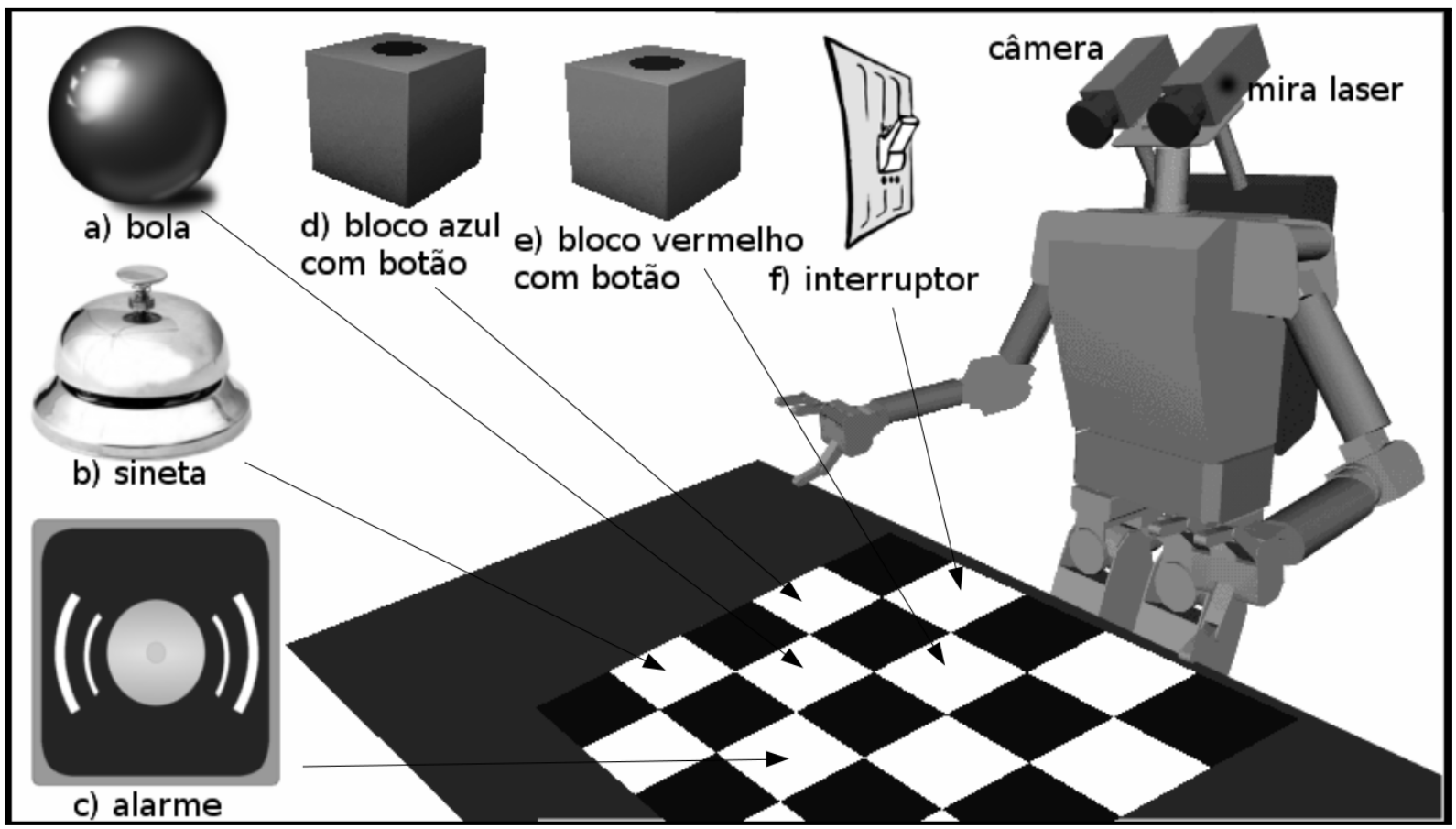

Figura 5.1: Domínio utilizado nos experimentos: um robô dispõe de uma mão mecânica, mira laser e câmera, com os quais pode interagir com os 6 objetos marcados na figura com as letras $a-f$. As setas indicam que os objetos se encontram sobre o tabuleiro, sendo que as posições dos mesmos no tabuleiro podem variar livremente nos experimentos, de acordo com as ações executadas pelo robô.

O objetivo do robô é descobrir como ativar o alarme executando a menor sequência de ações possível ${ }^{2}$. Para auxiliar nessa tarefa, o robô está equipado com sensores que detectam variações de som e luz no ambiente, sendo que essas variações disparam eventos salientes, associados a subproblemas e utilizados para a obtenção das políticas parciais para resolvê-los.

As ações associadas a cada objeto e o correspondente evento saliente disparado são relacionados na Tabela 5.1. Na coluna Movimentação, objetos marcados com $M$ movemse para a posição atual da mira laser e as marcadas com $V$, para uma célula vizinha aleatória, sorteada aleatoriamente dentre as oito possíveis, ao ser executada a ação da linha correspondente, como exemplificado a seguir.

Caso a luz da sala esteja desligada, a ativação do interruptor a liga, desencadeando uma variação significativa na luminosidade da sala, representada pelo evento saliente $l u z_{O N}$; o interruptor permanece na mesma posição do tabuleiro ao ser ativado, como indicado na tabela por um "-" na coluna Movimentação.

2 Vale ressaltar que o alarme pode ser ativado e desativado; dessa forma, após a ativação do alarme, o robô necessita primeiramente desativá-lo para que seja possível ativá-lo novamente. 
Tabela 5.1: Objetos, ações e eventos salientes.

\begin{tabular}{|l|c|c|c|}
\hline Objeto & Ação & Evento Saliente & Movimentação \\
\hline \hline \multirow{2}{*}{ interruptor } & $\begin{array}{c}\text { pressionar } \\
\text { pressionar }\end{array}$ & $\begin{array}{c}\text { luz } \\
\text { luz }\end{array}$ & - \\
\hline \multirow{2}{*}{ bloco azul } & $\begin{array}{c}\text { pressionar } \\
\text { empurrar }\end{array}$ & música & - \\
\hline \multirow{2}{*}{ bloco vermelho } & - & - \\
& $\begin{array}{c}\text { pressionar } \\
\text { empurrar }\end{array}$ & música & $\mathrm{V}$ \\
\hline bola & mover & - & - \\
\hline sineta & - & sineta $_{O N}$ & $\mathrm{~V}$ \\
\hline \multirow{2}{*}{ alarme } & - & alarme $_{O N}$ & $\mathrm{M}$ \\
\hline alarme $_{O F F}$ & - \\
\hline
\end{tabular}

O bloco azul por sua vez, possui duas ações associadas a si, "pressionar" e "empurrar": caso seja pressionado, o botão em sua face superior é ativado e uma música começa a tocar, disparando o evento saliente música ${ }_{O N}$; entretanto, o bloco não se move ao ser pressionado, como indicado por um "_" na coluna Movimentação. Caso o bloco azul seja empurrado, não ocorrem variações de luz e som, logo, não são disparados eventos salientes, como indicado por um "-" na coluna Evento Saliente; entretanto, ao ser empurrado, o bloco se move para uma posição vizinha sorteada aleatoriamente, como indicado pelo $V$ na coluna Movimentação.

A sineta não possui ações associadas a si, mas sua ativação dispara o evento saliente sineta $_{O N}$ e ela se move após a ativação para uma célula vizinha sorteada aleatoriamente, como indicado na tabela. O som emitido pela sineta possui duração de um passo somente, ou seja, o som da sineta inicia e cessa no mesmo passo. Dessa forma, nos passos em que a sineta é ativada, ela é desativada automaticamente antes de iniciar o próximo passo, dessa forma não sendo necessário o evento saliente $\operatorname{sinet}_{O F F^{3}}$.

Como um último exemplo, temos o alarme que não possui ações associadas a si e não se movimenta após ativado, mas pode disparar a ocorrência de dois eventos salientes na

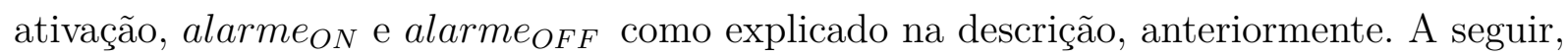
apresenta-se um exemplo de inicialização do experimento, ilustrado através de uma figura.

Na Figura 5.2 é apresentado um exemplo de disposição inicial dos objetos no tabuleiro: interruptor, bloco azul, bloco vermelho, bola, sineta e alarme, dispostos cada um sobre uma posição do tabuleiro. Juntamente aos objetos, estão dispostas no tabuleiro

3 Estritamente, como o agente detecta variações de som e a ativação da sineta desencadeia duas variações no mesmo passo, uma "positiva" e uma "negativa", relacionadas ao início e fim, respectivamente do som associado à sineta, poder-se-ia argumentar que o mais correto seria denominar o evento saliente correspondente à ativação da sineta por algo como sineta $a_{O N / O F F}$, sineta $a_{O N, O F F}$ ou sineta $\operatorname{sN}_{O N F F}$, por exemplo. Entretanto, para fins de clareza, optou-se por denotar o evento saliente associado à ativação da sineta simplesmente por sineta $_{O N}$, notando que a sineta é sempre desativada ao final do passo em que for ativada. 

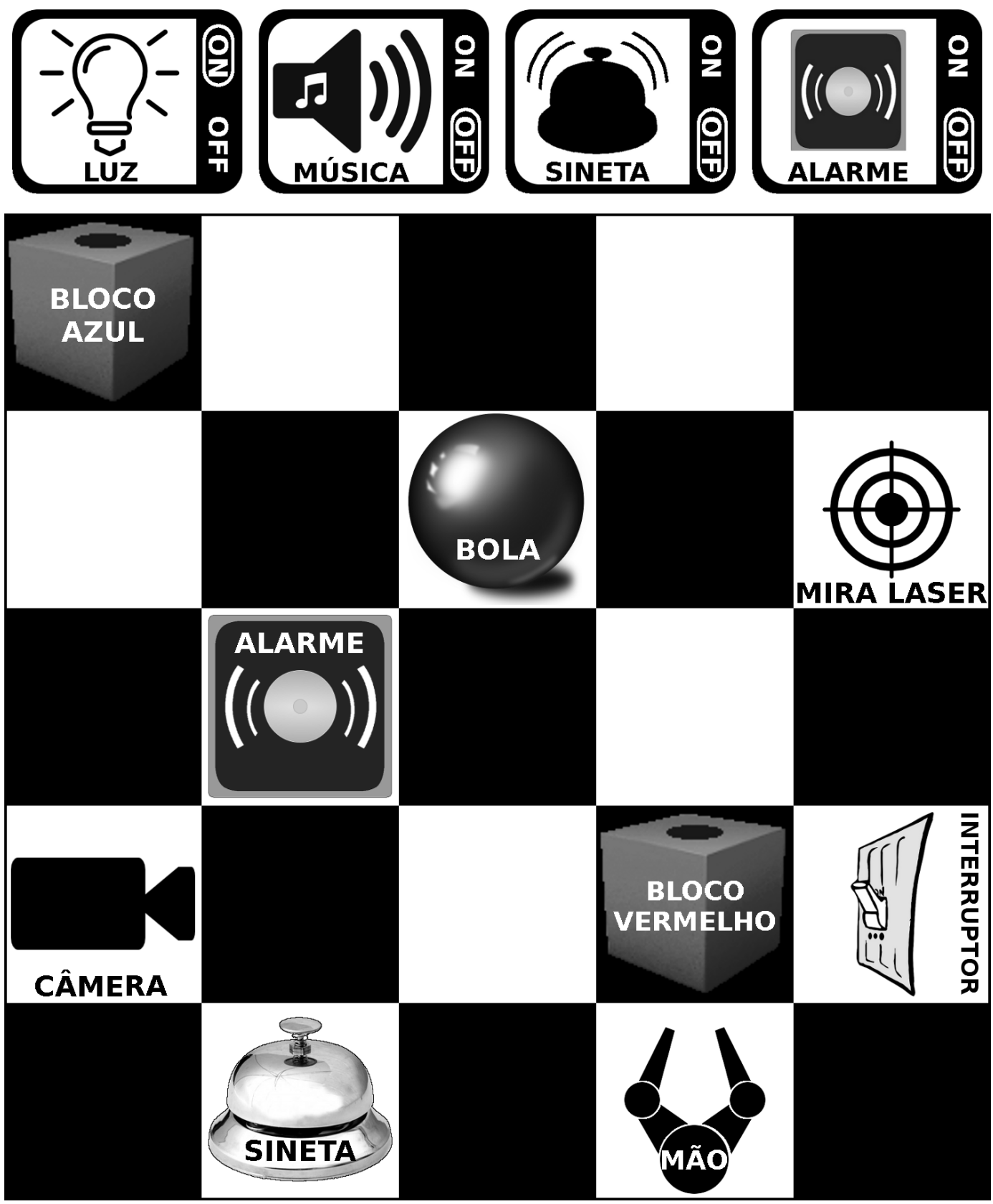

Figura 5.2: A figura mostra um exemplo de disposição inicial dos objetos no tabuleiro (interruptor, bloco azul, bloco vermelho, bola, sineta e alarme), juntamente com as posições relacionadas às partes do robô (câmera, mão mecânica e mira laser). Na parte superior da figura, encontram-se a situação atual (ON, OFF referentes aos elementos da sala ou do tabuleiro que interferem na luz e som ambientes (cuja variação dispara eventos salientes)).

as partes do robô, denotando a posição sobre a qual se encontra a mão mecânica e as posições para as quais estão sendo apontadas a câmera e a mira laser ${ }^{4}$.

4 Apesar de ser possível a sobreposição de objetos, ou seja, é possível que dois ou mais objetos ocupem a mesma posição no tabuleiro, para maior clareza optou-se por apresentar na Figura 5.2 cada objeto e cada parte do robô em uma célula individual. 
Na parte superior da figura, estão presentes quatro indicadores da situação atual (ON, $O F F)$ dos quatro elementos que podem afetar a luz e o som ambientes: a própria luz da sala, a música (emitida por uma caixa de som também presente na sala) e os objetos sobre o tabuleiro, a sineta e o alarme. Na situação apresentada na Figura 5.2, a luz encontra-se ligada, o que é denotado por uma "borda" ao redor de $O N$, sendo que música, sineta e alarme encontram-se todos desligados, denotado, analogamente, por uma borda ao redor de $O F F$.

A disposição inicial apresentada na Figura 5.2 é utilizada a seguir para exemplificar a solução do problema do domínio: "Ligar o alarme". Para explicitar a estrutura hierárquica do problema, a solução é apresenta em termos dos subproblemas gerados. Neste trabalho, são utilizados eventos salientes para a descoberta automática de subproblemas e, como visto acima, os eventos salientes são disparados quando ocorrem variações significativas de luz e som.

De acordo com as regras do domínio, o alarme liga automaticamente se a sineta for ligada quando simultaneamente a luz estiver desligada e a música ligada. Na situação que está sendo resolvida neste exemplo (ilustrada na Figura 5.2), a luz está ligada e a música, a sineta e o alarme estão desligados. Nesse caso, para resolver o problema de ligar o alarme, o robô precisa:

1. ligar a música (disparando o evento saliente música ${ }_{O N}$ ),

2. desligar a luz (disparando o evento saliente $l u z_{O F F}$ ) e

3. ligar a sineta (disparando simultaneamente os eventos salientes sineta ON $_{\text {e }}$ larme $_{O N}$ ).

Como cada uma das atividades que o robô precisa realizar para ligar o alarme dispara um evento saliente, o problema de ligar o alarme pode ser subdividido em três subproblemas, cada um responsável por disparar um dos três eventos salientes: música $_{O N}, l u z_{O F F}$ e sineta ${ }_{O N}$. Além disso, a solução do problema, ou seja, ligar o alarme, também dispara um evento saliente: alarme $_{O N}$. Dessa forma, o problema e os respectivos subproblemas estão encadeados em uma relação de dependência hierárquica de ocorrência de eventos salientes.

Essa relação de dependência é ilustrada no grafo presente na Figura 5.3. Primeiramente o grafo será explicado de maneira formal, sendo apresentado um exemplo em seguida. Cada nó do grafo representa um problema ou subproblema a ser resolvido. Como neste domínio os problemas e subproblemas são associados a eventos salientes (ou seja, os (sub)problemas são solucionados ao disparar um evento saliente), os nós do grafo contém os eventos salientes associados aos (sub)problemas que representam. As arestas do grafo representam as relações de dependência de solução: uma aresta $A \rightarrow B$ indica que o (sub)problema correspondente ao nó $A$ precisa ser resolvido antes que o (sub)problema 


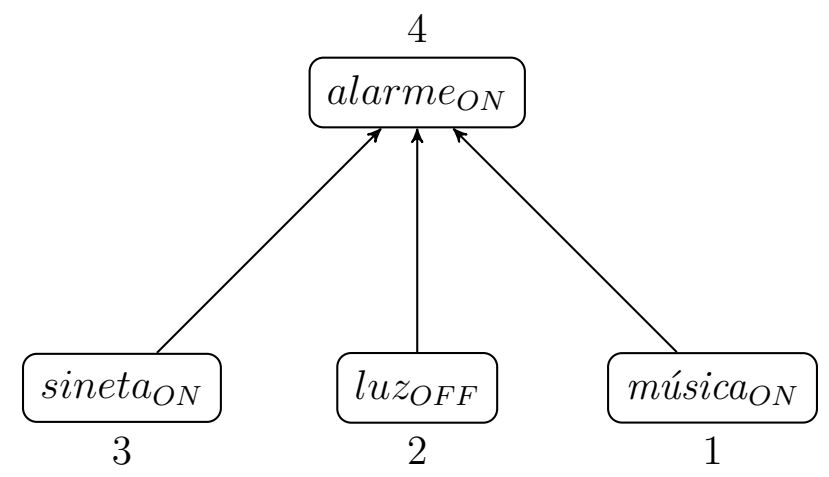

Figura 5.3: Grafo de dependência entre o problema de ativar o alarme (4) e os subproblemas ativar música (1), desativar luz (2) e ativar sineta(3), representados pelos eventos salientes que são disparados na solução dos respectivos (sub)problemas. No grafo, os nós representam o problema a ser resolvido e os respectivos subproblemas e as arestas representam a dependência entre as soluções: uma aresta $A \rightarrow B$ entre os nós $A$ e $B$ indica que a solução de $B$ depende primeiramente da solução de $A$. A numeração dos nós indica a ordem em que as soluções devem ser obtidas: devem ser resolvidos primeiramente os (sub)problemas de menor numeração. O grafo se refere à solução do problema, ou seja, ligar o alarme, caso a luz esteja ligada e a música, a sineta e o alarme estejam desligados.

correspondente ao nó $B$ possa ser resolvido. A numeração presente junto aos nós indica a ordem em que os (sub)problemas devem ser resolvidos, devendo-se resolver primeiramente os (sub)problemas de menor número.

Por exemplo, para que ocorra alarme $_{O N}$, é necessário que ocorra música ${ }_{O N}$ (é necessário que o robô ligue a música), luz $z_{O F F}$ (desligue a luz) e em seguida sineta $a_{O N}$ (ligue a sineta, com a luz já desligada e a música ligada) e que isso seja feito nessa ordem. Por exemplo, caso sineta $a_{O N}$ seja disparado antes da ocorrência de $l u z_{O F F}$, a luz ainda estará ligada e, pelas regras do domínio, não será disparado alarme $O N$ (o problema não será solucionado).

Abaixo, estão relacionadas as sequências de ações que o robô deve executar de forma a disparar cada um dos eventos salientes associados aos subproblemas:

1. música $a_{O N}$ - Apontar a câmera para o bloco azul $l^{5}$; mover a mão mecânica para a posição atualmente apontada pela câmera; executar a ação pressionar relacionada ao bloco azul.

2. $l u z_{O F F}$ - Apontar câmera para o interruptor; mover a mão mecânica para a posição atualmente apontada pela câmera; executar a ação pressionar relacionada ao interruptor. 
3. sinet $a_{O N}$ - Apontar câmera para a sineta; apontar a mira laser para a posição atualmente apontada pela câmera; mover a câmera para a posição em que se encontra a bola; mover a mão mecânica para a posição atualmente apontada pela câmera; executar a ação mover, relacionada à bola.

Ao executar a sequência de ações descrita acima, com a configuração inicial ilustrada na Figura 5.2, a sineta será ativada nas condições adequadas para que o alarme seja ativado. Dessa forma, o problema "Ativar alarme" é solucionado.

Neste ponto, é importante considerar a solução do problema em que a luz também iniciasse desligada. Essa modificação não trará sobrecarga substancial de leitura (pois a modificação na solução é mínima), mas tornará mais clara a relação de dependência entre (sub)problemas, motivando a exploração da característica hierárquica no aprendizado.

Caso a luz também iniciasse desligada, a ação pressionar, do bloco azul(utilizada para ligar a música), não estaria disponível ${ }^{6}$. Dessa forma, antes de disparar música $_{O N}$, o robô precisaria disparar luz $z_{O N}$, ligando a luz e liberando a ação pressionar, do bloco azul. O novo encadeamento entre os (sub)problemas, incluindo o novo subproblema de disparar $l u z_{O N}$, é ilustrado no grafo presente na Figura 5.4.

Esse grafo é similar ao da Figura 5.3, pois as configurações iniciais são similares, mas há duas diferenças importantes:

1. foram acrescentados o nó $l u z_{O N}$ e uma aresta apontando deste para o nó música ${ }_{O N}$, indicando a dependência entre os dois subproblemas (é necessário que o robô dispare luz $z_{O N}$ antes de disparar música $\left.{ }_{O N}\right) \mathrm{e}$

2. a ordem de solução foi modificada: o subproblema que surgiu deverá ser o primeiro a ser solucionado.

A ativação do interruptor pelas especificações do objeto, dispara ambos luz $O N$ e $l u z_{O F F}$. Dessa forma, a sequência de ações necessárias para resolver o novo subproblema é idêntica à apresentada anteriormente para disparar $l u z_{O F F}$ e não é apresentada novamente.

Com isso, conclui-se a explicação do domínio utilizado neste trabalho. Procurou-se mostrar a característica hierárquica do problema que o robô precisa resolver de forma a justificar a escolha deste domínio pela motivação principal: este domínio foi escolhido para validar a proposta deste trabalho, que consiste no armazenamento do histórico aplicação das políticas parciais e exploração interna às políticas parciais.

5 Como o robô não dispõe de ações que apontem a câmera especificamente para um objeto sobre o tabuleiro, para apontar a câmera para o bloco azul (ou qualquer outro objeto), o robô deve executar a ação "apontar câmera para um objeto aleatório" até que a câmera aponte para o bloco azul. Essa característica acrescenta dificuldade e estocasticidade ao domínio.

6 Essa ação somente fica disponível com a luz ligada (descrição do bloco azul). 


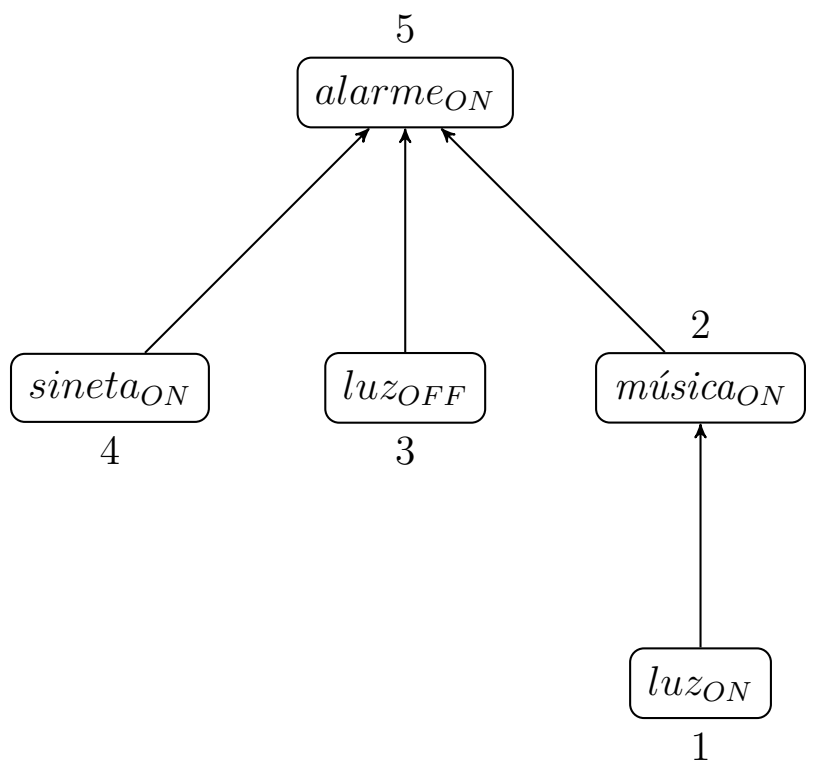

Figura 5.4: Grafo de dependência entre os eventos salientes associados aos (sub)problemas que precisam ser resolvidos para disparar alarme $_{O N}$ em uma configuração inicial em que luz, música, sineta e alarme iniciam desligados.

Um problema com forte caracterização hierárquica é adequado para a validação das propostas deste trabalho, considerando-se que elas foram direcionadas ao ARMI, um algoritmo que identifica subproblemas através de eventos salientes e cria e aprende políticas parciais para resolvê-los.

Na próxima seção, apresenta-se a modelagem do problema, através da descrição do formalismo utilizado para descrever os elementos do domínio em termos dos elementos formais utilizandos no ferramental de aprendizado aplicado neste trabalho.

\subsection{Modelagem do Problema}

Nesta seção é apresentada a modelagem do problema, aprensentando-se a definição da descrição fatorada dos estados, as ações disponíveis para execução e respectivas condições de disponibilidade, os eventos salientes juntamente à definição das regras de disparo (ocorrência), e as funções e valores das recompensas intrínseca (recebidas quando ocorre um evento saliente) e extrínseca (recebidas quando o robô resolve o problema, ou seja, quando consegue ligar o alarme).

\subsubsection{Conjunto de Estados}

Na modelagem utilizada para os experimentos, o estado foi descrito por um inteiro obtido de um vetor binário de 13 posições, cuja construção será detalhada. Para tornar 
mais clara a explicação, as posições do vetor serão apresentadas de forma agrupada, como ilustrado na Figura 5.5. Procurou-se também apresentar um exemplo concreto acompanhando cada definição formal.

\begin{tabular}{|c|c|c|c|c|c|c|c|c|c|c|c|c|}
\hline \multicolumn{4}{|c|}{ câmera } & \multicolumn{4}{c|}{ mão mecânica } & $*$ & \multicolumn{4}{c|}{ ON OFF } \\
\hline & & & & & & & & & & & & \\
\hline 0 & 1 & 2 & 3 & 4 & 5 & 6 & 7 & 8 & 9 & 10 & 11 & 12 \\
\hline
\end{tabular}

Figura 5.5: Vetor com 13 atributos binários que representa o estado do PSMD do problema.

Os quatro primeiros bits, correspondentes às posições $0,1,2$ e 3 do vetor, indicam os objetos presentes na posição atualmente apontados pela câmera. De forma a obter redução no custo de memória associado aos experimentos ${ }^{7}$, foram considerados somente os objetos que possuem ações associadas a si, ou seja, somente são considerados os objetos bola, bloco azul, bloco vermelho e interruptor, como ilustrado na Figura 5.6.

\begin{tabular}{|c|c|c|c|c|}
\hline \multicolumn{4}{|c|}{ câmera } & \\
\hline BO & BA & BV & IN & \\
\hline 0 & 1 & 2 & &
\end{tabular}

Figura 5.6: Atributos referentes à câmera- BO: bola; BA: bloco azul; BV: bloco vermelho; IN: interruptor.

O valor do bit é 1, caso o objeto correspondente esteja presente na posição apontada pela câmera, e 0 , caso contrário. Por exemplo, se a posição do tabuleiro para a qual câmera aponta estiver vazia, os bits correspondentes serão \begin{tabular}{ll|l|l|l|l|l}
0 & 0 & 0 & 0 &
\end{tabular} ; caso a posição apontada pela câmera contenha o bloco azul e o interruptor, os bits serão \begin{tabular}{l|l|l|l|l|l|l|l|}
0 & 1 & 0 & 1. \\
\hline
\end{tabular}

Analogamente, os bits de 4, 5, 6 e 7 indicam os objetos que se encontram na mesma posição do tabuleiro sobre a qual se encontra a mão mecânica como ilustrado na Figura 5.7. Por exemplo, se a mão mecânica estiver sobre a uma posição em que se encontrem a bola e o bloco vermelho, os valores dos atributos 4, 5, 6 e 7 serão \begin{tabular}{|l|l|l|l|}
\hline 1 & 0 & 1 & 0 \\
\hline
\end{tabular}

$7 \quad$ Isso foi realizado devido ao fato de diversas estruturas de dados utilizadas no aprendizado serem indexadas pelos estados. Dessa forma, o acréscimo de cada bit na representação dos estados representaria, em termos de memória, no mínimo, uma duplicação no espaço de memória necessário para armazenar as estruturas de dados utilizadas no aprendizado. 


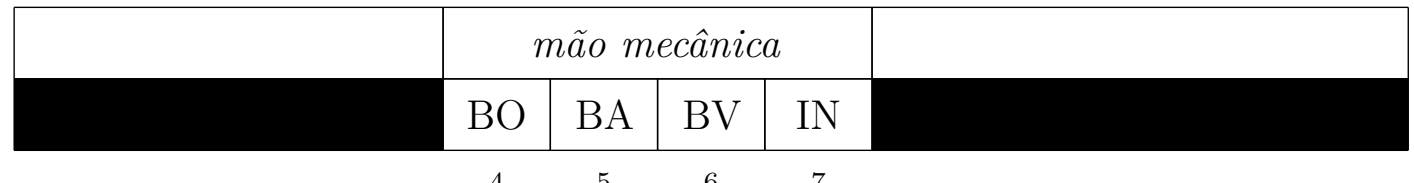

Figura 5.7: Atributos referentes à mão mecânica- BO: bola; BA: bloco azul; BV: bloco vermelho; IN: interruptor.

O bit 8 indica se a mira laser está apontando para a sineta. Dessa forma, se a mira laser estiver apontando para a mesma posição do tabuleiro em que se encontra a sineta, o bit 8 terá valor 1 ; caso contrário, o valor do bit 8 será 0 .

Os quatro últimos bits do vetor de estado indicam se os elementos que interferem na luz e som ambientes estão ligados ou desligados. O valor do bit é 1, caso o elemento esteja ligado e 0 caso contrário. A posição de cada elemento é ilustrada na Figura 5.8.

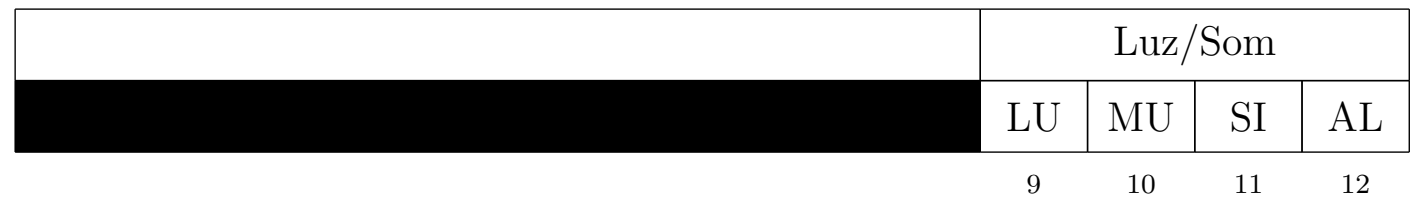

Figura 5.8: Atributos referentes à situação dos objetos que interferem na luz e som ambientes - LU: luz; MU: música; SI: sineta; AL: alarme.

Por exemplo, na situação representada na Figura 5.2, todos os elementos se encontram desligados, logo, os bits correspondentes são \begin{tabular}{rl|l|l|l|l}
\hline 0 & 0 & 0 & 0 & \\
\hline
\end{tabular} . Já no momento da solução do problema, música, sineta e alarme estarão ligados, o que é representado por \begin{tabular}{ll|l|l|l|l|}
\hline 0 & 1 & 1 & 1 \\
\hline
\end{tabular} bits $9,10,11$ e 12 .

Assim, a descrição completa do estado é dada pelo vetor binário de 13 posições representado na Figura 5.9.

\begin{tabular}{|c|c|c|c|c|c|c|c|c|c|c|c|c|}
\hline \multicolumn{4}{|c|}{ câmera } & \multicolumn{4}{c|}{ mão mecânica } & $*$ & \multicolumn{4}{c|}{ ON/OFF } \\
\hline BO & BA & BV & IN & BO & BA & BV & IN & SI & LU & MU & SI & AL \\
\hline 0 & 1 & 2 & 3 & 4 & 5 & 6 & 7 & 8 & 9 & 10 & 11 & 12 \\
\hline
\end{tabular}

Figura 5.9: 13 bits do vetor de estado - BO: bola; BA: bloco azul; BV: bloco vermelho; IN: interruptor; SI: sineta; LU: luz; MU: música; SI: sineta; AL: alarme.

Com isso, conclui-se a modelagem dos estados do problema, que, como visto, é realizada através da descrição fatorada por um vetor binário. Em seguida, apresenta-se a modelagem utilizada para o conjunto de ações do problema. 


\subsubsection{Conjunto de Ações}

As ações estão divididas em dois grupos: 1) sempre disponíveis para o robô e 2) associadas a objetos. As ações do primeiro grupo podem ser executadas pelo robô a qualquer passo do experimento, sem condições adicionais. Por exemplo, o robô sempre pode executar a ação "mover a mão mecânica para a posição atualmente apontada pela câmera" independentemente da disposição dos objetos ou partes do robô no tabuleiro. Abaixo, encontra-se a lista completa das ações sempre disponíveis para o robô:

- apontar a câmera para a posição onde se encontra a mira laser;

- apontar a câmera para a posição onde se encontra a mão mecânica;

- mover a mira laser para a posição atualmente apontada pela câmera;

- mover a mão mecânica para a posição atualmente apontada pela câmera;

- apontar a câmera para um objeto sobre o tabuleiro sorteado; aleatoriamente. Os objetos incluídos no sorteio aleatório são: interruptor, bloco azul, bloco vermelho, bola, sineta e alarme; as partes do robô (câmera, mão mecânica e mira laser) não são incluídas no sorteio.

Adicionalmente, alguns objetos possuem ações associadas a si, mas que somente ficam disponíveis para o robô se a câmera estiver apontando e a mão mecânica estiver sobre a posição em que o respectivo objeto se encontra. Por exemplo, o objeto bola possui a ação "mover", mas, para que o robô possa executá-la, a câmera deve estar apontada para posição da bola e a mão mecânica deve estar sobre a posição da bola. Os objetos e respectivas ações associadas encontram-se na Tabela $5.2^{8}$.

Tabela 5.2: Objetos e respectivas ações associadas.

\begin{tabular}{|l|c|}
\hline Objeto & Ação \\
\hline \hline interruptor & $\begin{array}{c}\text { pressionar } \\
\text { pressionar }\end{array}$ \\
\hline bloco azul & $\begin{array}{c}\text { pressionar } \\
\text { empurrar }\end{array}$ \\
\hline bloco vermelho & $\begin{array}{c}\text { pressionar } \\
\text { empurrar }\end{array}$ \\
\hline bola & mover \\
\hline
\end{tabular}

8 A respectiva informação foi apresentada na Tabela 5.1, que é reproduzida em partes aqui para conveniência do leitor. 


\subsubsection{Eventos Salientes}

Neste trabalho, os eventos salientes são definidos pela variação de determinados atributos da descrição fatorada do estado, denominados atributos salientes. Para tornar esse conceito mais claro, os atributos salientes utilzados neste trabalho são destacados da descrição fatorada do estado, ilustrada na Figura 5.10.

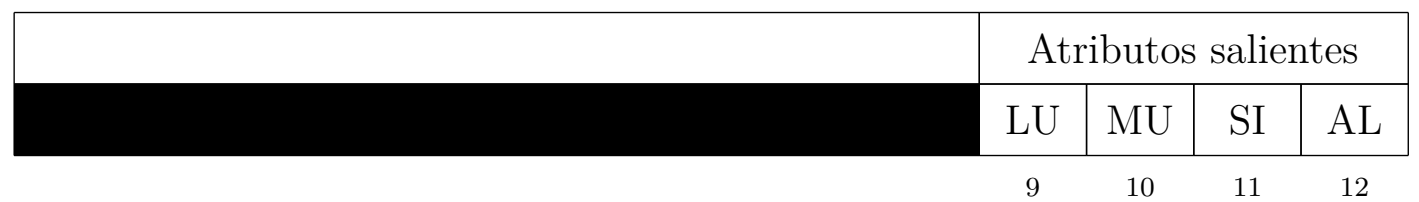

Figura 5.10: Atributos salientes — LU: luz; MU: música; SI: sineta; AL: alarme.

Ou seja, os atributos salientes correspondem às quatro últimas posições do vetor binário que representa a descrição fatorada do estado. Essas posições, por sua vez, correspondem à situação $(O N / O F F)$ dos elementos que interferem na luz e som ambientes: luz, música, sineta, alarme.

Disparo de um evento saliente - Dessa forma, um evento saliente será disparado (ocorrerá) quando houver uma ou mais alterações em um ou mais bits das posições de 9 a 12 do vetor binário utilizado na descrição fatorada do estado, ou seja, quando ocorrer um (ou mais) dentre os seguintes ${ }^{9}$ :

- a luz for ligada,

- a luz for desligada,

- a música for ligada,

- a música for desligada,

- a sineta for ligada ${ }^{10}$,

- o alarme for ligado ou

- o alarme for desligado.

A relação entre evento saliente, subproblemas, políticas parciais e recompensas intrínsecas, é delineada da seguinte maneira:

$9 \quad$ Vale ressaltar que a quantidade exata de políticas parciais que serão definidas e utilizadas pelo agente nos experimentos é obtida na modelagem experimental, onde são definidos os atributos salientes e a indexação de políticas parciais, como detalhado na Seção 5.2.

10 A sineta é sempre desligada ao fim do passo em que for ligada (ou seja, o som da sineta tem duração de um passo, somente). Dessa forma, a ativação da sineta dispara dois eventos salientes ao ser ativada. Entretanto, para as técnicas de aprendizado utilizadas neste trabalho, basta considerar um dos eventos salientes associados à ativação da sineta para a criação de uma política parcial. Dessa forma, considera-se somente o evento saliente correspondente a ligar a sineta, sineta $a_{O N}$. 
- no algoritmo ARMI, quando ocorre um evento saliente, o algoritmo identifica um subproblema, correspondente a disparar esse evento saliente;

- para auxiliar na solução do subproblema que acabou de ser identificado, cria-se uma política parcial associada a ele, que é aprimorada à medida em que o agente a aplica para resolver o subproblema, disparando o evento saliente;

- cada disparo do evento saliente gera uma recompensa intrínseca que é recebida pelo agente, motivando-o a repetir a aplicação dessa política parcial, fazendo com que o modelo dessa política parcial seja aprimorado.

Dessa forma, conclui-se a apresentação dos eventos salientes, utilizados para identificar subproblemas e criar políticas parciais para solucioná-los. Para motivar o aprendizado das políticas parciais, utiliza-se um conjunto especial de recompensas, denominadas recompensas intrínsecas, detalhadas na próxima seção, juntamente com as recompensas usuais recebidas ao solucionar o problema (denominadas recompensas extrínsecas para diferenciação).

\subsubsection{Recompensas Intrínsecas e Recompensas Extrínsecas}

Para motivar a aplicação de uma política parcial, dessa forma promovendo o aprimoramento da mesma, foram inseridas recompensas denominadas intrínsecas que são recebidas sempre que o agente resolve o subproblema associado à política parcial, ou seja, sempre que o agente dispara o evento saliente associado ao subproblema que a política parcial tem a função de resolver.

Dessa forma, além da recompensa que o agente recebe ao solucionar o problema completo (denominadas extrínsecas), são recebidas recompensas para a solução de subproblemas. Assim, o agente pode receber recompensas de duas categorias, listadas abaixo, exemplificadas e detalhadas nesta seção:

- Recompensas Intrínsecas - recebidas sempre que ocorre um evento saliente, utilizadas no aprendizado para motivar o agente a repetir o evento saliente que lhe recompensou, ou seja, as recompensas intrínsecas motivam o agente a atingir objetivos intermediários, aplicando as políticas parcias associadas aos subproblemas, (disparar o evento saliente associado ao subproblema), e

- Recompensas Extrínsecas - recebidas sempre que o agente consegue resolver o pro-

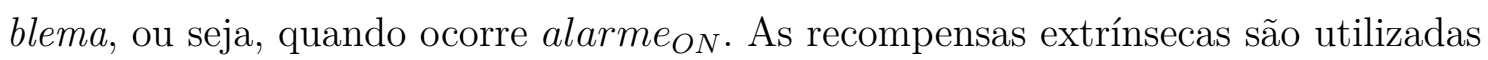
no aprendizado para motivar o agente a atingir o objetivo final do problema da maneira mais eficiente possível, utilizando as ações primitivas e políticas parciais de que dispõe. 
Por exemplo, ao executar a ação "pressionar" no interruptor, ligando a luz pela primeira vez, o robô dispara o evento saliente $l u z_{O N}$. Nesse momento, o agente recebe uma recompensa intrínseca pela ocorrência de $l u z_{O N}$ independentemente de ele ter ou não atingido a solução final do problema. A função das recompensas intrínsecas é promover a repetição da ocorrência dos eventos salientes de forma a refinar as políticas parciais, como será visto mais adiante.

Um exemplo de interesse se dá no momento em que o robô consegue solucionar o problema: com a luz desligada e a música ligada, o robô liga a sineta, ligando automaticamente o alarme. Nesse momento, são recebidas recompensas das duas categorias: uma intrínseca, pela ativação de evento saliente, e uma extrínseca, que o robô recebe por ter conseguido resolver o problema.

Conforme visto na Seção 3.3, o valor da recompensa intrínseca recebido é dado pela fórmula

$$
r_{t+1}^{i}=\tau\left[1-P^{\phi_{e}}\left(s_{t+1} \mid s_{t}\right)\right]
$$

em que o valor de $\tau$ utilizado neste trabalho foi $\tau=0.5$ para todos os experimentos ${ }^{11}$. Intuitivamente, a fórmula fornece um valor de recompensa intrínseca cada vez menor à medida que o agente repete a ocorrência do evento saliente associado. Isso porque o valor de $P^{\phi_{e}}\left(s_{t+1} \mid s_{t}\right)$ reflete a probabilidade de se alcançar $s_{t+1}$ partindo de $s_{t}$ e tende a aumentar à medida que o modelo da política parcial é aprimorado.

Por exemplo, à medida que o agente repete o evento saliente $l u z_{O N}$, os valores de $P^{\phi_{l u z O N}}\left(s_{t+1} \mid s_{t}\right)$ tendem a aumentar, refletindo o conhecimento que o agente adquiriu sobre a probabilidade dessa transição. Com o aumento de $P^{\phi_{\text {luz }} O N}\left(s_{t+1} \mid s_{t}\right)$, o valor da recompensa intrínseca tende a diminuir. Esse fato é ilustrado a seguir.

A Tabela 5.3 mostra o decaimento da recompensa intrínseca com o aprimoramento da política parcial para as dez primeiras repetições do evento saliente $l u z_{O N}$. Pela análise dos valores presentes na tabela, pode-se perceber que o valor das recompensas intrínsecas diminuem à medida que o evento saliente é repetido. Isso ocorre porque o modelo da política parcial é aprimorado, causando um aumento no valor de $P^{\phi_{l u z} O_{N}}\left(s_{t+1} \mid s_{t}\right)$.

Por exemplo, na quinta vez que ocorre $l u z_{O N}$, o agente aprimorou o modelo da política parcial $\phi^{l u z_{O N}}$, obtendo o valor $P^{\phi_{l u z_{O N}}}\left(s_{t+1} \mid s_{t}\right)=0,405415$, que, aplicado na fórmula, resulta em uma recompensa intrínseca no valor de 0,297293; na décima repetição de $l u z_{O N}$ o modelo foi ainda mais aprimorado (nesse momento, $P^{\phi_{l u z O N}}\left(s_{t+1} \mid s_{t}\right)$ vale 0,644808), resultando em um valor ainda menor de recompensa intrínseca, 0,177596 ${ }^{12}$.

11 O parâmetro $\tau$ corresponde a uma constante que expressa quão expressivos são os valores das recompensas intrínsecas em relação aos valores das recompensas extrínsecas, conforme detalhado na Seção 3.3 .

12 O decaimento das recompensas intrínsecas é controlado pelos parâmetros $\alpha$ e $\gamma$, utilizados no aprendizado, sendo possível obter um decaimento mais ou menos rápido através da modificação dos valores dos mesmos. Já a função do parâmetro $\tau$ é estabelecer o peso das recompensas intrínsecas em 
Tabela 5.3: Exemplo de decaimento da recompensa intrínseca com a repetição do evento saliente associado. A tabela mostra exemplos de valores de recompensas intrínsecas recebidas à medida em que o agente dispara o evento saliente luz $z_{O N}$.

\begin{tabular}{|r|r|r|}
\hline$l u z_{O N}$ & $P^{\phi_{l u z} O N}\left(s_{t+1} \mid s_{t}\right)$ & $r_{t+1}^{i}$ \\
\hline \hline 1 & 0,099000 & 0,450500 \\
2 & 0,188100 & 0,405950 \\
3 & 0,268290 & 0,365855 \\
4 & 0,340461 & 0,329770 \\
5 & 0,405415 & 0,297293 \\
6 & 0,463873 & 0,268063 \\
7 & 0,516486 & 0,241757 \\
8 & 0,563837 & 0,218081 \\
9 & 0,606454 & 0,196773 \\
10 & 0,644808 & 0,177596 \\
\hline
\end{tabular}

O efeito do decaimento das recompensas intrínsecas no aprendizado é duplo:

- nas primeiras vezes em que o agente recebe a recompensa intrínseca associada à ocorrência de um evento saliente, ele é motivado (pelos maiores valores que são recebidos) a repetir esse evento saliente, aprimorando o modelo da política parcial associada;

- à medida que o modelo é aprimorado, o valor da recompensa intrínseca decai, fazendo com que o agente diminua o interesse pela repetição do evento saliente associado, podendo concentrar seus esforços de aprendizado em políticas parciais menos aprimoradas (ou seja, cujos eventos salientes fornecem um maior valor de recompensas intrínsecas).

Em relação às recompensas extrínsecas, que são recebidas pelo agente somente ao solucionar o problema, os valores recebidos pelo robô são constantes e valem sempre 10, nos experimentos deste trabalho. Dessa forma, sempre que o agente resolve o problema, ligando o alarme, ele recebe uma recompensa no valor de 10, independentemente de já tê-lo feito múltiplas vezes anteriormente ${ }^{13}$.

Com isso, conclui-se a apresentação da modelagem do problema utilizada na configuração experimental. Na próxima seção, são apresentados e discutidos os resultados

relação às recompensas extrínsecas na atualização da função $Q$ do Q-Learning.

13 Ao leitor interessado em reproduzir os resultados deste trabalho, é importante notar um detalhe de implementação que foi utilizado: a indexação das políticas parciais foi realizada utilizando-se os quatro atributos salientes. Isso foi realizado de forma a aumentar a especificidade das políticas parciais aprendidas pelo agente. Apesar de a modificação implicar em um maior consumo de memória (pois são criadas mais políticas parciais, dezesseis ao invés de quatro), a modificação auxiliou a aumentar a rapidez de execução dos experimentos (cujo custo computacional se mostrou alto). 
obtidos nos testes das propostas deste trabalho.

\subsection{Resultados e Discussão}

Nesta seção são apresentados os resultados experimentais obtidos nos testes das propostas desta dissertação. As propostas foram implementadas no algoritmo ARMI (SINGH; BARTO; CHENTANEZ, 2005) gerando o algoritmo A-EIP ${ }^{3}$ (ARMI com Exploração Interna e Pilha de Políticas Parciais), que foi utilizado para no aprendizado da solução do problema do domínio descrito anteriormente. Os resultados experimentais foram divididos em dois grupos, apresentados nas seções a seguir. O primeiro grupo de experimentos avalia se o A-EIP 3 é capaz de manter as qualidades desejáveis do ARMI, e o segundo avalia o desempenho de aprendizado apresentado pelo A-EIP ${ }^{3}$.

\subsubsection{Manutenção das características desejáveis do ARMI}

A implementação das propostas deste trabalho afetam diretamente os mecanismos de identificação e aprendizado de políticas parciais presentes no ARMI, que são características expressivamente positivas para o aprendizado de problemas com estrutura hierárquica, portanto, desejava-se mantê-las. Dessa forma, verificou-se inicialmente se a implementação das propostas no A-EIP ${ }^{3}$ preservava as seguintes características do algoritmo original:

- explorar a estrutura hierárquica de um problema, identificando subproblemas através de eventos salientes, criando e associando políticas parciais para solucionar esses subproblemas, e

- aprender e simultanamente utilizar as políticas parciais identificadas, de forma a melhorar o desempenho de aprendizado final do agente.

O algoritmo utilizado no aprendizado fornece recompensas intrínsecas cujos valores são inversamente proporcionais à predictibilidade do evento saliente correspondente. Assim, quanto menos previsível é para o agente a ocorrência de um evento saliente segundo uma sequência de ações, maior o valor da recompensa intrínseca recebida. Como a predictibilidade está relacionada ao modelo da função de transição de estados da política parcial, o agente é motivado pelas recompensas intrínsecas a priorizar o aprendizado dos modelos das políticas parciais que mais necessitam.

Inicialmente, foram plotados os valores de motivação intrínseca recebidos para cada um dos eventos salientes possíveis no domínio. Isso foi feito para analisar o mecanismo de utilização de motivação intrínseca no aprendizado de políticas parciais.

No gráfico da Figura 5.11 são apresentados os valores de recompensa intrínseca recebidos por cada evento saliente que o robô foi capaz de disparar em passos iniciais do 

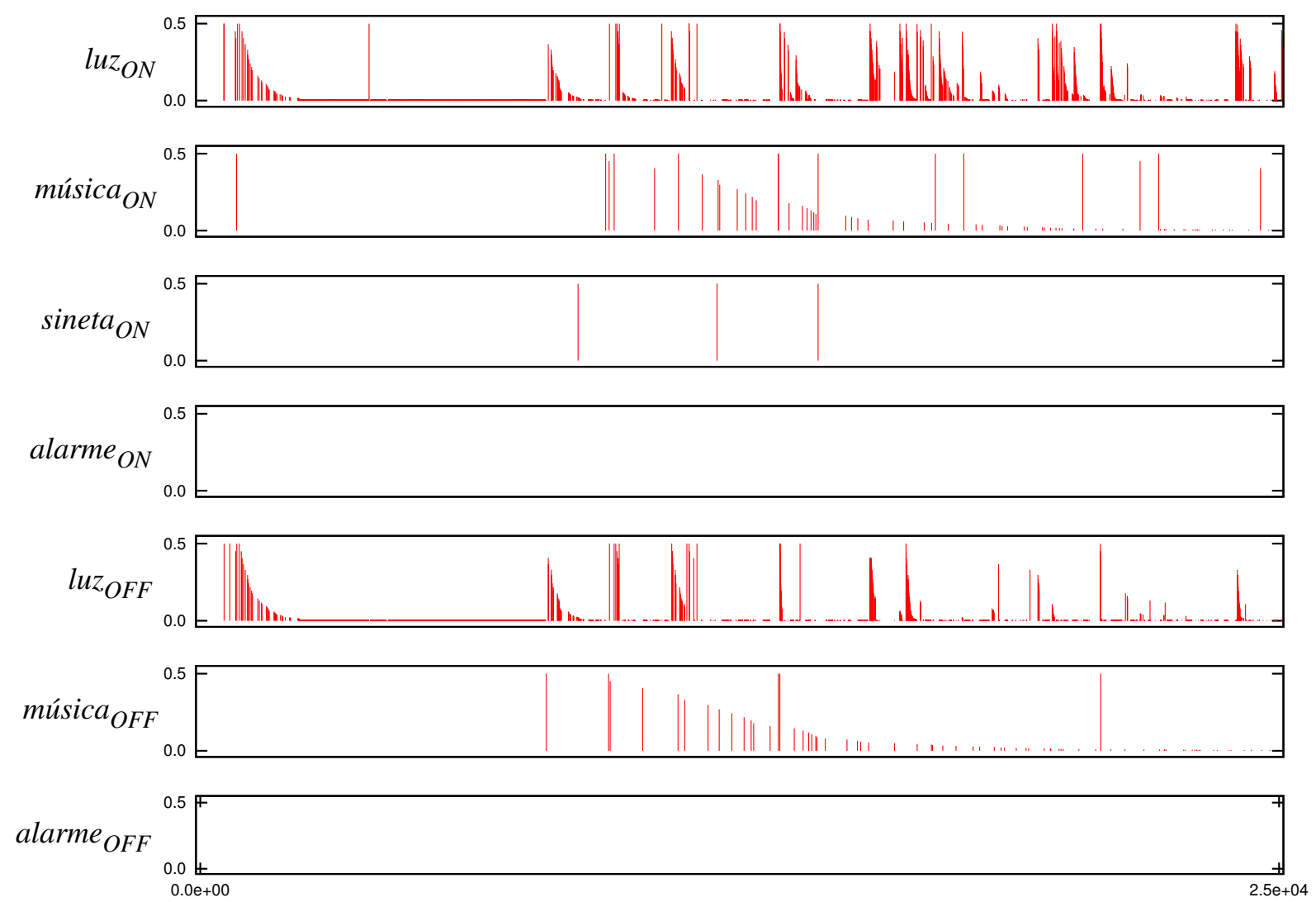

Figura 5.11: Valores das recompensas intrínsecas recebidas pelo robô para cada evento saliente que ele foi capaz de disparar nos primeiros vinte e cinco mil passos do aprendizado (abscissa). O robô foi capaz de disparar os eventos salientes mais simples, mas ainda não conseguiu resolver o problema (disparar alarme $_{O N}$ ). O gráfico mostra o valor recebido para cada ativação por passo do experimento. Dessa forma, a presença da barra indica a ocorrência do evento saliente e o comprimento da barra indica o valor recebido. Subproblemas mais simples, como disparar $l u z_{O N}$, são resolvidos mais rápida e frequentemente (as barras aparecem logo no início e com mais frequência); já subproblemas mais complexos, como disparar sineta ${ }_{O N}$, ocorrem após algum tempo de aprendizado e com menos frequência (as barras correspondentes aparecem mais tardiamente e em menor quantidade).

experimento (primeiros vinte e cinco mil passos). A presença de uma barra no gráfico indica a ocorrência do respectivo evento saliente; o comprimento da barra indica o valor da recompensa intrínseca recebida ao disparar o evento saliente.

Concentrando-se inicialmente no evento saliente $l u z_{O N}$, pode-se perceber que sua ocorrência se dá logo nos primeiros passos do experimento (pois as barras começam a aparecer logo no início do gráfico), refletindo a simplicidade do subproblema associado, de disparar $l u z_{O N}$ : o agente simplesmente precisa mover a câmera até o interruptor, a mão mecânica até a câmera e executar a ação "pressionar" do interruptor. 
Além disso, o evento saliente $l u z_{O N}$ ocorre com uma frequência relativamente alta: as barras estão mais próximas entre si, mostrando que o intervalo entre os disparos do eventos saliente $l u z_{O N}$ é relativamente menor. Essa maior frequência na ocorrência de $l u z_{O N}$ pode ser explicada pela facilidade que o robô tem para repeti-lo: basta permanecer com a mão mecânica sobre o interruptor, executando múltiplas vezes a ação "pressionar".

É importante considerar que o disparo de múltiplos $l u z_{O N}$ depende do disparo de outro evento saliente, $l u z_{O F F}$. Nesse sentido, os eventos salientes $l u z_{O N}$ e $l u z_{O F F}$ são complementares, pois é necessário desligar a luz para ligá-la novamente. Isso é mostrado no gráfico pela relativa sincronia entre o recebimento de recompensas intrínsecas para $l u z_{O N}$ e $l u z_{O F F}$, ilustrando a dependência entre eles.

Voltando a concentrar-se em $l u z_{O N}$ outra característica importante é o decaimento do valor das recompensas intrínsecas recebidas: à medida que ocorre a repetição, os valores recebidos diminuem, refletindo o mecanismo de recompensa intrínseca discutido na Seção 5.2.4, onde é explicado que a função do decaimento é dupla:

1. maiores recompensas intrínsecas nas primeiras repetições, quando a política parcial associada ao subproblema de disparar o evento saliente ainda não foi expressivamente aprimorada, motivando a repetição do disparo do evento saliente, e consequente aplicação e aprimoramento da política parcial associada;

2. menores recompensas intrínsecas nas repetições mais tardias, quando a política parcial associada ao subproblema de disparar o evento saliente já foi aplicada múltiplas vezes, tendo sido aprimorada, momento em que o robô pode se concentrar em descobrir novas formas de disparar eventos saliente ou aprimorar as políticas parciais de eventos salientes que foram repetidos uma menor quantidade de vezes.

Pela observação do primeiro "agrupamento" de barras (barras relativamente próximas, no gráfico) relacionadas à ocorrência de $l u z_{O N}$, pode-se perceber o decaimento no comprimento das barras, refletindo a diminuição dos valores de recompensas intrínsecas recebidos para $l u z_{O N}$ à medida em que o $l u z_{O N}$ se repete.

O decaimento no valor das recompensas intrínsecas para luz $z_{O N}$ é tal que, após um tempo, os valores recebidos são próximos de zero, permanecendo assim por alguns passos, mas ocorrendo novamente o recebimento de maiores valores após alguns passos. O aumento nos valores se dá porque as recompensas intrínsecas são calculadas considerando-se a transição de estados que ocorreu no disparo do evento saliente ${ }^{14}$.

Por exemplo, considere as duas transições ilustradas na Figura 5.12 em que o robô pressiona o interruptor e liga a luz: em ambas a câmera está na mesma posição em que a

14 Esse mecanismo é detalhado na Seção 5.2.4, mas será brevemente retomado aqui, para conveniência do leitor. 
mão mecânica, que também é a posição em que se encontra o interruptor; entretanto, na primeira transição a música não está ligada, mas na segunda transição sim.

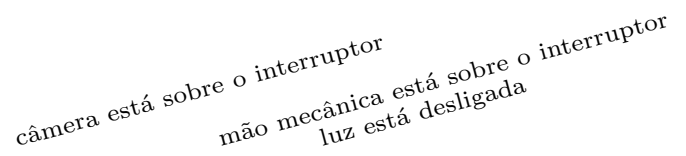

$$
\begin{aligned}
& \text { luz foi ligada }
\end{aligned}
$$

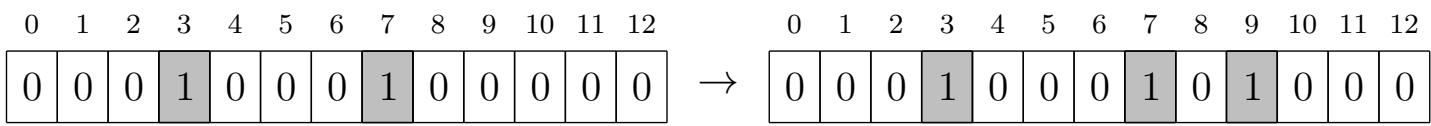

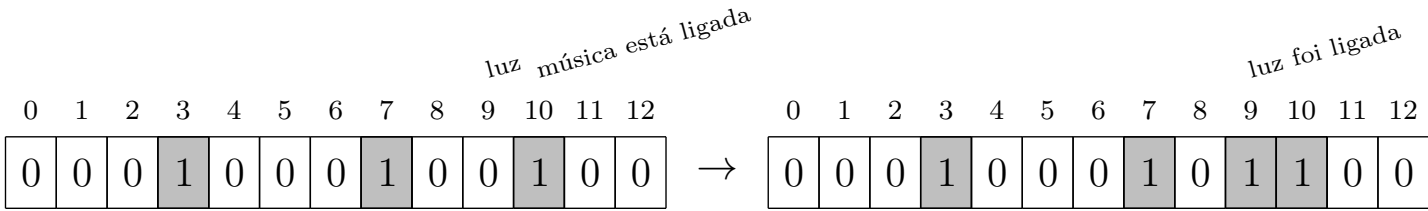

Figura 5.12: Exemplos de transições de estados que disparam o evento saliente $l u z_{O N}$, porém a partir de estados diferentes, implicando no cálculo em separado do decaimento das recompensas intrínsecas correspondentes.

Pode-se observar que nas duas transições a luz é ligada, disparando $l u z_{O N}$ : o bit correpondente à situação $(O N / O F F)$ da luz passa de 0 para 1. Entretanto, as duas transições são diferentes, pois na primeira transição a música inicia e permanece desligada, sendo que na segunda a música inicia e permanece ligada.

Com isso, o cálculo do decaimento das recompensas intrínsecas será realizado separadamente para as duas transições mostradas acima, mesmo que elas disparem o mesmo evento saliente, pois a fórmula utilizada para calcular o valor da recompensa intrínseca recebida na transição $s_{t} \rightarrow s_{t+1}$ utiliza $s_{t}$ e $s_{t+1}$, como mostrado abaixo e exemplificado a seguir:

$$
r_{t+1}^{i}=\tau\left[1-P^{\phi_{l u z} O N}\left(s_{t+1} \mid s_{t}\right)\right],
$$

onde $\tau$ é uma constante ( $\tau=0,5$ em todos os experimentos deste trabalho), $\phi_{l u z_{O N}}$ é a política parcial associada ao subproblema de disparar $l u z_{O N}$ e $P^{\phi_{l u z}{ }_{\text {N }}}\left(s_{t+1} \mid s_{t}\right)$ indica quão provável é, segundo o aprimoramento atual de $\phi_{l u z_{O N}}$, a transição $s_{t} \rightarrow s_{t+1}{ }^{15}$.

Por exemplo, se o robô ligar a luz utilizando somente a primeira transição até que a recompensa intrínseca associada tenha decaído a um valor baixo ( 0,1 , por exemplo), na primeira vez em que ele ligar a luz utilizando a segunda transição o valor recebido será o valor máximo $(0,5$, por exemplo), pois essa transição ainda não havia ocorrido, logo, não houve decaimento para a recompensa intrínseca associada, pois, como visto acima, o decaimento é calculado separadamente para as transições diferentes.

15 Indica, intuitivamente (mas não se restringe a), a probabilidade da transição em questão. Esse aspecto da função $P^{\phi}$ foi destacado individualmente neste ponto do texto pela sua importância na clarificação da ideia que é apresentada: decaimento de recompensas intrínsecas. A função $P^{\phi}$ também indica a probabilidade de terminar uma política parcial em um determinado estado, aspecto que não é utilizado especificamente neste contexto. A análise formal mais aprofundada da função $P^{\phi}$ é realizada na Seção 3.3. 
Dessa forma, voltando a apreciar a ocorrência de $l u z_{O N}$, na Figura 5.11, pode-se perceber o comportamento de decaimento da recompensa intrínseca associado à repetição, mas percebe-se que ocorre um recebimento posterior de recompensas de maior valor, que pode ser explicado pelo cálculo separado para transições diferentes e considerando que, com o decorrer do aprendizado, o robô aprende a ligar a luz, disparando $l u z_{O N}$, em estados diferentes.

As características analisadas para $l u z_{O N}$ também se aplicam a música ${ }_{O N}$, entretanto há duas diferenças significativas:

1. música ${ }_{O N}$ é disparado com mais frequência mais tardiamente, ou seja, em passos posteriores do experimento, se consideradas as primeiras ocorrências de $l u z_{O N}$;

2. os intervalos entre os disparos música ${ }_{O N}$ são maiores do que os intervalos entre os disparos de $l u z_{O N}$.

As duas características estão fortemente relacionadas porque música ${ }_{O N}$ também possui um evento saliente complementar, música $a_{O F}$. Ou seja, após a primeira ocorrência de música ${ }_{O N}$, para que música ${ }_{O N}$ possa ocorrer novamente, o robô precisa desligar a música, disparando música ${ }_{O F F}$. Entretanto, diferentemente do que ocorre com o interruptor, que liga e desliga a luz, a música é ligada pelo bloco azul e desligada pelo bloco vermelho.

Dessa forma, para que o robô consiga múltiplos música ${ }_{O N}$, ele precisa realizar uma quantidade maior de ações, pois, após ligar a música, para ligá-la novamente, ele precisaria:

1. apontar a câmera para bloco vermelho;

2. mover a mão mecânica para (a posição apontada) pela câmera;

3. executar a ação "pressionar", do bloco vermelho, desligando a música e disparando música ${ }_{O F F}$;

4. apontar a câmera para o bloco azul;

5. mover a mão mecânica para a câmera;

6. "pressionar" o bloco azul, ligando a música, e disparando música ${ }_{O N}$.

Analisando a sequência acima, pode-se perceber que a obtenção de disparos múltiplos de música ${ }_{O N}$ é mais complexa do que a sequência de ações para disparos múltiplos de $l u z_{O N}$, onde o robô só precisaria permanecer com a mão mecânica e a câmera sobre o interruptor e executar "pressionar" múltiplas vezes.

Outra característica importante no disparo de múltiplos música ${ }_{O N}$ é que eles dependem da solução de um subproblema: disparar música ${ }_{O F F}$. Assim, quanto melhor for a política parcial para disparar música $a_{O F F}$, mais rapidamente o agente conseguirá múltiplos disparos de música $O F F$. 
Note-se que o mesmo raciocínio se aplica à ocorrência de múltiplos música ${ }_{O F}$ : caso o agente queira repetir os disparos de música ${ }_{O F F}$ para receber as recompensas intrínsecas associadas, ele deverá também repetir música ${ }_{O N}$, ou seja, como são eventos salientes complementares, o agente tende a aprendê-los de forma sincronizada.

Essa sincronia pode ser percebida no gráfico em duas características. A primeira delas é a ocorrência de música ${ }_{O N}$ e música ${ }_{O F F}$ em passos próximos, o que pode ser explicado pela complementaridade de música ${ }_{O N}$ e música ${ }_{O F F}$ : um evento saliente somente pode ser disparado após o outro.

A segunda característica é o comprimento similar das barras relativas às recompensas intrínsecas recebidas ao disparar música ${ }_{O N}$ e música ${ }_{O F F}$ em passos próximos, o que pode ser explicado pelo aprendizado simultâneo das duas políticas parciais: uma é responsável por ligar e outra por desligar a música, e ambas são aprendidas de forma sincronizada; dessa forma, é de se esperar que os modelos das duas políticas variem também de forma sincronizada. Como as recompensas intrínsecas dependem do modelo, devido à sincronia é de se esperar que as recompensas intrínsecas também decaiam de forma sincronizada.

Neste ponto, pode-se levantar uma característica de hierarquia: a dependência (e auxílio) mútua de $l u z_{O N}$ e música ${ }_{O N}$ : se o robô, ao tentar obter múltiplos disparos de música $a_{O N}$, desligar a luz, ele precisará ligá-la novamente para liberar a ação que dispara música $_{O N}$. Nesse momento, caso o agente possua uma política parcial aprimorada para ligar a luz, isso poderá auxiliá-lo a disparar $l u z_{O N}$ e, em seguida, música ${ }_{O N}$, mais rapidamente. Dito de outra maneira, música ${ }_{O N}$ e luz $z_{O N}$ estão relacionados hierarquicamente, ou seja, há uma relação de dependência (auxílio) entre os subproblemas (políticas parciais).

Essa característica de hierarquia, ou dependência, entre $l u z_{O N}$ e música $a_{N}$ é sugerida no gráfico pela ocorrência mais tardia de música ${ }_{O N}$ com maior frequência. Isso pode ser explicado ao se considerar que em passos mais avançados do aprendizado o robô pôde aprimorar também a política parcial $l u z_{O N}$, que, como vista acima, está encadeada com música $_{O N}$ em uma relação de dependência e pode auxiliar o robô a ligar a música caso a luz esteja (seja) desligada.

Procedendo à análise do gráfico da Figura 5.11 relacionada ao evento saliente sineta $_{O N}$, cuja complexidade de disparo é relativamente alta, como pode ser visto pela sequência de ações necessárias:

1. apontar câmera para sineta;

2. mover mira laser para (a posição apontada pela) câmera;

3. apontar câmera para bola;

4. mover mão mecânica para câmera; 
5. executar ação "mover", da bola, que a moverá para a sineta, atualmente apontada pela mira laser, disparando sineta $a_{O N}$.

Pela análise do gráfico, pode-se perceber que o robô conseguiu disparar sineta $a_{O N}$ uma quantidade de vezes expressivamente menor em relação aos eventos salientes discutidos anteriormente, o que pode ser explicado pela complexidade do subproblema associado, dada a sequência de ações listada acima, mais complexa em relação às discutidas anteriormente, para $l u z_{O N}$ e música ${ }_{O N}$.

A complexidade do disparo de alarme $_{O N}$ é ainda maior, pois depende do disparo de sineta $_{O N}$, além de ter duas condições: a luz deve estar desligada e a música ligada quando sineta $_{O N}$ for disparado. Pode-se perceber, pelo gráfico, que o agente não foi capaz de

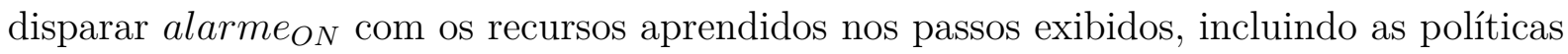
parciais já aprendidas e aprimoradas. Note-se também que, caso o robô tenha aprendido as políticas parciais para $l u z_{O F F}$ e música $a_{O N}$, é de se esperar que elas auxiliem o robô a disparar alarme $_{O N}$, que delas depende para satisfazer as condições listadas acima.

Com isso, conclui-se a análise do gráfico da Figura 5.11. A análise realizada sugere que a estrutura de aprendizado foi capaz de auxiliar o robô a explorar a característica hierárquica do problema, aprendendo políticas parciais para alguns subproblemas. Entretanto, o robô, nos primeiros vinte e cinco mil passos, não foi capaz de resolver o problema: disparar alarme $_{O N}$. Em seguida será apresentado o gráfico para um experimento mais completo, cuja duração é de quinhentos mil passos.

Após a análise anterior, a análise do gráfico do experimento é mais imediata. $\mathrm{Na}$ Figura 5.13, são exibidos os valores das recompensas intrínsecas para os passos apreciados anteriormente e os restantes, até o final do experimento. Pode-se perceber que as características de "espaçamento" (intervalo entre os disparos) permanecem similares às discutidas anteriormente, juntamente com o comportamento de decaimento e aumento posterior, além da sincronia entre recompensas intrínsecas para eventos salientes complementares, vistos anteriormente.

A diferença significativa é a ocorrência de alarme $_{O N}$, ou seja, o robô foi capaz de solucionar o problema utilizando os recursos de aprendizado. Pode-se perceber que, apesar de relativamente tardia ( alarme $_{O N}$ somente ocorre na segunda metade do experimento), os disparos de alarme $_{O N}$ possuem comportamentos de ocorrência, decaimento e sincronia com alarme $_{O F F}$, similares aos dos demais eventos salientes. Adicionalmente, surge uma nova sincronia, porém já esperada, com $\operatorname{sineta}_{O N}$ (dado que a ocorrência de alarme $_{O N}$ é obrigatoriamente simultânea à de sineta $_{O N}$, segundo as regras do domínio).

Uma análise visual interessante se dá ao concentrar-se nos valores correspondentes a $l u z_{O N}$, música $_{O N}$, sineta $a_{O N}$ e alarme $_{O N}$ em conjunto: 
1. a frequência de ocorrência de $l u z_{O N}$ permanece alta e constante, o que pode ser explicado pela sua importância durante todo o processo: é necessário ligar a luz para ligar a música e desligá-la para ligar o alarme;

2. música ${ }_{O N}$ parece ser mais frequente na primeira metade do experimento, ocorrendo com menor frequência na segunda metade, quando começa a ocorrer alarme $O N$. Isso pode ser explicado pelo fato de que a música, uma vez ligada, não precisa ser desligada e ligada novamente para disparar alarme $O N$ (como é o caso da luz). De fato, caso o agente desligue a luz, isso representará uma sobrecarga para disparar alarme $_{O N}$, pois ele precisará disparar música ${ }_{O N}$ antes. Isso sugere que o robô tenha aprendido que é mais interessante, do ponto de vista da solução do problema, manter a música ligada, dessa forma, não mais disparando música $a_{O N}$, nem seu complementar, música ${ }_{O F F}$;

3. sineta $_{O N}$ ocorre mais tardiamente, porém, com mais frequência quando música ${ }_{O N}$ para de ocorrer: mostrando a priorização do robô não mais em disparar música ${ }_{O N}$ ou música ${ }_{O F F}$, e sim em resolver o problema, ou seja, disparar alarme $_{O N}$;

4. alarme $_{O N}$, a solução do problema, ocorre de forma sincronizada com $\operatorname{sineta}_{O N}$, como discutido acima, e com mais frequência nos passos mais tardios, quando as políticas parciais que podem auxiliar o robô a dispará-lo já puderam ser aprimoradas.

Com isso, conclui-se a análise dos resultados experimentais responsáveis por avaliar o A-EIP ${ }^{3}$ quanto à preservação das qualidades positivas do algoritmo ARMI, do qual se originou. A análise dos resultados presentes no gráfico e discutidas acima sugere que o AEIP $^{3}$ foi capaz de identificar subproblemas, associando e aprendendo políticas parciais aos subproblemas identificados, de forma a utilizá-las na solução de um problema hierárquico, como é o caso do domínio utilizado. Na próxima seção, são apresentados os resultados da avaliação experimental do desempenho de aprendizado do A-EIP 3 .

\subsubsection{Desempenho de Aprendizado do A-EIP ${ }^{3}$}

É importante notar que o domínio utilizado é altamente estocástico e os gráficos apresentados nas Figuras 5.11 e 5.13 correspondem a um experimento. Para realizar uma análise mais representativa do desempenho de aprendizado do A-EIP ${ }^{3}$, foram realizadas múltiplas repetições de um mesmo experimento e obtida a média do desempenho apresentado, como apresentado a seguir.

Nesse novo conjunto de experimentos, o desempenho do robô aprendendo com o A-EIP ${ }^{3}$ foi comparado com o desempenho de um robô aprendendo através do Q-Learning, que não utiliza o conceito de eventos salientes, portanto não cria nem disponibiliza políticas parciais para o robô, ou seja, o robô que aprende com o Q-Learning não subdivide o 

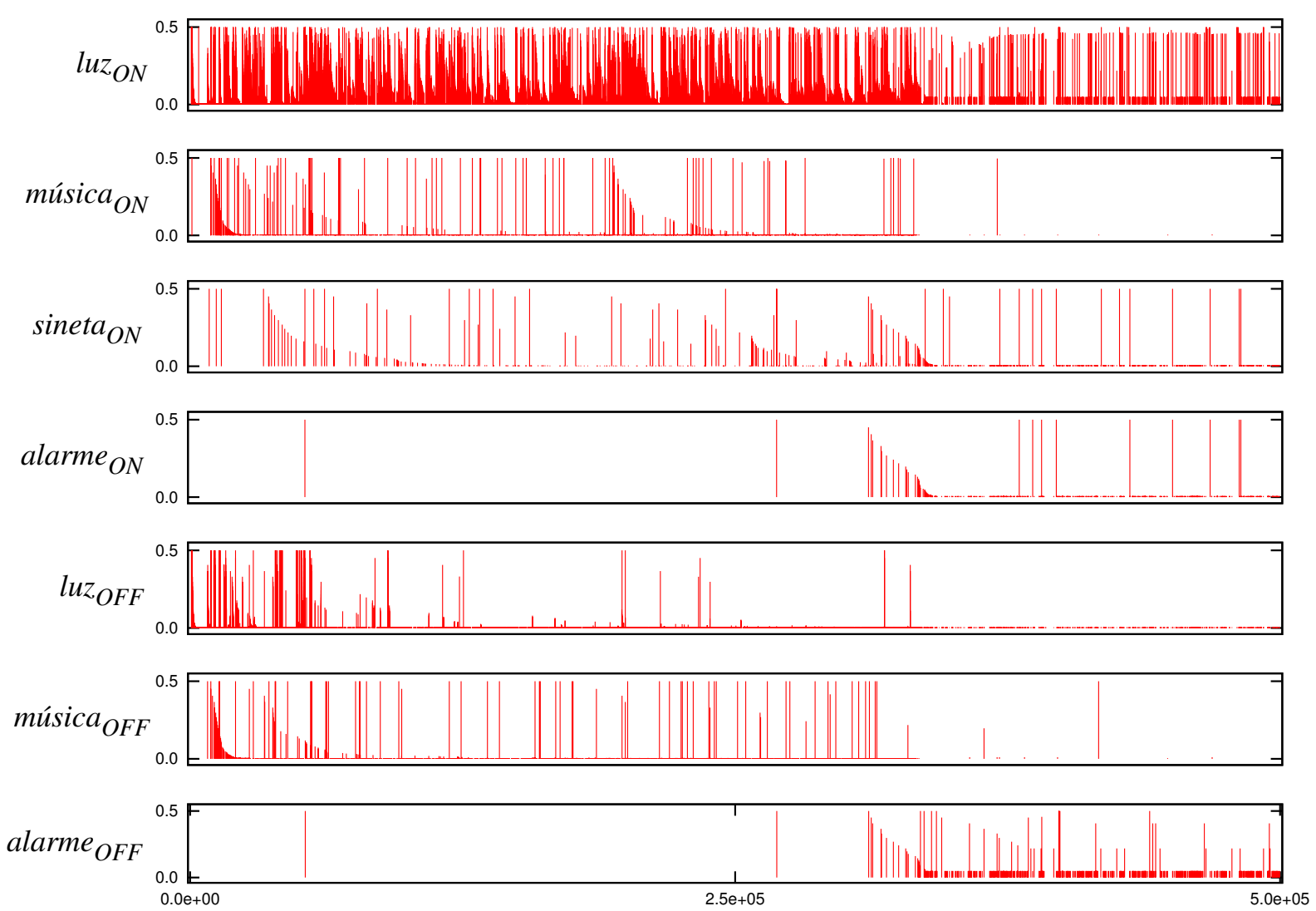

Figura 5.13: Recebimento de recompensas intrínsecas por evento saliente por passo de aprendizado.

problema em subproblemas, nem recebe recompensas intrínsecas, mas somente recompensas extrínsecas ao resolver o problema, disparando alarme $O N$.

Esse conjunto de experimentos foi realizado para verificar o impacto no aprendizado obtido através da exploração das características hierárquicas do problema. Dessa forma, esperava-se que o robô, aprendendo com o A-EIP ${ }^{3}$, apresentasse um melhor desempenho em relação ao robô aprendendo com Q-Learning, obtido através da identificação de subproblemas e utilização de políticas parciais para resolvê-los.

Para cada um dos dois robôs, o que aprendeu com Q-Learning, e o que aprendeu com o A-EIP ${ }^{3}$, foram realizados 100 repetições de experimentos com duração de $5 \times 10^{5}$ passos cada, utilizando os parâmetros $\alpha=0,1, \gamma=0,99$ e $\epsilon=0,1$ para o Q-Learning e o A$\mathrm{EIP}^{3}$, que utilizou o valor de $\tau=0,5$ (esse parâmetro não é utilizado pelo Q-Learning, pois é utilizado no decaimento de recompensas intrínsecas). Os experimentos foram sequenciais, ou seja, caso o robô resolvesse o problema (disparasse alarme $_{O N}$ ), ele precisaria disparar alarme $_{O F F}$ antes de poder resolver o problema novamente.

Para cada um dos robôs, foram calculados quantos passos eram utilizados (em 
média) para resolver o problema (disparar alarme $_{O N}$ ). Isso foi feito para as quinhentas primeiras vezes que os robôs resolveram o problema. Ou seja, foram calculados quantos passos o robô consome para disparar alarme $_{O N}$ pela primeira vez, igualmente para o segundo disparo, e assim por diante, para os quinhentos primeiros disparos de alarme $_{O N}$.

Como os robôs estão realizando aprendizado enquanto disparam alarme $_{O N}$, esperavase que a quantidade de passos necessária para disparar alarme $O N$ fosse diminuindo à medida que os robôs conseguiam o disparo, mostrando a aquisição gradual do conhecimento e aprimoramento da capacidade de resolver o problema, realizando-o cada vez mais rapidamente.

Esperava-se ainda que o robô aprendendo com o A-EIP ${ }^{3}$ apresentasse um melhor desempenho, pois o problema possui forte estrutura hierárquica e o robô que aprende com o A-EIP ${ }^{3}$ dispõe de mecanismos (eventos salientes, identificação de subproblemas e criação e aprendizado de políticas parciais para resolvê-los) que possibitam explorar a estrutura hierárquica para melhorar o desempenho de aprendizado.

No gráfico da Figura 5.14 são apresentados os resultados obtidos. As coordenadas dos pontos exibidas no gráfico devem ser lidas da seguinte maneira:

- o primeiro valor indica o número do disparo, ou seja, "1" indica o primeiro, "2" o segundo, e assim sucessivamente;

- o segundo valor indica a quantidade média de passos consumidos pelo robô para conseguir o disparo, como será exemplificado a seguir.

Por exemplo, o ponto $(1 ; 7097,56)$, marcado no gráfico, indica que o robô que aprendeu com o Q-Learning consumiu, em média, 7097, 56 passos para conseguir disparar alarme $_{O N}$ pela primeira vez. Por sua vez, o ponto $(1 ; 36188,52)$ indica que o robô que aprendeu com o A-EIP ${ }^{3}$ consumiu uma quantidade maior de passos para disparar alarme $_{O N}$ pela primeira vez: 36188,52 .

Pelo exemplo, pode-se perceber que, para conseguir solucionar o problema pela primeira vez, o robô que aprendeu com o A-EIP ${ }^{3}$ consumiu uma quantidade de passos aproximadamente 5 vezes maior, em média, do que o robô que aprendeu com o Q-Learning. Esse resultado inicial é claramente desvantajoso para o A-EIP ${ }^{3}$, mas a relativa demora na obtenção da primeira solução pode ser explicada pela estratégia de aprendizado utilizada pelo A-EIP ${ }^{3}$ : primeiramente, o robô identifica subproblemas e aprende as políticas parciais para resolvê-los, que, à medida que vão sendo aprimoradas, são utilizadas para resolver subproblemas cada vez mais complexos até que se obtenha a solução do próprio problema. Como o aprendizado das políticas parciais consome passos do experimento, a obtenção da solução final pela primeira vez pode ser mais tardia, ou seja, inicialmente o robô que aprende com o A-EIP ${ }^{3}$ concentra-se na solução dos subproblemas, consumindo passos 


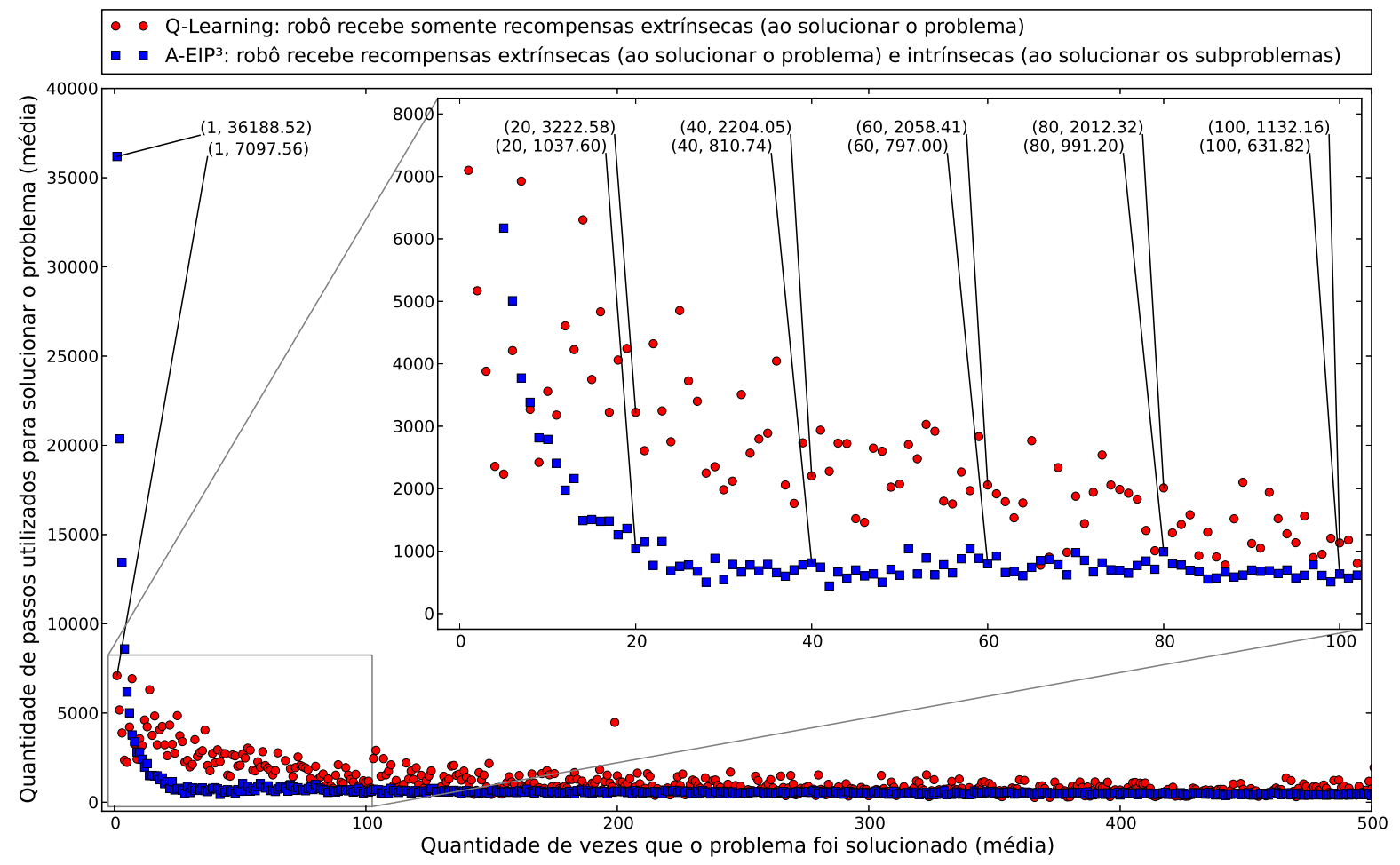

Figura 5.14: Avaliação do efeito motivação intrínseca no aprendizado. O gráfico mostra a quantidade de passos necessários para o robô resolver o problema à medida que ele o resolve.

adicionais em relação ao robô que aprende com o Q-Learning, que não utiliza o conceito de subproblemas. Entretanto, a desvantagem inicial é compensada posteriormente, como será apresentado a seguir.

Considere-se agora as 100 primeiras ativações, destacadas no gráfico. Na região destacada, foram marcadas as médias de passos consumidos por cada robô para os 100 primeiros disparos, a intervalos de 20. Pelas coordenadas apresentadas, pode-se perceber que, na vigésima vez que os robôs disparam alarme $_{O N}$, o que aprendeu com Q-Learning consumiu uma média de 3222,58 passos, enquanto o que aprendeu com o A-EIP ${ }^{3}$ conseguiu ser aproximadamente três vezes mais rápido, consumindo uma média de 1037, 60 passos.

Esse resultado vantajoso para o ${\mathrm{A}-\mathrm{EIP}^{3}}^{3}$ sugere que, na vigésima ativação, o robô dispõe de recursos aprendidos que lhe permitem solucionar o problema mais rapidamente em relação ao que aprendeu com o Q-Learning. Isso poderia ser explicado pelo avanço dos experimentos em relação às primeiras ativações: enquanto ativava as 19 vezes anteriores, o robô que aprendia com o A-EIP ${ }^{3}$ pôde aprender e aprimorar as políticas parciais para os subproblemas que compõem o problema completo. Dessa forma, nesse momento do aprendizado, ele pôde utilizá-las para resolver os subproblemas que compõem o problema completo mais rapidamente, conseguindo uma melhora de desempenho relativa ao robô que aprendeu com o Q-Learning. 
Como pode ser percebido pelo gráfico, a vantagem relativa de desempenho se mantém para os quadra, sexa e octogésimo, incluindo o centésimo disparos de alarme $_{O N}$, indicando que o aprimoramento das políticas parciais permanece ocorrendo, dessa forma fazendo com que o robô que aprendeu com o A-EIP ${ }^{3}$ mantenha uma margem de desempenho positiva em relação ao robô que aprendeu com o Q-Learning.

Os resultados presentes no gráfico da Figura 5.14 sugerem, portanto, pelo desempenho médio apresentado pelo aprendizado através do A-EIP ${ }^{3}$ em relação ao Q-Learning, em um problema com caracterização hierárquica, que o A-EIP ${ }^{3}$ é capaz de identificar subproblemas através de eventos salientes, criando e aprendendo políticas parciais para resolvê-los, dessa forma obtendo um desempenho de aprendizado no longo prazo relativamente superior ao Q-Learning, que não utiliza as referidas técnicas. Dessa forma, os resultados discutidos apoiam a hipótese de que o $\mathrm{A}-\mathrm{EIP}^{3}$ herdou as características positivas do ARMI citadas anteriormente.

Neste ponto, é importante notar que os resultados experimentais apresentados anteriormente foram obtidos utilizando-se a implementação completa do A-EIP ${ }^{3}$, ou seja, aplicaram as estratégias de exploração interna e pilha de políticas parciais. Dessa forma, os resultados sugerem que a utilização dessas estratégias apresenta potencial de impacto positivo no desempenho de aprendizado, como será discutido a seguir.

Como visto no Capítulo 4, a proposta de exploração interna utiliza o parâmetro $\xi_{p}$, que controla a exploração interna à política parcial. Nos experimentos acima, o valor utilizado foi de $\xi_{p}=0,8$, que, dentre os avaliados, como será mostrado a seguir, foi o que apresentou o melhor desepenho. Entretanto, o A-EIP ${ }^{3}$ apresenta forte dependência do valor escolhido para $\xi_{p}$, inclusive sendo possível que uma má escolha de $\xi_{p}$ prejudique expressivamente o aprendizado, o que é uma característica significativamente indesejável apresentada pela proposta.

Para avaliar o impacto de $\phi$ no aprendizado, logo, do percentual de exploração interna à política parcial, foram realizados 100 experimentos de $5 \times 10^{5}$ passos cada nos quais os valores de $\xi_{p}$ variaram em $\xi_{p} \in\{0,0 ; 0,2 ; 0,4 ; 0,6 ; 0,8 ; 1,0\}$, com valores dos demais parâmetros idênticos aos listados acima ${ }^{16}$. O desempenho desses robôs foi comparado com um robô aprendendo pelo Q-Learning e um robô executando ações aleatórias, sem nenhuma estratégia e sem realizar aprendizado.

Os resultados obtidos são apresentados no gráfico da Figura 5.15. No gráfico foi plotada a média acumulada da quantidade de vezes que cada robô conseguiu resolver o problema por passo do experimento. No primeiro passo o valor é 0 para todos os robôs,

16 Ou seja, foram realizados 100 experimentos de $5 \times 10^{5}$ passos cada, para cada valor de $\xi_{p} \in$ $\{0,0 ; 0,2 ; 0,4 ; 0,6 ; 0,8 ; 1,0\}$, sendo 100 para $\xi_{p}=0,1,100$ para $\xi_{p}=0,2$, e assim por diante, até $\xi_{p}=1,0$, totalizando 600 experimentos, utilizando os parâmetros $\alpha=0,1, \gamma=0,99, \epsilon=0,1 \mathrm{e}$ $\tau=0,5$. 


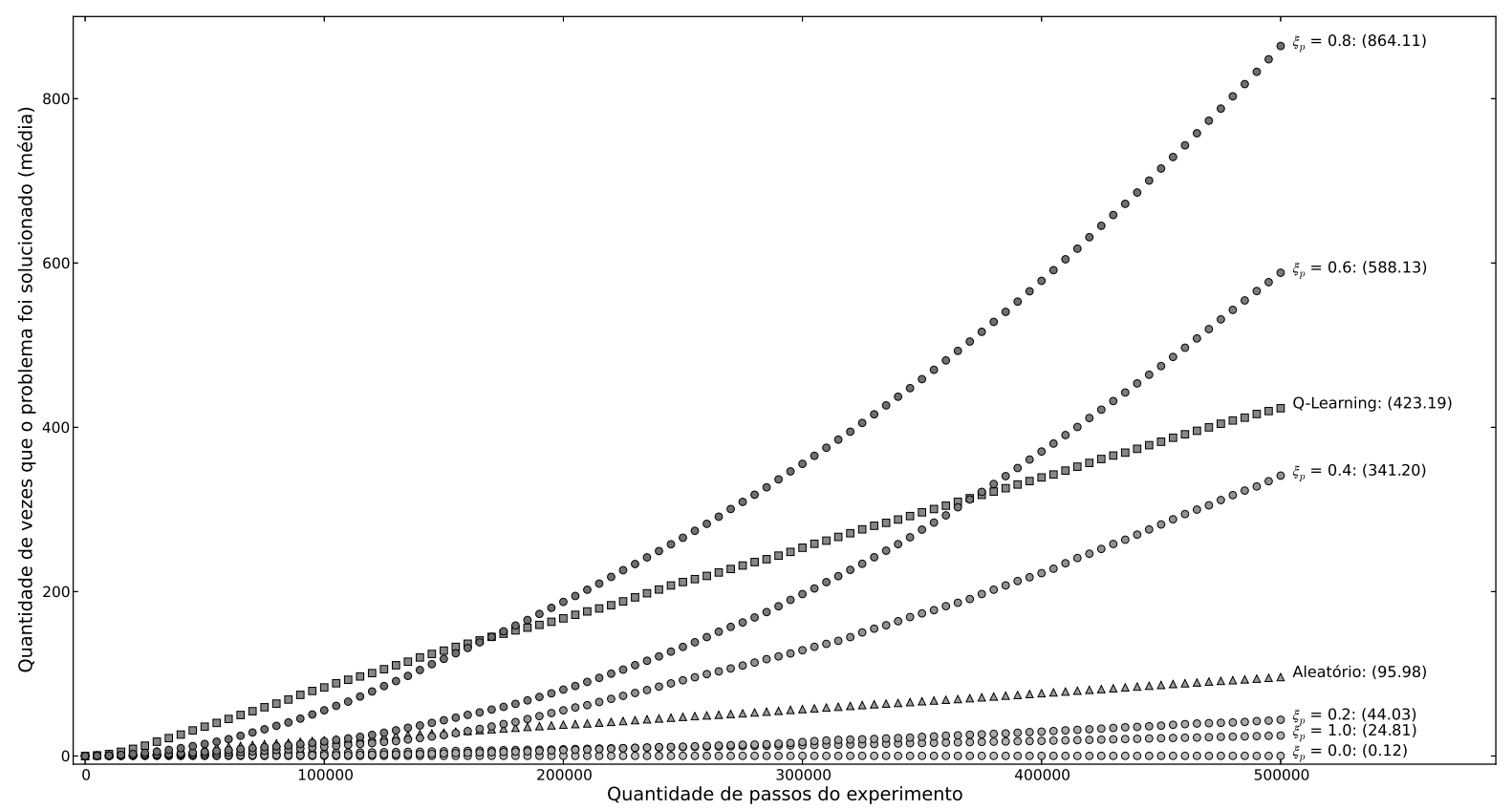

Figura 5.15: Avaliação da estratégia de pilhas de políticas parciais para exploração interna com diferentes valores de $\xi_{p}$, versus Q-Learning e comportamento aleatório. O gráfico mostra a quantidade média acumulada de vezes que cada agente conseguiu resolver o problema.

pois com um passo nenhum robô é capaz de disparar alarme $_{O N}$; após os quinhentos passos do aprendizado, o valor corresponde à média da quantidade total de vezes que o respectivo

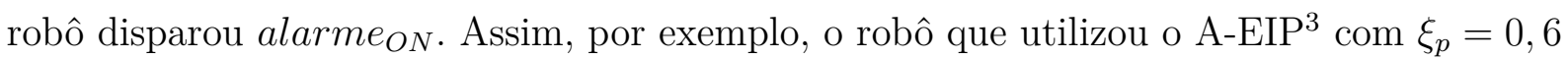
conseguiu disparar alarme $_{O N} 588,13$ nos quinhentos mil passos, sendo a média calculada para as 100 repetições, o robô que aprendeu com o Q-Learning disparou uma média de 423, 19 vezes e o robô que executou ações aleatórias, 95, 98.

Procedendo à análise dos dados presentes no gráfico, inicialmente considere-se o robô que aprendeu com o A-EIP ${ }^{3}$, utilizando os valores de $\xi_{p} \in\{0,2 ; 0,4 ; 0,6 ; 0,8\}$. Observando-se o gráfico, pode-se perceber que um maior valor de $\xi_{p}$ parece obter um melhor desempenho, ou seja, o desempenho dos respectivos robôs é proporcional ao valor de $\xi_{p}$ utilizado, sendo o melhor desempenho do conjunto apresentado pelo robô que utilizou $\xi_{p}=0,8$. Outra maneira de ler os dados é a de que quanto maior a exploração interna à política parcial, melhor o desempenho do robô, dado que essa exploração é controlada pelo parâmetro $\xi_{p}$.

Esse resultado pode parecer contra-intuitivo à primeira vista, dado que a função da política parcial é auxiliar o robô a resolver os subproblemas, dessa forma esperando-se que quanto mais o robô se ativer às recomendações da política parcial, melhor será seu desempenho.

Entretanto, é importante considerar que as políticas parciais são descobertas, criadas 
e aprendidas no A-EIP ${ }^{3}$. Dessa forma, é de se esperar que a qualidade das mesmas somente esteja relativamente satisfatória após algum tempo de aprendizado. Assim, o auxílio da exploração interna à política parcial no desempenho dos robôs pode ser explicada pela importância que a exploração interna tem no próprio aprendizado da política parcial, ou seja, os resultados sugerem a necessidade de o robô realizar exploração no aprendizado das políticas parciais.

A hipótese de que a exploração interna à política parcial favorece o aprendizado é corroborada pelo resultado correspondente ao robô que utilizou o valor de $\xi_{p}=0,0$, ou seja, o robô que não realizou exploração interna às políticas parciais, e que apresentou o desempenho menos favorável do conjunto. Esse resultado apoia, portanto, a hipótese de que o aprendizado das políticas parciais pode ser auxiliado pela exploração interna.

Comparando-se os resultados apresentados pelo robô que aprendeu com o A-EIP 3 utilizando $\xi_{p}=0,8$ e pelo robô que aprendeu com o Q-Learning, os dados presentes no gráfico sugerem uma desvantagem de desempenho final por parte do robô que aprendeu com o Q-Learning, corroborando os dados apresentados anteriormente, referentes à Figura 5.14. Entretanto, o desempenho inicial correspondente ao Q-Learning supera o do A-EIP ${ }^{3}$, o que é revertido somente pouco antes da metade do experimento. Esse resultado pode ser explicado pela sobrecarga representada pelo aprendizado das políticas parciais relacionada ao A-EIP ${ }^{3}$, também corroborando os resultados anteriores apresentados na discussão relacionada à Figura 5.14.

Por outro lado, o robô que utilizou $\xi_{p}=0,4$ apresentou um desempenho inferior ao do Q-Learning, o que aponta uma característica indesejável do A-EIP ${ }^{3}$ : uma dependência em termos da escolha do valor do parâmetro $\xi_{p}$. Um resultado ainda mais expressivo é o apresentado pelo robô que utilizou $\xi_{p}=0,2$ : esse robô apresentou um resultado inferior ao robô que executou ações aleatórias. Esse resultado sugere, portanto, uma significativa sensibilidade do $\mathrm{A}_{-} \mathrm{EIP}^{3}$ ao valor de $\xi_{p}$, sendo que uma má escolha de $\xi_{p}$ pode comprometer substancialmente o desempenho de aprendizado.

Assim, os resultados obtidos para o aprendizdo com o A-EIP ${ }^{3}$ utilizando os valores de $\xi_{p} \in\{0,2 ; 0,4 ; 0,6 ; 0,8\}$ sugerem a aplicabilidade da técnica proposta para o aprendizado, inclusive podendo superar uma técnica de aprendizado tradicional como o Q-Learning. Entretanto, a técnica é fortemente dependente do valor escolhido para $\xi_{p}$, sendo que uma má escolha de $\xi_{p}$ pode prejudicar expressivamente o aprendizado.

O robô que realizou o aprendizado utilizando o valor de $\xi_{p}=1,0$ realizou exploração $100 \%$ das vezes em que uma política parcial era aplicada, ou seja, no momento em que o agente iria obter uma ação através da política parcial sendo aplicada, no lugar era realizado um sorteio de uma ação aleatória a ser executada ao invés da ação que seria sugerida pela política parcial. Esse robô ainda realizou o aprendizado paralelo, realizado por um módulo similar ao utilizado pelo Q-Learning, como detalhado na Seção 3.3, onde 
as ações primitivas ainda eram escolhidas segundo uma estratégia $\epsilon$-gulosa. Entretanto, devido ao fato de explorar sempre que aplicava uma política parcial, esperava-se que o desempenho apresentado pelo robô que utilizou $\xi_{p}=1,0$ fosse similar ao robô que realizou ações aleatórias, o que não ocorreu. Esse resultado representou uma surpresa na fase experimental, e será discutido com o auxílio dos resultados apresentados a seguir.

Para verificar o impacto isolado da proposta de empilhamento de políticas parciais, realizou-se um conjunto de experimentos em que os robôs que aprenderam com $\xi_{p} \in$ $\{0,0 ; 0,2 ; 0,4 ; 0,6 ; 0,8 ; 1,0\}$, mas, nesse novo conjunto de experimentos, os robôs não utilizaram a pilha de políticas parciais, ou seja, aplicaram as políticas parciais aprendidas até a terminação, sem, entretanto, empilhá-las, como proposto neste trabalho.

Os resultados são aprentados na Figura 5.16, que apresenta um gráfico análogo ao da Figura 5.15, mas considerando os robôs que não utilizaram a pilha de políticas parciais. Analisando primeiramente o desempenho do robô que utilizou $\xi_{p}=1,0$, pode-se perceber que, ao não utilizar a pilha de políticas parciais, o robô, explorando $100 \%$ das vezes em que aplicou as políticas parciais, apresentou um resultado comparável ao do agente que realizou ações aleatórias, como era esperado que ocorresse e que não ocorreu quando o robô utilizou o empilhamento de políticas parciais.

Dessa forma, a análise conjunta dos resultados para $\xi_{p}=1,0 \mathrm{com}$ e sem empilhamento de políticas parciais sugere que o empilhamento de políticas parciais pode ser prejudicial ao processo de exploração interna às políticas parciais, ou seja, as propostas deste trabalho são conflitantes. Uma interpretação alternativa seria a de que há um compromisso entre o fator de exploração e o fator de empilhamento.

Comparando os desempenhos dos robôs que utilizaram a pilha de políticas parciais e dos robôs que não utilizaram, e considerando a alta estocasticidade do domínio, não é possível afirmar que a estratégia de empilhamento de políticas parciais apresente um impacto significativo no desempenho de aprendizado, dada a similaridade dos desempenhos entre os dois conjuntos de robôs, como pode ser visto pela análise conjunta dos gráficos das Figuras 5.15 e 5.16. Entretanto, o desempenho crescente com o valor de $\xi_{p}$ corrobora a hipótese anterior, de que a exploração interna favorece o aprendizado das políticas parciais.

Na Figura 5.17 é apresentado um gráfico, análogo ao da Figura 5.14, entretanto considerando os desempenhos dos robôs que utilizaram ou não empilhamento de políticas parciais, sendo os dois resultados correspondentes a um valor de exploração interna com $\xi_{p}=0,8$. Pela análise do gráfico, pode-se perceber que os dois robôs apresentaram um desempenho similar, mas o robô que não realizou empilhamento apresentou um resultado relativamente superior, sendo capaz de disparar alarme $_{O N}$ mais rapidamente do que o robô que utilizou pilhas de políticas parciais.

Com isso, conclui-se a apresentação dos resultados experimentais deste trabalho. 


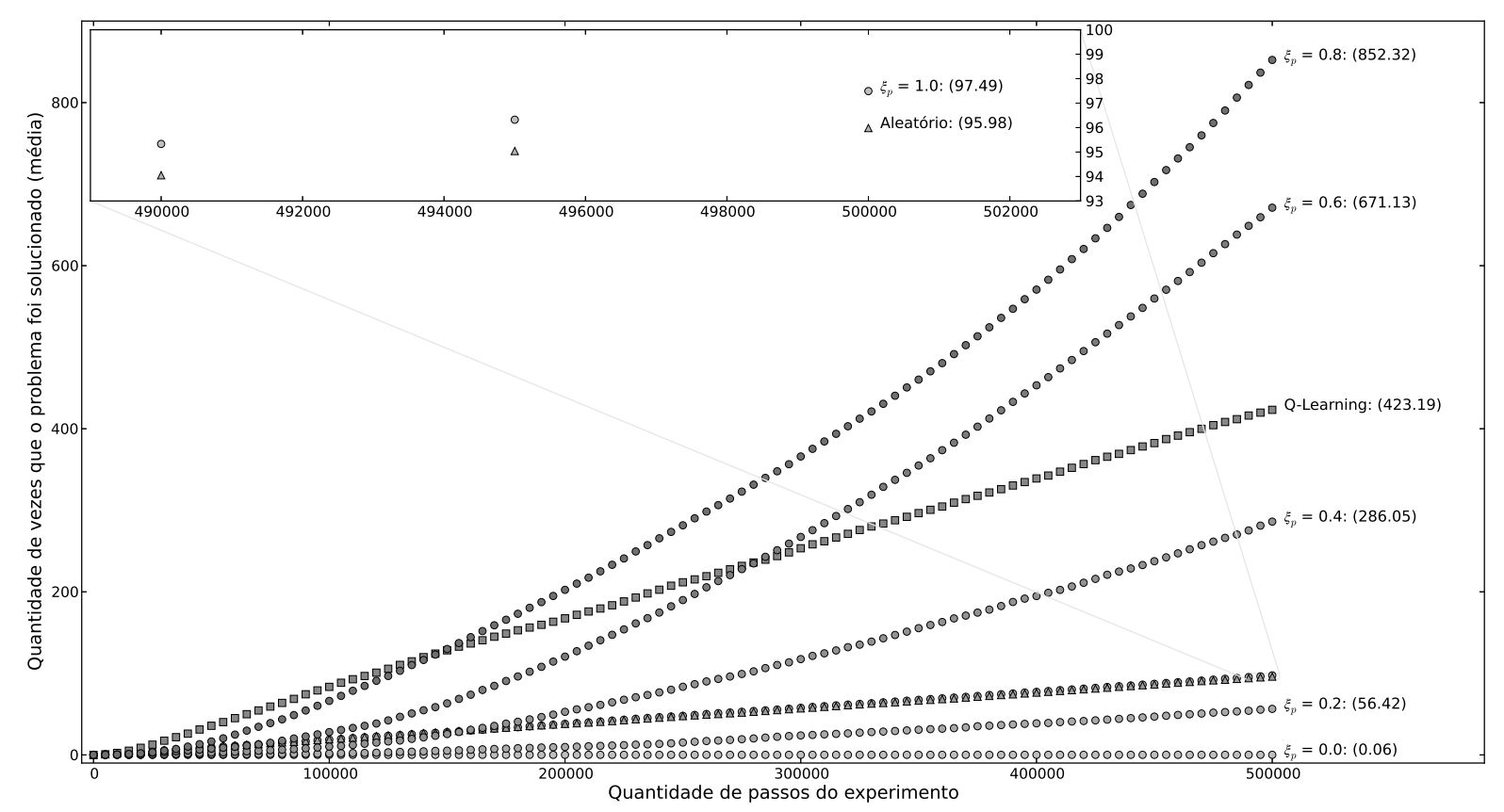

Figura 5.16: Avaliação do impacto da utilização da estratégia de pilhas. O gráfico é análogo ao da Figura 5.15, com a diferença de que este gráfico apresenta o desempenho dos robôs utilizando exploração interna sem utilizar empilhamento de políticas parciais.

Nesta seção, foram apresentados resultados experimentais que sugerem que a utilização da proposta foi capaz de identificar os subproblemas através de eventos salientes, detectando, criando, aprendendo e aplicando políticas parciais com complexidade aumentada gradualmente, refletindo a estrutura hierárquica do problema. A proposta de exploração interna às políticas parciais apresentou um impacto positivo na utilização do A-EIP , entretanto, a investigação do parâmetro $\xi_{p}$ sugere uma forte dependência do desempenho de aprendizado relacionada à escolha dos valores para o parâmetro.

A investigação experimental do impacto da utilização de empilhamento de políticas não apresentou resultados favoráveis: os resultados obtidos sugerem que o empilhamento de políticas parciais não impacta significativamente no processo de aprendizado, além da possibilidade de ser conflitante com o processo de exploração interna, também proposto neste trabalho. No próximo capítulo, serão apresentadas as conclusões deste trabalho, juntamente com possibilidades de investigações futuras. 


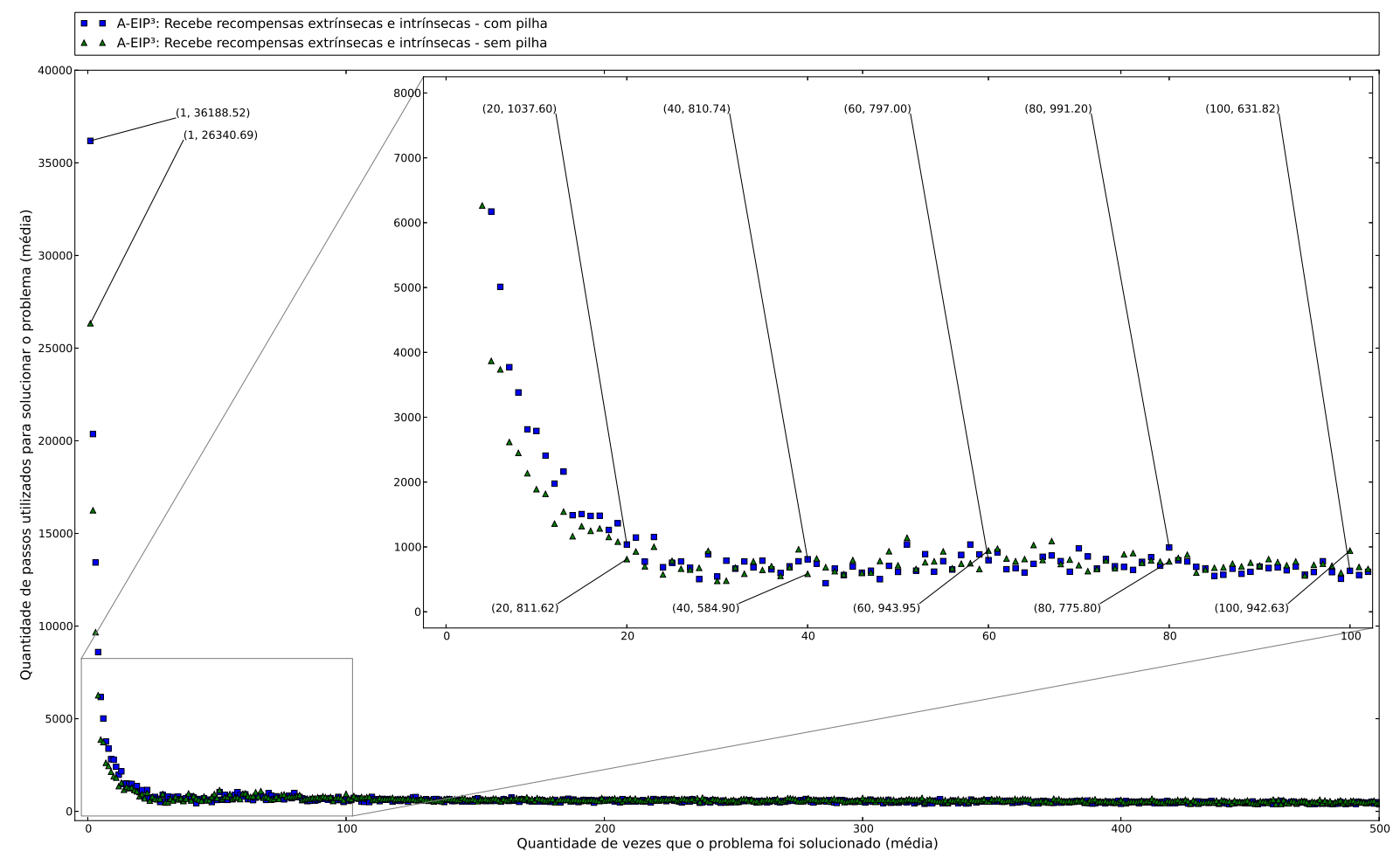

Figura 5.17: Avaliação do efeito do empilhamento de políticas parciais. O gráfico mostra a quantidade de passos necessários para resolver o problema à medida que o robô o resolve, considerando os robôs que utilizaram ou não empilhamento de políticas parciais, ambos utilizando exploração interna à política parcial com valor de $\xi_{p}=0,8$. Ambos os robôs recebem recompensas intrínsecas e extrínsecas, inclusive o robô que não utiliza a pilha de políticas parciais. 



\section{Conclusão}

Neste trabalho foram propostas estratégias de aplicação de políticas parciais com motivação intrínseca. Empilhamento de políticas parciais e exploração interna às mesmas foram implementadas no algoritmo ARMI (SINGH; BARTO; CHENTANEZ, 2005), gerando o algoritmo A-EIP ${ }^{3}$. O novo algoritmo foi avaliado experimentalmente em um problema com fortes características hierárquicas, onde é possível identificar facilmente o encadeamento de subproblemas, que podem ser resolvidos por políticas parciais.

A identificação dos subproblemas foi realizada através de eventos salientes, dados por variações significativas em determinados atributos da descrição fatorada de estados. $\mathrm{O}$ aprendizado das políticas parciais foi auxiliado pela presença de recompensas intrínsecas, recompensas adicionais recebidas ao resolver um subproblema (disparar um evento saliente). A utilização conjunta de eventos salientes e políticas parciais apresentou resultados experimentais que sugerem que elas são capazes de explorar a estrutura hierárquica de um problema de forma a melhorar o desempenho de aprendizado. Essas características, herdadas do ARMI, foram preservadas no algoritmo proposto neste trabalho.

As propostas deste trabalho foram avaliadas experimentalmente e os resultados sugerem que a exploração interna às políticas parciais potencialmente impacta positivamente no aprendizado. Entretanto, o processo de exploração interna depende de um parâmetro cuja escolha de valores é de expressiva importância para o desempenho obtido, sendo que uma má escolha do valor do mesmo pode prejudicar o aprendizado.

O empilhamento de políticas parciais, proposto neste trabalho, foi investigado através de avaliação experimental, em que o impacto da utilização dessa proposta foi isolado, comparando o aprendizado com e sem a utilização do conceito de empilhamento. Os resultados experimentais obtidos sugerem que o impacto da utilização do empilhamento de políticas parciais não apresenta impacto expressivo no desempenho de aprendizado.

Considerando os resultados desta dissertação, conclui-se que o empilhamento de políticas parciais não parece representar o caminho mais adequado para melhorar o desempenho da aplicação de políticas parciais no algoritmo ARMI.

O Aprendizado por Reforço com Motivação Intrínseca, investigado neste trabalho, utiliza o conceito de eventos salientes, cuja utilização depende da definição dos respectivos atributos salientes, que são os atributos da descrição fatorada do estado cuja modificação dispara os eventos salientes.

A utilização de eventos salientes para a descoberta de políticas parciais apresenta um potencial de diminuição da sobrecarga representada pela definição prévia das mesmas 
por parte do projetista. Ademais, os resultados positivos obtidos através da utilização de eventos salientes para descoberta automática de políticas parciais sugerem que a utilização de eventos salientes e motivação intrínseca pode melhorar o desempenho final de aprendizado do agente.

Entretanto, a utilização dos eventos salientes também depende de uma definição prévia: a dos atributos salientes. Para contornar a eventual sobrecarga representada pela definição prévia dos atributos salientes, poderiam ser investigadas estratégias de descoberta automática desses atributos.

Outra possibilidade futura de investigação se dá por uma análise mais detida das consequências da exploração interna em conjunto à exploração usual do aprendizado. Nesse caso, poderiam ser elaboradas estratégias que aliassem os dois processos exploratórios de forma a diminuir a exploração interna às políticas parciais à medida que o agente adquire conhecimento sobre o problema, dessa forma aplicando as políticas parciais com mais frequência à medida em que o respectivo processo de aprendizado pôde ocorrer com mais expressividade.

Dessa forma, conclui-se a apresentação deste trabalho. No decorrer da realização das atividades investigativas, pôde-se entrar em contato com o conceito de políticas parciais, cuja descoberta pode ser feita de forma automática através de eventos salientes, que representam uma metodologia de acréscimo de motivação intrínseca ao ferramental de Aprendizado por Reforço. Conclui-se que a utilização de políticas parciais no Aprendizado por Reforço com Motivação Intrínseca possui significativo potencial de aplicação, mas que a inter-relação entre os componentes carece de investigação cuidadosa para que, de fato, seja obtida uma melhora no aprendizado. 


\section{REFERÊNCIAS}

ABBEEL, P.; COATES, A.; QUIGLEY, M.; NG, A. Y. An application of reinforcement learning to aerobatic helicopter flight. In: SCHöLKOPF, B.; PLATT, J.; HOFFMAN, T. (Ed.). Advances in Neural Information Processing Systems 19. MIT Press, 2007. p. 1-8. Disponível em: <http://papers.nips.cc/paper/ 3151-an-application-of-reinforcement-learning-to-aerobatic-helicopter-flight.pdf $>$. Citado 2 vezes nas páginas 29 e 33.

BAKKER, B.; SCHMIDHUBER, J. Hierarchical reinforcement learning based on subgoal discovery and subpolicy specialization. In: Proc. of the 8-th Conf. on Intelligent Autonomous Systems. Amsterdam, Netherlands: IOS Press, 2004. p. 438-445. Citado na página 29.

BARTO, A. G.; CRITES, R. H. Improving elevator performance using reinforcement learning. In: TOURETZKY, D.; MOZER, M.; HASSELMO, M. (Ed.). Advances in Neural Information Processing Systems 8. MIT Press, 1996. p. 1017-1023. Disponível em: <http://papers.nips.cc/paper/ 1073-improving-elevator-performance-using-reinforcement-learning.pdf $>$. Citado 2 vezes nas páginas 29 e 33.

BARTO, A. G.; MAHADEVAN, S. Recent advances in hierarchical reinforcement learning. Discrete Event Dynamic Systems, Kluwer Academic Publishers, Hingham, MA, USA, v. 13, n. 1-2, p. 41-77, jan. 2003. ISSN 0924-6703. Disponível em: <http://dx.doi.org/10.1023/A:1022140919877>. Citado 3 vezes nas páginas 29, 33 e 47.

BARTO, A. G.; SINGH, S. P.; CHENTANEZ, N. Intrinsically motivated learning of hierarchical collections of skills. In: Proc. 3rd Int. Conf. Development Learn. [S.l.: s.n.], 2004. p. 112-119. Citado 2 vezes nas páginas 36 e 38.

BEIRIGO, R. L.; PEREIRA, F. A.; KOGA, M. L.; MATOS, T.; SILVA, V. F. d.; COSTA, A. H. R. Avaliação de políticas abstratas na transferência de conhecimento em navegação robótica. Revista de Sistemas e Computação-RSC, v. 2, n. 2, 2012. Citado na página 33.

BEIRIGO, R. L.; SILVA, V. F. d.; COSTA, A. H. R. Descoberta automática de atributos salientes para obtenção de macro-ações. In: Workshop de Tecnologia Adaptativa, WTA. São Paulo, Brasil: WTA2014, 2014. Citado na página 38.

BELLMAN, R. The theory of dynamic programming. Bulletin of the American Mathematical Society, v. 60, p. 503-515, 1954. Citado na página 43.

BERGamo, Y. P.; MATOS, T.; SILVA, V. F. da; COSTA, A. H. R. Accelerating reinforcement learning by reusing abstract policies. In: VIII Encontro Nacional de Inteligência Artificial. [S.l.: s.n.], 2011. p. 596-606. Citado na página 33.

BRUNSKILL, E.; LI, L. Pac-inspired option discovery in lifelong reinforcement learning. Proceedings of the $31^{\text {st }}$ International Conference on Machine Learning, v. 32, 2014. Citado na página 34. 
CHI, M.; VANLEHN, K.; LITMAN, D.; JORDAN, P. Empirically evaluating the application of reinforcement learning to the induction of effective and adaptive pedagogical strategies. User Modeling and User-Adapted Interaction, Springer, v. 21, n. 1-2, p. 137-180, 2011. Citado 2 vezes nas páginas 29 e 33.

DIETTERICH, T. G. Hierarchical reinforcement learning with the maxq value function decomposition. Journal of Artificial Intelligence Research, v. 13, p. 227-303, 2000. Citado na página 34 .

EDWARDS, A. L.; DAWSON, M. R.; HEBERT, J. S.; SUTTON, R. S.; CHAN, K. M.; PILARSKI, P. M. Adaptive switching in practice: Improving myoelectric prosthesis performance through reinforcement learning. In: Proceedings of MEC14: Myoelectric Controls Symposium. Fredericton, New Brunswick: MEC14, 2014. p. 69-73. Citado 2 vezes nas páginas 29 e 33.

KOGA, M. L.; SILVA, V. F. d.; COZMAN, F. G.; COSTA, A. H. R. Speeding-up reinforcement learning through abstraction and transfer learning. In: Proceedings of the 2013 international conference on Autonomous agents and multi-agent systems. Saint Paul, Minnesota, USA: [s.n.], 2013. p. 119-126. Citado na página 33.

KONIDARIS, G.; BARTO, A. G. Skill discovery in continuous reinforcement learning domains using skill chaining. In: Advances in Neural Information Processing Systems 22. [S.l.]: Curran Associates, Inc., 2009. p. 1015-1023. Citado na página 34.

LENAT, D. B. AM: An Artificial Intelligence Approach to Discovery in Mathematics as Heuristic Search. Tese (Doutorado) — Stanford, 1976. Citado na página 35.

LITTMAN, M.; BOYAN, J. Reinforcement learning scheme for network routing. In: PSYCHOLOGY PRESS. Proceedings of the international workshop on applications of neural networks to telecommunications. [S.1.], 2013. Citado 2 vezes nas páginas 29 e 33.

MATOS, T.; BERGAMO, Y.; SILVA, V. da; COSTA, A. Stochastic abstract policies for knowledge transfer in robotic navigation tasks. Advances in Artificial Intelligence, Springer, p. 454-465, 2011. Citado na página 33.

MATOS, T.; BERGAMO, Y. P.; SILVA, V. F. da; COZMAN, F. G.; COSTA, A. H. R. Simultaneous abstract and concrete reinforcement learning. In: Proceedings of the 9th Symposium on Abstraction, Reformulation and Approximation (SARA'11). [S.1.: s.n.], 2011. p. 82-89. Citado na página 33.

MCGOVERN, A.; BARTO, A. G. Automatic discovery of subgoals in reinforcement learning using diverse density. In: International Conference on Machine Learning. [S.l.: s.n.], 2001. Citado 2 vezes nas páginas 29 e 35.

MERRICK, K. E.; MAHER, M. L. Motivated Reinforcement Learning. Berlin: Springer-Verlag, 2009. Citado na página 35.

MERRICK, K. E.; SHAFI, K. A game theoretic framework for incentive-based models of intrinsic motivation in artificial systems. Frontiers in Psychology, Frontiers Media SA, v. 4, 2013. Citado na página 36 .

MUGAN, J.; KUIPERS, B. Autonomously learning an action hierarchy using a learned qualitative state representation. In: IJCAI. [S.1.: s.n.], 2009. p. 1175-1180. Citado na página 35. 
O'NEILL, D.; LEVORATO, M.; GOLDSMITH, A.; MITRA, U. Residential demand response using reinforcement learning. In: IEEE. Smart Grid Communications (SmartGridComm), 2010 First IEEE International Conference on. [S.1.], 2010. p. 409-414. Citado 2 vezes nas páginas 29 e 33.

OUDEYER, P.-Y.; KAPLAN, F. What is intrinsic motivation? a typology of computational approaches. Frontiers in Neurorobotics, Frontiers Research Foundation, v. 1, 2007. Citado na página 35.

OUDEYER, P.-Y.; KAPLAN, F.; HAFNER, V. V. Intrinsic motivation systems for autonomous mental development. Evolutionary Computation, IEEE Transactions on, IEEE, v. 11, n. 2, p. 265-286, 2007. Citado na página 35.

PARR, R. E. Hierarchical control and learning for Markov decision processes. Tese (Doutorado) - Citeseer, 1998. Citado na página 33.

SCARDUA, L. A.; CRUZ, J. J. D.; COSTA, A. H. R. Optimal control of ship unloaders using reinforcement learning. Advanced Engineering Informatics, Elsevier, v. 16, n. 3, p. 217-227, 2002. Citado 2 vezes nas páginas 29 e 33.

SCHEMBRI, M.; MIROLLI, M.; BALDASSARRE, G. Evolving internal reinforcers for an intrinsically motivated reinforcement-learning robot. In: IEEE. Development and Learning, 200\%. ICDL 200\%. IEEE 6th International Conference on. [S.l.], 2007. p. 282-287. Citado 2 vezes nas páginas 37 e 38.

SCHMIDHUBER, J. A possibility for lmplementing curiosity and boredom in model-building neural controllers. In: PRESS, M. (Ed.). From Animals to Animats: Proceedings of the First International Conference on Simulation of Adaptive Behavior. Cambridge, MA: [s.n.], 1991. p. 222-227. Citado na página 35.

ŞIMŞEK, Ö.; BARTO, A. G. Using relative novelty to identify useful temporal abstractions in reinforcement learning. In: Proceedings of the Twenty-first International Conference on Machine Learning. New York, NY, USA: ACM, 2004. (ICML '04), p. 95-. ISBN 1-58113-8385. Disponível em: <http://www-anw.cs.umass.edu/pubs/2004/simsek_b_ICML04.pdf>. Citado 2 vezes nas páginas 33 e 35.

ŞIMŞEK, Ö.; BARTO, A. G. Intrinsic motivation for reinforcement learning systems. In: CENTER FOR SYSTEMS SCIENCE, DUNHAM LABORATORY, YALE UNIVERSITY, NEW HAVEN CT. Proceedings of the Thirteenth Yale Workshop on Adaptive and Learning Systems. Becton Center, Yale University, New Haven, Connecticut: Yale University, 2005. p. 113-118. Citado 3 vezes nas páginas 37, 38 e 67.

ŞIMŞEK, Ö.; BARTO, A. G. An intrinsic reward mechanism for efficient exploration. In: Proceedings of the 23rd international conference on Machine learning. New York, NY, USA: ACM, 2006. p. 833-840. ISBN 1-59593-383-2. Disponível em: <http://doi.acm.org/10.1145/1143844.1143949>. Citado 2 vezes nas páginas 35 e 38.

ŞIMŞEK, Ö.; BARTO, A. G. Skill characterization based on betweenness. In: KOLLER, D.; SCHUURMANS, D.; BENGIO, Y.; BOTTOU, L. (Ed.). Advances in Neural Information Processing Systems 21. Curran Associates, Inc., 2009. p. 1497-1504. Disponível em: $<$ http://papers.nips.cc/paper/3411-skill-characterization-based-on-betweenness.pdf $>$. Citado na página 35. 
SINGH, S.; LEWIS, R. L.; BARTO, A. G.; SORG, J. Intrinsically motivated reinforcement learning: An evolutionary perspective. Autonomous Mental Development, IEEE

Transactions on, v. 2, n. 2, p. 70-82, June 2010. ISSN 1943-0604. Old singh2010intrinsically. Citado na página 36.

SINGH, S. P.; BARTO, A. G.; CHENTANEZ, N. Intrinsically motivated reinforcement learning. In: SAUL, L.; WEISS, Y.; BOTTOU, L. (Ed.). Advances in Neural Information Processing Systems 17. MIT Press, 2005. p. 1281-1288. Old chentanez2004imrl. Disponível em: < http://papers.nips.cc/paper/2552-intrinsically-motivated-reinforcement-learning. pdf $>$. Citado 14 vezes nas páginas 29, 30, 35, 36, 37, 38, 41, 42, 47, 51, 59, 67, 83 e 101.

TAATGEN, N.; RIJN, H. van (Ed.). Where do rewards come from? Amsterdam, Netherlands: Cognitive Science Society, Inc., 2009. Citado na página 36.

STOLLE, M.; PRECUP, D. Learning options in reinforcement learning. In: Abstraction, Reformulation, and Approximation. [S.l.]: Springer, 2002. p. 212-223. Citado 2 vezes nas páginas 29 e 33 .

STOUT, A.; KONIDARIS, G. D.; BARTO, A. G. Intrinsically motivated reinforcement learning: A promising framework for developmental robot learning. In: Proceedings of the AAAI Spring Symposium on Developmental Robotics. Stanford University, Stanford, CA: [s.n.], 2005. Citado 2 vezes nas páginas 37 e 38.

SUTTON, R. S.; BARTO, A. G. Reinforcement Learning: An Introduction. Cambridge, Mass: MIT Press, 1998. ISBN 9780262193986. Citado 6 vezes nas páginas 29, 33, 41, 42, 43 e 45.

SUTTON, R. S.; PRECUP, D.; SINGH, S. P. Intra-option learning about temporally abstract actions. Proceedings of the $15^{\text {st }}$ International Conference on Machine Learning, v. 98, 1998. Citado 4 vezes nas páginas 33, 34, 42 e 47.

SUTTON, R. S.; PRECUP, D.; SINGH, S. P. Between mdps and semi-mdps: A framework for temporal abstraction in reinforcement learning. Artificial intelligence, Elsevier, v. 112, n. 1, p. 181-211, 1999. Citado 6 vezes nas páginas 29, 33, 34, 41, 42 e 47.

SZEPESVÁRI, C. Algorithms for Reinforcement Learning. [S.l.]: Morgan \& Claypool, 2010. Citado 3 vezes nas páginas 29, 33 e 43.

TESAURO, G. Temporal difference learning and td-gammon. Communications of the $A C M$, v. 38, 1995. Citado 2 vezes nas páginas 29 e 33.

WATKINS, C. J. C. H. Learning from delayed rewards. Tese (Doutorado) - University of Cambridge, 1989. Citado 3 vezes nas páginas 42, 43 e 45. 